Old Dominion University ODU Digital Commons

Summer 2012

\title{
Relational Exchange in Nonprofits: The Role of Identity Saliency and Relationship Satisfaction
}

Jennifer Anne Taylor

Old Dominion University

Follow this and additional works at: https://digitalcommons.odu.edu/publicservice_etds

Part of the Marketing Commons, Nonprofit Administration and Management Commons, and the Public Administration Commons

\section{Recommended Citation}

Taylor, Jennifer A.. "Relational Exchange in Nonprofits: The Role of Identity Saliency and Relationship Satisfaction" (2012). Doctor of Philosophy (PhD), dissertation, , Old Dominion University, DOI: $10.25777 /$ zwea-t882

https://digitalcommons.odu.edu/publicservice_etds/39 
RELATIONAL EXCHANGE IN NONPROFITS:

THE ROLE OF IDENTITY SALIENCY

AND RELATIONSHIP SATISFACTION

by

Jennifer Anne Taylor

B.A., August 1995, University of South Carolina

M.A., May 1998, The Ohio State University

A Dissertation Submitted to the Faculty of Old Dominion University in Partial Fulfillment of the Requirements for the Degree of

DOCTOR OF PHILOSOPHY

PUBLIC ADMINISTRATION AND URBAN POLICY

OLD DOMINION UNIVERSITY

August 2012

Revidwedbs:

Gilbert Yochum, Ph.D., Dean

College of Business and Public Administration

John C. Morris, Ph.D.

Graduate Program Director

Professor of Public Administration

and Urban Studies
Approved by:

William M. Leavitt, Ph.D. (Director)

Associate Professor of Public

Administration and Urban Studies

John B. Ford, Ph.D. (Member)

Profe Ssor of Marketing and

International Business

Kattina KM. Stevens (MNember)

Assistant Professor of Public

Administration and Urban Studies 


\begin{abstract}
RELATIONAL EXCHANGE IN NONPROFITS:

THE ROLE OF IDENTITY SALIENCY AND RELATIONSHIP SATISFACTION
\end{abstract}

\author{
Jennifer Anne Taylor
}

Old Dominion University, 2012

Director: Dr. William M. Leavitt

Research and practice in nonprofit fundraising has increasingly been focused on the benefits of relational exchange. This dissertation examines relationships between donors and nonprofit organizations and their impact on the charitable giving levels using identity salience and relationship satisfaction as key mediators of nonprofit relational exchange. Previous research has shown that there are a plethora of charitable giving motivations that contribute to supportive behaviors in the nonprofit context; however, this research does not provide a comprehensive understanding of the intervening variables. This study modified previous studies by introducing relationship satisfaction in addition to identity saliency, as mediating constructs. Results confirm that both identity saliency and relationship satisfaction partially mediate charitable giving motivations and charitable giving. Additionally, perceived organizational performance, emotional utility, and parental socialization and youth participation were significantly related to identity salience. Finally, perceived organizational performance, emotional utility, and satisfaction with the solicitation process were found to significantly related to relationship satisfaction. 
This dissertation is dedicated to the Settlement Women who came before me in public service who witnessed wicked problems in the world and worked tirelessly to solve them and to the transformational public servants who I hope to mentor and teach. 


\section{ACKNOWLEDGMENTS}

This dissertation is the beginning of what I hope to be a long career of scholarly work, which will support transformation in public service, how we implement change in the world and how we view public service in government and the nonprofit sectors. This work was developed with enormous support from friends and colleagues in university and practitioner environments, as well as, personal friends and my family.

First, I would like to thank Dr. William Leavitt, my dissertation advisor for recognizing the gamble that a stay-at-home mother of three and military spouse represented and betting on me anyway. Your detailed editing and willingness to oversee a methodologically complex charitable giving dissertation is appreciated. I am also deeply indebted to Dr. John B. Ford, my cognate advisor, methodologist, and content area expert on this dissertation, for recognizing and encouraging my potential as a nonprofit scholar and reaffirming the value I bring to the academy. I am also grateful for the support of Dr. Katrina Miller Stevens, not only for guiding me as a dissertation committee member but also for her sage advice and motivation to just keep swimming.

There were several other faculty members in the Ph.D. program who taught and guided me through the program deserving recognition: Dr. John C. Morris, whose early questions and support developed the core of the proposed model in this study; Dr. John R. Lombard, for helping me to understand methodological concepts and processes; and Dr. Mohamad G. Alkadry, who encouraged me to think differently and to ask hard questions, even if unpopular. I must also recognize the significant contribution of my 
tenth grade English teacher, Mrs. Kirkley, for demanding us to memorize the rules of comma usage.

I am deeply grateful to my colleagues and friends in the Ph.D. program with whom I studied, with whom I coauthored research, with whom I shared the passion for public service, and with whom I consumed a lot of wine. Most especially, I am grateful to the other mothers with whom I shared the blessing of managing a family and pursuing a Ph.D., simultaneously. You kept me swimming.

I am indebted to my family for their love and support of this long mission to complete my doctorate, make a career change, and uproot our family once more for a new life in the Shenandoah Valley. My husband, Asa, who knew twenty years ago that I would be a college professor, was extremely supportive of this endeavor in ways most cannot imagine - renting hotel rooms for the weekend so I could finish papers and take comprehensive exams, being Super Dad to three young children, and for following me in this transition. Thank you for believing in me.

Finally, I am indebted to the time I spent with Linda Davidson, Regional Vice President of the Florida Division of the American Cancer Society. In the short time that I worked with you, I witnessed firsthand the power of combining active listening, bonding with donors, and relationship management as tools of nonprofit fundraising strategy. You helped me to understand donors and volunteers as unique individuals, who shared with me, the desire to make real change in the world. From this practical foundation grew the seeds of what is transformational giving. 
TABLE OF CONTENTS

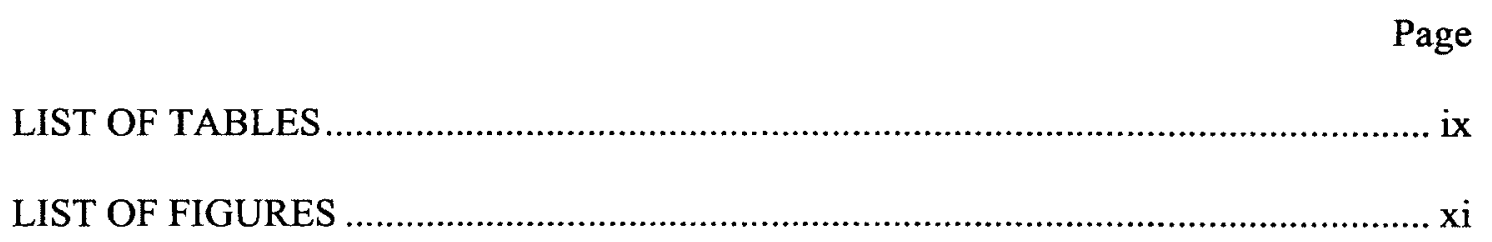

Chapter

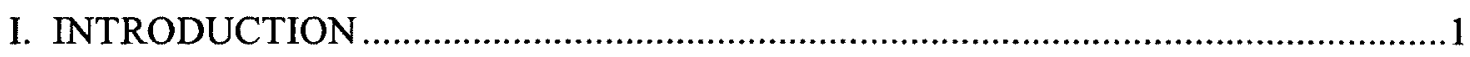

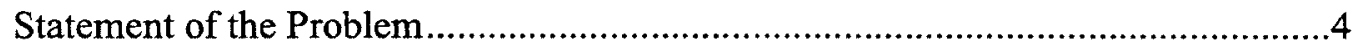

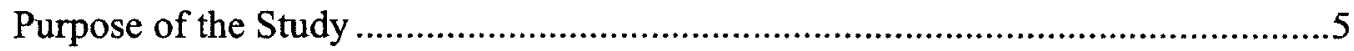

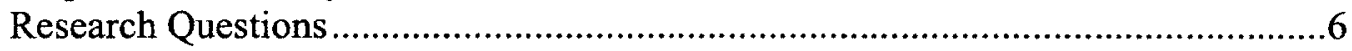

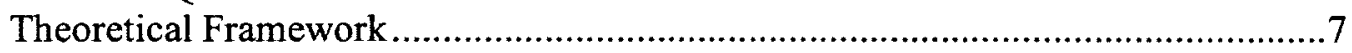

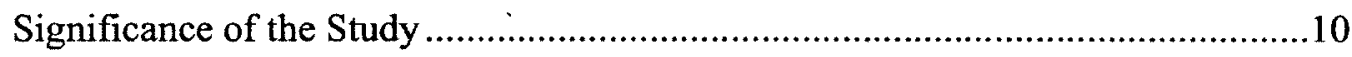

Organization of this Dissertation ..............................................................11

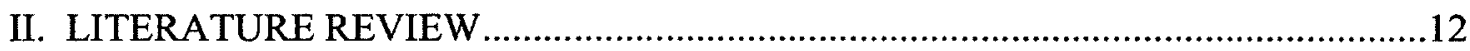

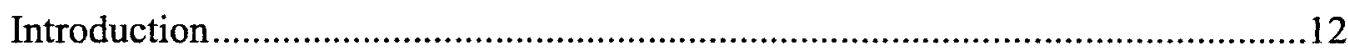

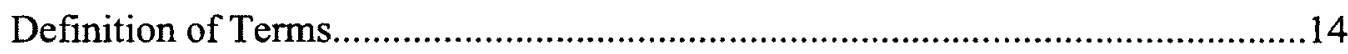

Theoretical Framework.............................................................. 17

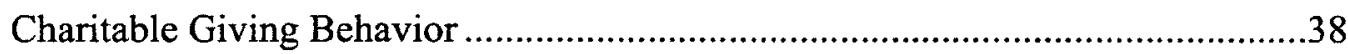

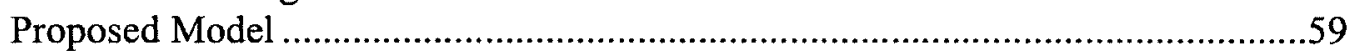

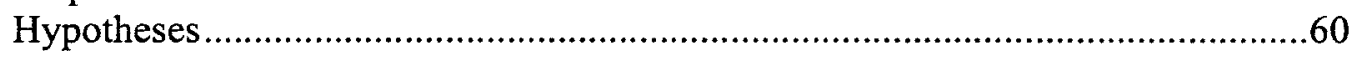

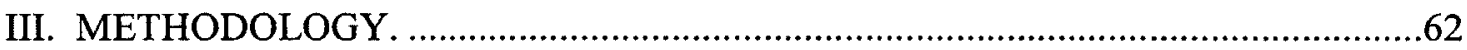

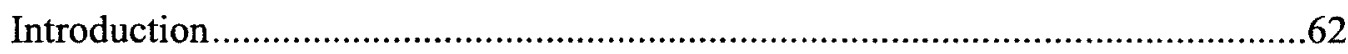

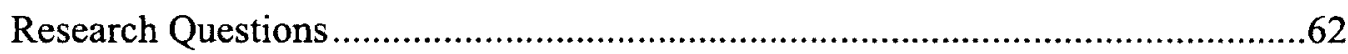

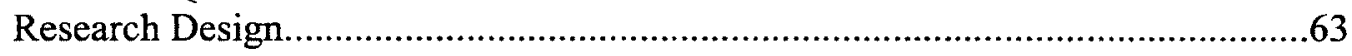

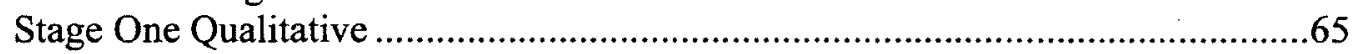

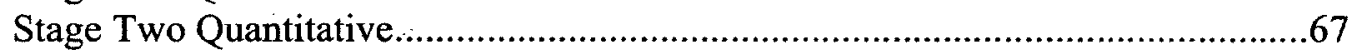

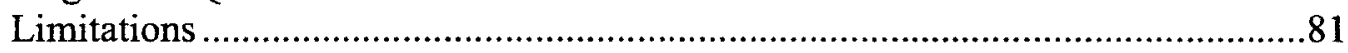

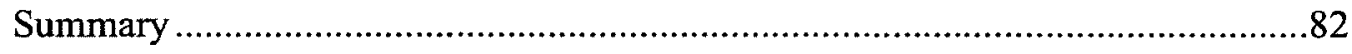

IV. RESULTS

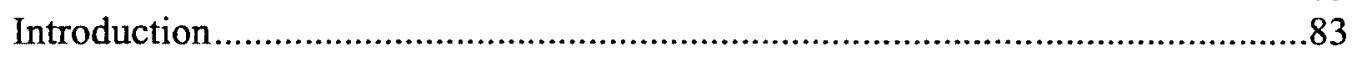

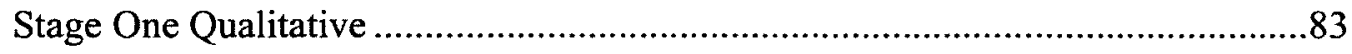

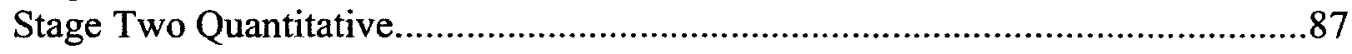

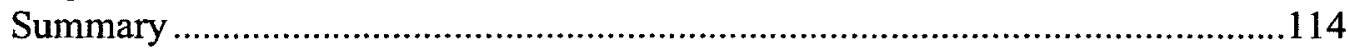

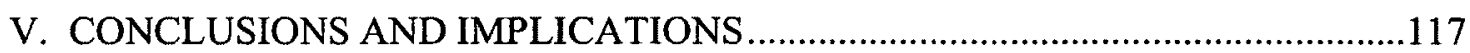

Discussion of the Findings...............................................................................117

Managerial Implications and Suggestions for Future Research ......................127 
Limitations of the Study

\section{APPENDICES}

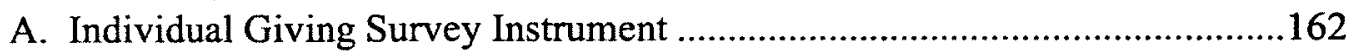

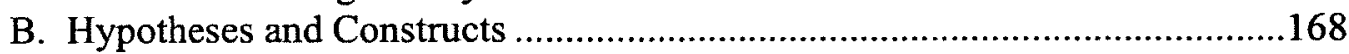

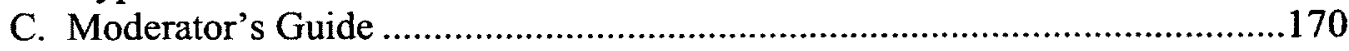

D. Informed Consent for Focus Groups .....................................................173

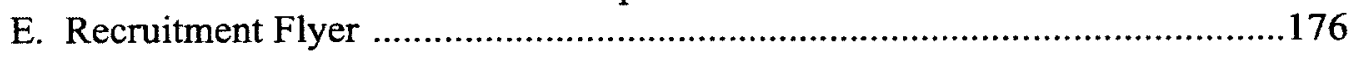

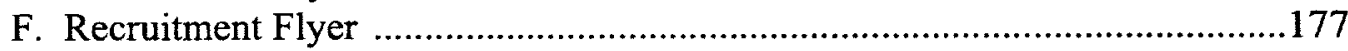

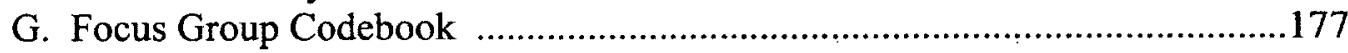

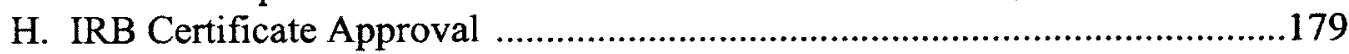

I. Proposed Measurement Model ..............................................................180

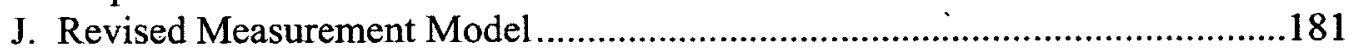

K. Proposed Structural Model....................................................................182

L. Structural Model without Identity Saliency and Relationship Satisfaction....183

M. Structural Model with only Identity Saliency .............................................184

N. Structural Model with only Relationship Satisfaction .................................185 


\section{LIST OF TABLES}

\begin{tabular}{|c|c|c|}
\hline$\#$ & Table & Page \\
\hline 3.1 & Procedure for Validating Constructs & 64 \\
\hline 3.2 & Charitable Giving & 72 \\
\hline 3.3 & Intention to Donate & 73 \\
\hline 3.4 & Identity Saliency & 73 \\
\hline 3.5 & Relationship Satisfaction & 74 \\
\hline 3.7 & Trust & 76 \\
\hline 3.8 & Perceived Need & 77 \\
\hline 3.9 & Perceived Organizational Performance & 77 \\
\hline 3.10 & Perceived Benefits: Demonstrable Utility & 78 \\
\hline 3.11 & Perceived Benefits: Emotional Utility & 78 \\
\hline 3.12 & Perceived Benefits: Familial Utility & 78 \\
\hline 3.13 & Solicitation & 79 \\
\hline 3.14 & Parental Socialization \& Youth Participation & 79 \\
\hline 4.1 & Keywords \& Statements in Focus Groups & 86 \\
\hline 4.2 & Age & 89 \\
\hline 4.3 & Gender & 89 \\
\hline 4.4 & Race & 89 \\
\hline 4.5 & Annual Household Income & 90 \\
\hline 4.6 & Educational Attainment Level & 90 \\
\hline 4.7 & Amount of Family Members with a Military Affiliation & 90 \\
\hline 4.8 & Attendance at religious services, church, or other place of worship & 91 \\
\hline 4.9 & Type of Nonprofit Organization & 92 \\
\hline 4.10 & Size of Nonprofit Organization & 92 \\
\hline 4.11 & Self-reported Estimate of Annual Charitable Giving in U.S. Dollars & 93 \\
\hline 4.12 & Frequency of Charitable Giving & 93 \\
\hline 4.13 & Length of time having been a donor & 94 \\
\hline 4.14 & Model Fit Indices Recommended Thresholds & 95 \\
\hline 4.15 & $\begin{array}{l}\text { Chi Square and Goodness of Fit Indices for the Proposed } \\
\text { Measurement Model }\end{array}$ & 97 \\
\hline 4.16 & $\begin{array}{l}\text { Chi Square and Goodness of Fit Indices for the Revised } \\
\text { Measurement Model }\end{array}$ & 100 \\
\hline 4.17 & Variance Explained by Endogenous Constructs & 102 \\
\hline 4.18 & $\begin{array}{l}\text { Chi Square and Goodness of Fit Indices for the Proposed Structural } \\
\text { Model }\end{array}$ & 103 \\
\hline 4.19 & $\begin{array}{l}\text { Chi Square and Goodness of Fit Indices for the Structural Model } \\
\text { without Identity Saliency and Relationship Satisfaction }\end{array}$ & 111 \\
\hline 4.20 & $\begin{array}{l}\text { Chi Square and Goodness of Fit Indices for the Structural Model } \\
\text { with only Identity Saliency }\end{array}$ & 112 \\
\hline 4.21 & $\begin{array}{l}\text { Chi Square and Goodness of Fit Indices for the Structural Model } \\
\text { with only Relationship Satisfaction }\end{array}$ & 113 \\
\hline
\end{tabular}




\section{LIST OF FIGURES}

$$
\text { \# }
$$

1.1

Figure

Mediating Relational Exchange in the Donor-Nonprofit Relationship

Page

2.1 Schervish Havens Identification Model

6

2.2 Amett, German, \& Hunt Identity Salience Model of Relationship

26 Marketing Success

2.3 Proposed Model of Individual Charitable Giving

4.1 Proposed Structural Model Results

102

5.1 An Evolving Understanding of Marketing

129

5.2 An Evolving Understanding of Fundraising

130 


\section{CHAPTER I}

\section{INTRODUCTION}

A significant social and economic force, the nonprofit sector is experiencing unprecedented growth while shouldering the impact of the recession (Key, 2009; Talansky and Deshmukh, 2011). Consequently, the increased competition for financial resources is requiring new and improved approaches to fundraising. Since 1995, when this data was first tracked, the number of nonprofit organizations registered with the Internal Revenue Service (IRS) has increased $68 \%$ percent, numbering over 1.5 million in 2011 (Roeger, Blackwood and Pettijohn, 2011). Supported by several recent studies of the state of the nonprofit sector, the impact of the demand for services during the recession can also be attributed to an increase in unemployment, poverty, and government budget cuts.

Increased demand for services and increased competition for resources are consistent refrains in nonprofits in recent years. In a survey of 1,935 nonprofit organizations by the Nonprofit Finance Fund (NFF), eighty-seven percent of organizations surveyed report that current economic conditions continue to impact their operations and eighty-five percent anticipate that demand will continue to increase this year (Talansky and Deshmukh, 2011). Less than half of the nonprofits are able to meet the increased demand for services and sixty percent have less than three months of operating expenses put aside. In a separate study by the Nonprofit Research Collaborative, results also detail concerns over increased demand for services. A majority of nonprofit respondents cite increased demand for services over the past eight 
years, while seeing either a decline in funding or very modest growth in funding (Nonprofit Research Collaborative, 2011).

At the same time, charitable giving levels have decreased. In 2010, total private giving by individuals, foundations, and corporations was estimated to be $\$ 290.89$ billion, down 3.0 percent from 2008 (Nonprofit Research Collaborative, 2011). Individual giving is the largest revenue source for most nonprofit organizations and accounted for $\$ 234.6$ billion in 2010. These charitable contributions account for about eighty-one percent of total contributions, which demonstrates the importance of individual giving for nonprofit organizations in generating revenues (Nonprofit Research Collaborative, 2011). While nonprofits are facing limited resources to meet significant increases in demand, they are also looking at new fundraising strategies and opportunities for more meaningful relationships with supporters.

Research and practice in nonprofit marketing has increasingly been focused on the benefits of relational exchange, but only in the donor relationship mediated by donor identification with the charity or by donor satisfaction with the value exchange. In practice, nonprofits have long known the value of maintaining relationships with donors over time, that it is easier to retain donors and upgrade them than to constantly recruit new donors (Wilson and Pimm, 1996). However, recommended donor management, retention strategies, and tactics are not widespread practice in the sector (Sargeant, 2001; Hager and Brudney, 2004).

Philanthropic behaviors are similar to prosocial behaviors in that they share a concern for others and influence philanthropic acts. Philanthropic behaviors are voluntary action for the common good, including charitable giving, volunteering, and 
association (Martin, 1994). Whereas, prosocial behaviors are "voluntary actions that are intended to help or benefit another individual or group of individuals" (Eisenberg and Mussen, 1989, p. 3). They comprise actions that help the public good involving helping, sharing, donating, cooperating, and volunteering (Brief and Motowidlo, 1986). Likewise, both prosocial behavior and philanthropic action are inspired by a mix of both altruistic and self-interested motivations (Burlingame, 1993). This study explores one type of philanthropic behavior - donating.

The primary theories explored in this study are relationship marketing and identity saliency. Kotler and Armstrong's (1999) definition of relationship marketing “involves creating, maintaining and enhancing strong relationships with customers and other stakeholders. Relationship marketing is orientated towards the long-term. The goal is to deliver long-term value to customers and the measure of success is long-term customer satisfaction" (p. 50). Relationship marketing in nonprofits primarily focuses on the donor-nonprofit relationship; however, other stakeholders can include volunteers, vendors, funders, and elected officials, among others. Often called donor cultivation or stewardship, relationship marketing in the nonprofit context seeks to concretize relationships with stakeholders for the long-term.

Based in microsociology, a branch of sociology that focuses on the daily human interactions, identity theory investigates people's identity related behaviors through the associations between the self, individual roles, society, social structure, and role performance (Hogg, Terry, and White, 1995). These identity related behaviors influence the choices and decisions people make. Identity salience, the prominence of one identity over another, provides an understanding of the attraction of donors to a particular cause 
(Arnett, German, and Hunt, 2003). These two theories serve as the theoretical framework for this study.

\section{Statement of the Problem}

This research investigates relationship marketing in an emerging sector of interest and influence - nonprofit. Creating and cultivating long-term relationships with key stakeholders is the crux of relationship marketing. Most research in marketing has examined the relationships that are economic in nature, business to business, and in forprofit firms (Arnett, German, and Hunt, 2003). Only recently has the theory of relationship marketing been extended to the nonprofit context in nonprofit to donor relationships (Arnett et al., 2003; Bendapudi, Singh, and Bendapudi, 1996; Bhattacharya, Hayagreeva and Glynn, 1995). These studies conclude that by shifting the focus in practice from transactional exchange to relational exchange with donors, the nonprofit's organizational capacity will develop and be sustainable over the long-term.

The challenges faced by managers in the nonprofit sector are similar to those of the private sector. The nonprofit sector is challenged by the intense competition for resources and business management practices like accounting, public relations, strategic planning, human resources, and staff burn out; however, nonprofits are dependent on volunteer labor, contributions, and are held accountable to a mission that is public in nature. Increasingly, it is more difficult for nonprofit organizations to gain donor support because they are continuing to face increased competition from other charitable causes and organizations and diminishing government support (Bendapudi, Singh, and Bendapudi, 1996). Nonprofit organizations compete for limited resources while demand 
for services continues to rise. In response, both theorists and practitioners have adopted private sector marketing strategies to the nonprofit sector (Kotler and Levy, 1969; Kotler, 1979; Smith and Beik, 1982; Lovelock and Wineberg, 1984; Harvey, 1990; Kotler and Andreasen, 1991; Kotler, 1994; Keegan, Moriarity, and Duncan, 1995).

Developing a competitive advantage is achieved through market segmentation and targeting, as well as, positioning the organization. In relationship marketing, the key to success is the identification of relationship inducing and influencing factors of relational exchange and leveraging them to benefit of the organization (Morgan and Hunt, 1994). The sustainability of resources - donated time and labor, and financial support - in the nonprofit context is best achieved through relationship marketing approach.

\section{Purpose of the Study}

The purpose of this research is to support and extend recent nonprofit relationship marketing research, which has sought to explain the antecedents to successful relationships with nonprofit donors and the effects of identity saliency and donor satisfaction in nonprofit relationship marketing success. The thesis of this research is that two key relational factors, "identity saliency," drawn from social psychology and organizational behavior, and "relationship satisfaction," drawn from social exchange theory, mediate relationship exchange in the nonprofit context (Figure 1.1). In summary, this study explores relationship marketing in the nonprofit context by (1) positing that identity saliency and relationship satisfaction mediate relational exchange in the nonprofit 
context and (2) by investigating several relationship-inducing factors that influence identity saliency and relationship satisfaction.

\section{Research Questions}

This study investigates relational exchange between nonprofits and donors, in which financial and in-kind donations are given. The goal of this research is to provide nonprofit organizations with a means to evaluate their marketing strategy and make adjustments to streamline and focus their efforts with a relational approach to developing donor engagement and support. This research addresses the following questions:

(1) To what extent do identity saliency and relationship satisfaction mediate relational exchange between nonprofits and donors?

(2) What are the charitable giving motivations that influence identity saliency and relationship satisfaction in relational exchange between nonprofits and donors?

Figure 1.1 Mediating Relational Exchange in the Donor-Nonprofit Relationship

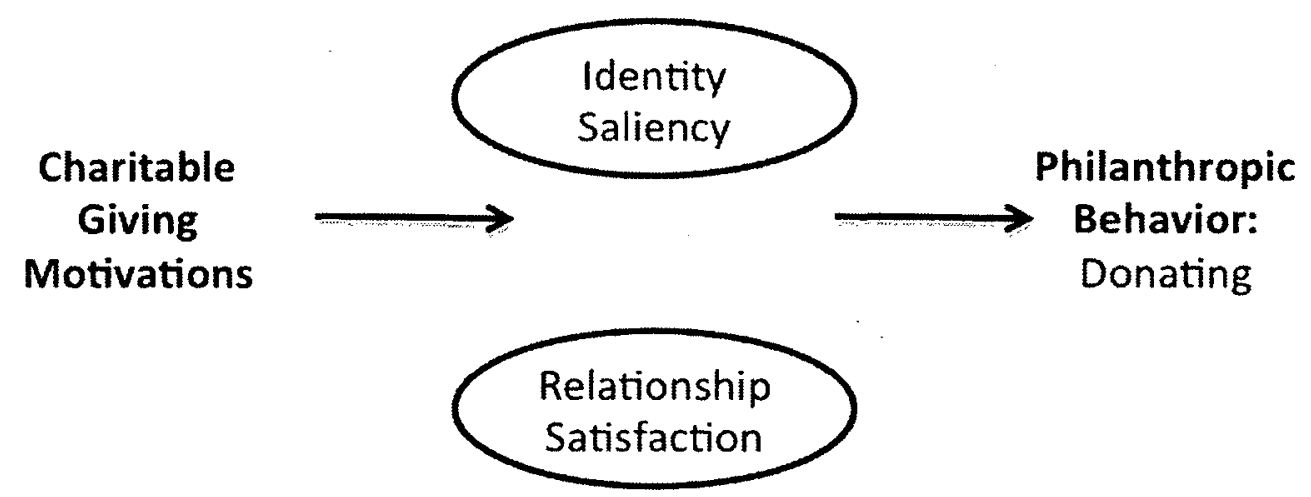




\section{Theoretical Framework}

Identity salience is a subfield of identity theory, which holds that people have several "identities," or understandings of themselves, that are arranged hierarchically (Burke, 1980; Laverie, Kleine, and Kleine, 2002). The more salient or prominent the identity, the more likely it is to affect behavior like donating. For example, a person can possess several identities like mother, wife, citizen, environmentalist, volunteer, university alumnus, arts enthusiast, and cancer survivor. In any given situation the identities move around in the hierarchy, rising and falling in salience. Arnett et al. (2003) found that alumni who were actively involved as students in organizations or groups were more likely to give years later as alumni. That is, they identify more with the university and that identity is stronger or more salient when they were involved, authentically as a student.

Social exchange theory becomes a theoretical foundation for measuring success in relationship marketing (Anderson and Narus, 1990; Dwyer, Schurr, and Oh, 1987; Morgan and Hunt, 1994). In business-to-business relationships, trust and commitment play a larger role than identity saliency (Morgan and Hunt, 1994; Arnett et al., 2003). In contrast, identity saliency plays a crucial role in contexts that have social exchange and benefits where participants derive complex personal, emotional, and non-economic benefits (Dwyer et al., 1987). Each partner in the social exchange earns rewards that support the development of trust and a commitment to each other (Blau, 1964; Dwyer et al., 1987; Homans, 1958). In the nonprofit context, relationship marketing success is measured by generating supporting behaviors from "key stakeholders" (Mael and Ashworth, 1992) or donors. 
Philanthropic behaviors can be conceptualized as a relational exchange rather than a simple transaction. Transactional marketing is focused on capturing customers for a one-time purchase or transaction while relationship marketing envisions the first sale or transaction as the beginning of a long-term relationship. With the goal of constantly acquiring new customers, transactional marketing concentrates on price, short-term benefits, and product performance with limited service. It is generally thought of as an exchange of money for something of value like products or services. After Kotler and Levy (1969) broadened the definition of marketing to include charitable activities, Kotler (1972) broadened the concept of transaction by defining it as an exchange of something of value between each party. In doing so, the criterion for exchange can be anything of value; for example, a donation or volunteer service in exchange for a warm, glowing feeling or gratification. Relationship marketing is centered on repeat sales, positive customer interactions, and a quality experience. Relationship marketing is customer centric, implying that the customer does not buy a product or service; but instead buys a complete solution for a specific problem or need. Accordingly, if the need is satisfied and the company can establish and cultivate a relationship with the customer, then the company will gain repeat sales. In the nonprofit context, successful relational exchanges with repeat donors, volunteers, and other stakeholders enable an organization's resources to grow and be more sustainable over the long-term (Brudney and Meijs, 2009).

Relationship marketing is about developing and nurturing long-term relationships with key stakeholders. The focus of nonprofit marketing research has been on the transactional goals of understanding donor motivations, predictors of charitable giving, and the recruitment of new donors. However, philanthropic behaviors differ from other 
marketing exchanges. Donors who donate money or in-kind gifts of products or services receive non-economic or monetary benefits. The reward of these motivating, intangible benefits is valued most in the relational exchange between donor and the nonprofit organization (Arnett et al., 2003). The two partners in the relational exchange of values invest time, money, commitment, and an emotional element (Rentschler, Radbourne, Carr and Rickard, 2002). Philanthropic relational exchange can be intensely personal where supporters donate for emotional reasons. The relationship marketing paradigm is more conducive than transactional exchange to developing philanthropic behaviors as "relationship marketing is about healthy relationships characterized by concern, trust, commitment, and service" (Buttle, 1996, p. 8). Having long-term relationships with donors enable nonprofit organizations to renew charitable giving and build sustainable financial and volunteer resources (Brudney and Meijs, 2009).

Arnett et al. (2003) propose that relationship marketing is a worthwhile strategy for relationships with "high levels of social exchange" like business to consumer and nonprofit marketing. However, in their research they hypothesize that the context of the relationship may require different relationship characteristics than those for-profit relationships that are purely economic in nature and include business-to-business transactions. They understand relationship marketing to be a strategic option that enables firms to gain a competitive edge with economic and noneconomic benefits.

Organizations are then competing for the warm, fuzzy feeling or other intrinsic motivations evoked in the social exchange relationship. In their study of higher education fundraising, results confirm that upon the implementation of relationship marketing strategies donors become partners in the success of the nonprofit mission 
(Arnett et al., 2003). The process of interacting with donors becomes one of creating value in the social exchange. The resulting partnerships or relationships with donors then become tools to increase the nonprofit organization's ability to compete for financial resources with other nonprofit organizations.

\section{Significance of the Study}

This research contributes to the literature of organization theory, relationship marketing, and nonprofit management. The findings of this research provide nonprofit organizations with a framework for nurturing existing donor relationships and attracting new donors. Greater and deeper knowledge of the donor base allows for more targeted strategies to attract and retain supporters, making the most efficient and effective use of limited organizational resources. This research makes the following contributions: A model of relational marketing for nonprofits using both identity saliency and relationship satisfaction as mediating variables. An exploration of relationship inducing factors for the donor/nonprofit relationship is investigated, which can be used in future scholarly research.

(3) An understanding of and empirical support for the importance of a more strategic approach conceptualized in relational exchange with donors.

This research provides management implications for nonprofit executives, development professionals, and public administrators as the public and nonprofit sectors 
endeavor to understand how best to create and nurture a caring society and to build a sustainable network of support.

\section{Organization of this Dissertation}

The dissertation is organized as follows. Chapter II presents an in-depth review of the relevant literature related to identity saliency, relationship satisfaction, charitable giving behavior, and the factors that influence giving. The conceptual model is discussed in greater detail and the research hypotheses are presented. Chapter III presents the methodology and a discussion of the various scales used to measure the constructs. Chapter IV presents a discussion of the data collection process, an assessment of the model constructs, how the structural equations model is run and the various hypotheses are tested, and the findings. Chapter V presents a discussion of the findings, the theoretical and managerial implications, limitations, and suggestions for future research. 


\section{CHAPTER II}

\section{LITERATURE REVIEW}

\section{Introduction}

While there is a significant amount of research in philanthropy from multiple disciplinary perspectives, philanthropy is a relatively new field of academic study (Graddy, Ferris and Sohn, 2011). Only since the early 1980s has the study of philanthropy developed into a distinct field (Katz, 1999; Graddy et al., 2011). Accordingly, the definition of philanthropy has evolved since its first use by Sir Francis Bacon in the $17^{\text {th }}$ century as goodness beyond a level of humanity (Bacon and Pitcher, 1985). The modern definition of philanthropy has shifted from a singular focus on "goodwill to fellow members of the human race" to a focus on the "active effort to promote human welfare, an act or gift done or made for humanitarian purposes" or "an organization distributing or supported by funds set aside for humanitarian purposes" (Merriam-Webster Online, 2011). Here, the understanding of philanthropy develops from the feeling of goodwill towards humanity to goodwill towards humanity put into action. "Voluntary action for the public good" (Payton, 1988) through charitable giving is the focus of this research.

Punctuated by periodic assessments of the literature, research about charitable giving behavior and fundraising strategy has progressed into "substantive, objective research rather than a casual acceptance of anecdotal evidence" (Lindahl and Conley, 2002, p. 91). Together with key scholars and fundraising practitioners, Carbone (1986) set an agenda for fundraising research, suggesting additional research in the field around 
three key areas: the philanthropic environment, the professional development of fundraisers, and fundraising management. Within the philanthropic environment, Carbone (1986) highlighted donor motivations as a key focus of future research, understanding what motivates people to give. Since then, our knowledge about the philanthropic environment and donor motivations has expanded significantly, supported by empirical research and theoretical efforts as well as continued assessments and meetings of scholars and practitioners to focus the line of inquiry.

Payton, Tempel, and Rosso (1991) and Bekkers and Wiepking (2011a, 2011b) suggest that theory building in philanthropy is best achieved through the use. of a multidisciplinary approach. The study of philanthropy is an applied social science like business and public administration, borrowing heavily from the liberal arts and social psychology, economics, marketing, and management. The philanthropic research agenda was refined again, in 1995, to focus on the demographics of donors, predictors and motivations of philanthropy, the management of nonprofits, the influence of government and the impact of public policy, social equity, ethical practices, and the fundraising profession (Burlingame, 1997).

Recently, the most thorough literature review to date on charitable giving behavior was conducted by Bekkers and Wiepking (2011a, 2011b). Reviewing over 550 empirical studies on charitable giving behavior, the authors propose a framework for future research around eight key mechanisms that have been studied as antecedents to charitable giving behavior: awareness of need, solicitation, cost and benefits, altruism, reputation, psychological benefits, values, and efficacy. They cite that the strongest limitation of previous research was because the primary focus had been on describing 
charitable donors, who gives, which produced lots of predictive data on the characteristics of donors and philanthropy; however, this descriptive research does not focus on understanding why they give, an approach found in limited quantities in the reviewed studies. "Knowledge on who gives what is of limited value to scholars who want to test theories on philanthropy and to fundraisers who wonder how they should design fundraising campaigns" (Bekkers and Wiepking, 2007, p. 19). These collaborative efforts by both scholars and fundraising professionals to assess the research and state of knowledge in our field and refine the future research agenda allows practitioners to base "more of their efforts as fundraisers on informed inquiry," a primary goal of this dissertation (Lindahl and Conley, 2002, p. 92).

This chapter focuses on the review of the literature and rationale for the development of the theoretical model presented in this research. At first, a discussion of the theoretical basis for charitable giving behavior and fundraising is presented. Next, the focus moves to a review of the literature on identity saliency and relationship marketing. Then the chapter discusses in detail the predictors of charitable giving and the motivational factors that affect charitable giving behavior. Support for charitable giving motivations is found both in the literature and in the results from the preliminary focus group interviews conducted for this study. Finally, the theoretical model linking the charitable giving motivations, identity saliency, relationship satisfaction, and level of charitable giving is presented along with the related research hypotheses.

\section{Definitions Of Terms}

In order to provide some clarity, the following definitions are provided for the terms used throughout the study. 


\section{Marketing}

The definition of marketing by scholars and professionals has evolved based on their understanding of marketing's role and function in an organization. The iterations range from the long accepted exchange paradigm, "to create exchanges that satisfy individual and organizational goals" (Lusch, 2007, para. 3; Alderson, 1957; Bagozzi, 1975; Houston and Gassenheimer, 1987; Hunt, 1976; Kotler and Levy, 1969) to an understanding of marketing as one of delivering value through customer relationships to value cocreation. Last revised in 2007, the American Marketing Association (AMA) defines marketing as "the activity, set of institutions, and processes for creating, communicating, delivering, and exchanging offerings that have value for customers, clients, partners, and society at large" (AMA, 2011). Sheth and Uslay (2007, p. 302) argue that this new definition of marketing is "not bold enough" and future revisions should adopt a value cocreation approach where the firm and the consumer create value together. This dissertation acknowledges that marketing "is now amidst a paradigm shift from exchange (value in exchange) toward value cocreation (value for all stakeholders), with an intermediate iteration at value creation (value in use and relationship marketing)" (Sheth and Uslay, 2007, p. 305).

\section{Philanthropy}

Although the commonly accepted definition of philanthropy has changed over time, "voluntary action for the public good" (Payton, 1988) is a succinct, yet comprehensive, definition of philanthropy because it encompasses both a sense of community and compassion. A sense of compassion includes nonprofit organizations 
like soup kitchens and homeless shelters, while a sense of community involves hospitals, schools, museums and most arts organizations (Lindahl, 2011).

\section{Nonprofit}

The nonprofit sector in the United States is comprised of institutions and organizations that are neither business nor government. Other names given for this sector are not-for-profit, the third sector, the independent sector, the philanthropic sector, the voluntary sector, the charitable sector, and the social sector. While the sector is called nonprofit, it does not mean that the organizations populating it cannot be profitable. It simply means that accomplishing a charitable mission as opposed to profits is the primary motivation (Board Source, 2011). The Association of Fundraising Professionals (AFP) defines nonprofit as "that pertains to or provides services of benefit to the public without financial incentive" (Association of Fundraising Professionals, 2011). In the United States these types of organizations are regulated under section 501 (c) of the Internal Revenue Service (IRS) tax code, which outlines the more than 25 classifications of nonprofits eligible for tax exemption. Also known as charities, 501 (c) 3 is the most common type of nonprofit organization, which are those nonprofit organizations receiving broad public support from multiple sources.

\section{Charitable}

"Giving to those in need, giving for benevolent purposes, for or pertaining to a charity or charities" (Merriam-Webster, 2011). Charitable can be used to refer to giving behaviors, giving motivations, and affiliation with a nonprofit. 


\section{Charitable gift or giving}

AFP defines charitable giving as "a (usually tax-deductible) gift made to a notfor-profit organization" (Association of Fundraising Professionals, 2011). Charitable giving can include several types of resources such as gifts of time, effort, money, or goods and services; however, this study exclusively examines charitable gifts of money. It is important to note here that charitable giving is often referred to as a philanthropic behavior, which also includes the donation of several types of resources as listed above (Martin, 1994).

\section{Fundraising}

While the term, fundraising, can be used to describe gathering financial resources for political campaigns or for raising capital investment for business, this study is focused exclusively on raising support for charitable nonprofit organizations. Fundraising is defined as "the raising of assets and resources from various sources for the support of an organization or a specific project" (Association of Fundraising Professionals, 2011). Lindahl $(2011$, p. 4) defines charitable fundraising "within a marketing framework...as the creation and ongoing development of relationships between a nonprofit organization and its various donors for the purpose of increasing gift revenue."

\section{Theoretical Framework}

Two primary theoretical streams support relational exchange between nonprofits and donors: social exchange and identity saliency. Social exchange is at the theoretical 
heart of relationship marketing and identity saliency is increasingly being used as a moderating construct in charitable giving (Callero, 1985; Callero, Howard, and Piliavin, 1987; Lee, Piliavin, and Call 1999, Arnett et al., 2003). The following section describes these theories and their application in understanding charitable giving behavior.

\section{Social exchange}

Originating in economics, psychology, and sociology, social exchange theory builds upon the theoretical foundations of systems theory (Lindahl, 2011). The balancing act of managing internal and external components of a system within the nonprofit fundraising environment is the purview of professional fundraisers. In the donornonprofit relationship, the donors make a contribution and the organization responds, providing both tangible and intangible rewards to the donors. As this pattern of behavior repeats, it takes on the appearance of relationship marketing or as Burnett (1988) calls it, relationship fundraising. Lindahl (2011) places professional fundraisers in the role of joining together donors and nonprofits in a mutually beneficial relationship (exchange). Fundraisers must "realize that every gift comes with a relationship that needs to be monitored and nourished" (p. 89).

First mentioned by Aristotle $(1999,1162 \mathrm{a} 34-1163 \mathrm{a} 24)$ in the context of gift giving, the theory of social exchange as an explanation for human behavior has been discussed in a number of different time periods. Aristotle compared gift giving to loans because it is "not based on stated terms, but the gift or other service is given as to a friend, although the giver expects to receive an equivalent or greater return, as though it had not been a free gift but a loan" $(1999,1162 \mathrm{a} 34-1163 \mathrm{a} 24)$. 
However, it was Homans (1958) who developed the first systematic theory to better explain the social behavior of humans in economic situations with tangible and intangible benefits.

Social behavior is an exchange of goods, material goods but also non-material ones, such as the symbols of approval or prestige. Persons that give much to others try to get much from them, and persons that get much from others are under pressure to give much to them. This process of influence tends to work out at equilibrium to a balance in the exchanges. For a person in an exchange, what he gives may be a cost to him, just as what he gets may be a reward, and his behavior changes less as the difference of the two, profit, tends to a maximum. (p. 606)

Social exchange, as understood by Blau (1964) and later incorporated into marketing theory by Bagozzi (1974), is "the voluntary actions of individuals that are motivated by the returns they are expected to bring and typically do in fact bring from others" (Blau, 1964, p. 91).

Separate from his treatise on the self-interested economic exchange, Adam Smith (1759) developed a moral theory, which focused on the understanding of two competing concepts: individual self-love and a social whole. In The Theory of Moral Sentiments, he suggested that there are intangible benefits from social exchange. Smith (1759) examined approval in social exchange, noting that people give approval aware of its diffuse return. "Kindness is the parent of kindness; and if to be beloved by our brethren be the great object of our ambition, the surest way of obtaining it is by our conduct to show that we really love them" (p. 22). Nord (1973) argued that contemporary social exchange theory has its origins in Smith's work but was largely ignored by latter theorists because it was overshadowed by Smith's economic volume, The Wealth of Nations (1776). 
Influenced by the work of B.F. Skinner and the Behavioral Psychologists, Homans (1961) attempted to reduce human behavior to a series of equations, formulating five propositions of social exchange: success, stimulus, value, aggression/approval, and rationality. (1) The success proposition suggests that for all actions taken by people, the more often a particular action is rewarded the more likely the person is to continue that action. (2) If the stimulus is similar to successful social exchanges in the past, the more likely the person is to perform the action. (3) The more valuable the rewards, the more likely the person repeats the action. (4) When expected returns go unawarded, anger begets aggressive action. Likewise, unexpected rewards beget additional action. (5) Finally, in choosing between alternative actions, a person will choose that which is perceived to be more valuable and achievable.

\section{Differences between social and economic exchange}

Understanding social interaction as an exchange process is logical because people are motivated by rewards in their social relations (Blau, 1968). There are three distinct differences between social and economic exchange. First, the obligations incurred and the return is not clearly specified in advance; one supplies benefits and creates diffuse future obligations (Blau, 1968, p. 454). Second, economic exchange can be enforced while social exchange requires some measure of trust in the relationship, growing from minor transactions to major transactions. For example, donors may make several smaller gifts before making a major donation to a nonprofit after trust has been established. Finally, the benefits received in social exchange are tied to the source unlike economic benefits whose value can be modified by the significance of the relationship (p. 455). 
The use of marketing in nonprofit and fundraising suggests that fundraisers understand exchange as a continuum from a simple sales transaction to a gift transaction. Lindahl (2011) suggested that donor expectations regarding exchange rewards in special event dinners and corporate sponsorship differ from those of purely gift transactions. There are limitations or boundaries to the applicability of exchange to explain all social behavior. Social exchange refers to voluntary social actions that are dependent on worthwhile benefits from others. These actions stop when the expected returns are not forthcoming (Blau, 1968). In this manner, social interaction outside the economic sphere is more similar to economic exchange where benefits rendered will yield returns. Miller (2005) stated that one of the primary limitations of social exchange theory is that it reduces social interaction to a rational process. If purely rational, then social exchange cannot explain altruistic actions or purely selfless acts, which sometimes occur in charitable giving behavior.

The use of social exchange theory in the explanation of charitable giving behavior is widespread. Mixer (1993) applied social exchange theory in fundraising:

The process of giving involves a circumstance in which individual prospects and donors have needs and desires that can be defined as internal motivations and that can be activated or channeled by external influences. The circumstance also includes recipients - individuals or organizations - with desires and needs that can be met in part by gifts. The transactions between the givers and the recipients are triggered by an argument or case for support, and result in what Blau (1968) calls social exchange. (p. 9)

Donors make a charitable gift and are rewarded with tangible and intangible benefits, however diffuse, in the exchange. Scholars have discussed the exchange of benefits or returns to the donor in a number of different ways: altruistic and nonaltruistic (Andreoni, 1990; Radley and Kennedy, 1995; Feldman and Feldman, 1985; Fultz, 
Batson, Fortenbach, McCarthy, and Varney, 1986), emotional and economic (Olson, 1965; Kottasz, 2004; Webber, 2004; Cialdini, 1987; Mathur, 1996; Kottasz, 2004; Sargeant, Ford, and West 2006), extrinsic and intrinsic (Sargeant et al., 2006). Perhaps the most comprehensive framework for understanding social exchange benefits in charitable giving behavior is 'perceived benefits,' encompassing demonstrable, emotional, and familial utilities (Sargeant et al., 2006). In this evolution from transactional exchange into donor-nonprofit relationships, social exchange theory becomes a theoretical foundation for measuring success (Anderson and Narus, 1990; Dwyer et al., 1987; Morgan and Hunt, 1994).

\section{Identity theory and identity salience}

Originating in microsociology, a branch of sociology focused on the different kinds of human social interactions, identity theory relates attitudes about the self to the role relationships and role-related behavior of individuals (Stryker, 1968). Identities are defined as "internalized sets of role expectations, with the person having as many identities as she or he plays roles in distinct sets of social relationships" (Stryker, 1980, p. 46). Identity theorists posit that the self consists of an assemblage of identities, each of which plays a particular role (Stryker, 1968, 1980; Callero, 1985; Greenwood, 1994; Stryker and Burke, 2000). The more salient or prominent the identity, the more likely it is to affect behavior like donating. For example, a person can possess several identities like father, husband, citizen, volunteer, university alumnus, and veteran. In any given situation the identities move around in the salience hierarchy, rising and falling in salience. The influence of identity salience is significant “...because the salience we 
attach to our identities influences how much effort we put into each role and how well we perform in each role" (Andreassi, Desrochers, and Thompson, 2004, p. 61).

Burke and Reitzes (1981) articulated three characteristics of an identity. First, identities are formed through the social processes of identifying with social groups or categories, social interaction with others, and the influence of role environments.

Second, identities are understandings of the self, formed in specific circumstances, and organized hierarchically. Lastly, "identities are symbolic and reflexive" whose self meanings are understood by the individual through interaction with others (p. 84).

The different roles one plays in social relations are an example of identities (Stryker and Serpe, 1982). Suitably, these role identities affect behavior because each role has related expectations (Burke and Reitzes, 1981). Over time, the self internalizes a particular identity. The role corresponding to the identity also personalizes the identity, which in turn creates ownership of the identity and influences human behavior, in this case charitable giving.

It is important to distinguish between identity theory and social identity theory. Social identity theory focuses on group process and intergroup relationship instead of role behavior. Social identity theory suggests that the groups to which people belong (e.g., theatre subscriber, religious denomination, nationality) help define who they are (Hogg et al., 1995). Identity theory focuses on the individual, encompassing the multiple roles or identities a person plays (e.g., wife, mother, daughter, teacher, artist).

Although they evolve, identities are relatively stable over time because they are influenced by beliefs, principles, and commitments of the individual, which are also relatively constant throughout lives (Serpe, 1987; Kihlstrom and Cantor, 1984; 
Rosenberg, 1979). These beliefs, principles, and commitments are a significant part of understanding intentional behavior of individuals, what we care about, and how we react emotionally in social interaction (Greenwood, 1994).

An example of a stable identity is military service. The feelings associated with military service tend to reflect what their feelings were when they left the service. Veterans may remember feelings of pride in wearing the uniform and in belonging to an elite group, and they may feel intense patriotism from serving their country and a sense of accomplishment regarding their promotions and awards, as well as, an appreciation for the values that military service cultivates. "Indeed the relationship between identity (self) and behavior is complex and probably reciprocal" (Burke and Reitzes, 1981, p. 88). Although these experiences are in the past, they contribute to the stability of the person's "veteran" identity and influence their behavior. Burke and Reitzes (1981) suggested that individuals are motivated to act based on actions that strengthen and confirm their identity.

Understanding the "self" and the "identities" associated with the self are key to understanding the decision process leading to charitable giving (German, 1997). Given that individuals often act based on behavior that reinforces, supports, and confirms their identities, as a nonprofit organization, it is important to recognize the impact of identification on charitable giving. Schervish and Havens (1997) also developed a theory of identification, the Identification Theory of Care, as it relates to charitable giving behavior based on research performed about wealth and philanthropy (Schervish, 1992; Schervish and Havens, 1997) that presented an identification model which includes five factors that induce philanthropic commitment. (Figure 2.1). It focuses on the intricacies 
of where, why, and how much people choose to give. The stronger the identification is, the greater the level of care and the greater the level of commitment. In contrast to the altruistic model of giving, the identification model suggests that research on charitable giving behavior should consider the "presence of the self and, in particular, the factors inducing the identification of self with the needs and aspirations of others" (Schervish and Havens, 1997, p. 236). They compare their identification theory to other scholars with similar contributions to the theory of identification (Martin, 1994; Jackson, Bachmeier, Wood, and Craft, 1995; Piliavian and Callero, 1991; Jenks, 1999; Coleman, 1990; Hornstein, 1972, 1976; and Staub, 1978). "The organisations in which we participate, the cultural frameworks we embrace, the pleas to which we are attuned and the resources we deem able to give are inextricably linked" (Schervish and Havens, 1997, p. 242). Voluntary philanthropic behavior motivated by the needs of others "is a central determinant of helping and results from the combination of personal beliefs and associational ties that bring the needs of others into one's purview" (p. 239). Their Identification Theory of Care suggests that individuals give to causes with which they personally identify. 
Figure 2.1 Schervish Havens Identification Model

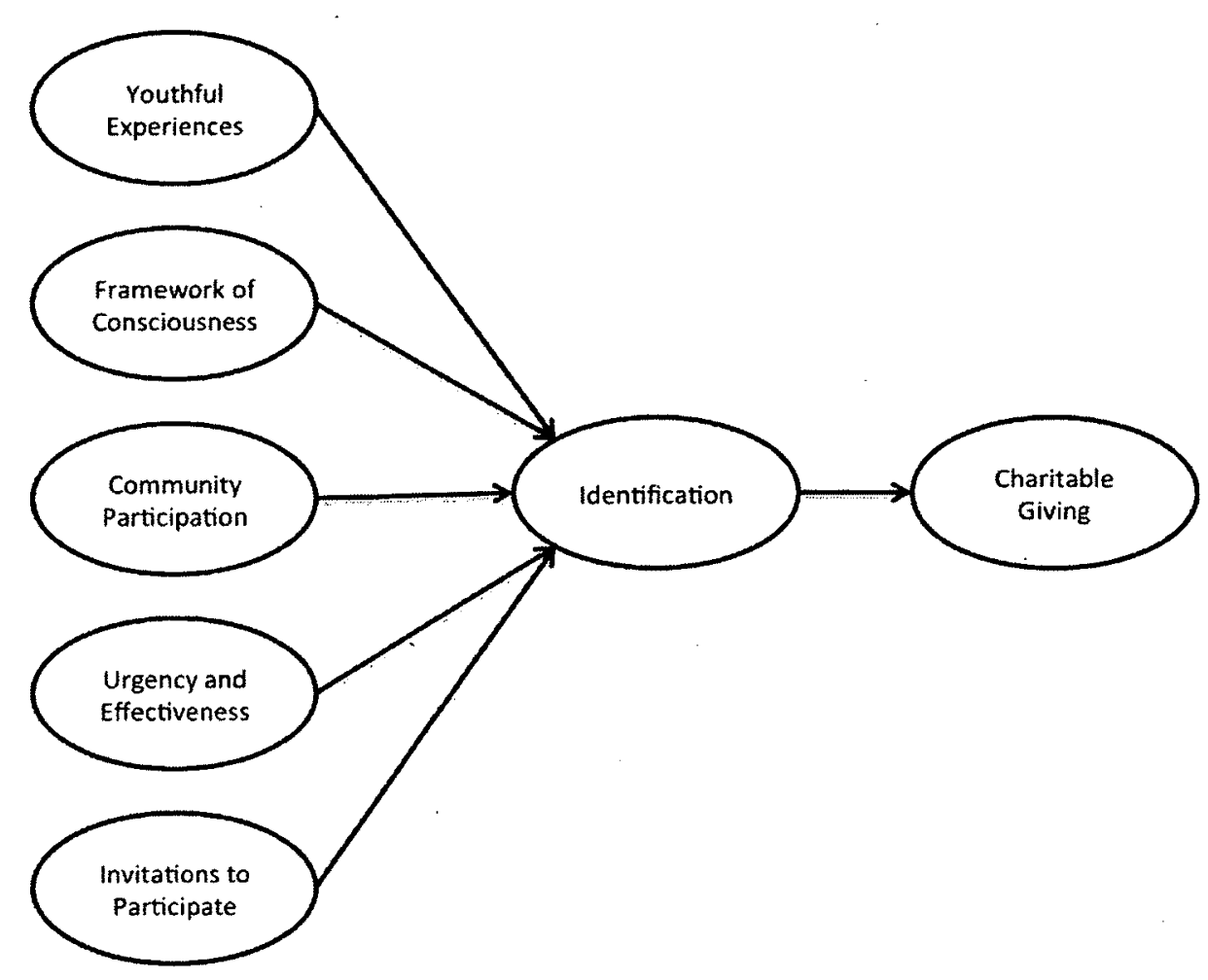

Source: Adapted from Social participation and charitable giving: A multivariate analysis by P. G. Schervish and J. Havens, (1997), Voluntas, 8(3), 235-260.

Arnett, German, and Hunt (2003) found support for the Identity Salience Model of Relationship Marketing which suggested that alumni donors are more likely to support their alma mater if their identity salience, their personal connection or identification, with the university is high (see Figure 2.2). Identity salience was measured using an adaptation of an identity salience scale developed by Callero (1985) in blood donating. The authors identify four relationship inducing factors that influence the rise of identity salience and donating and promoting behaviors: participation in university activities while attending the college, reciprocity in the relationship, prestige of university, and satisfaction with their university experience. Two non-relationship inducing factors were 
controlled for: perceived financial need of the school and level of income of the donors.

With a sample of 953 alumni from a large southwestern university, seven of the eight paths were supported in the model. Participation, prestige, and satisfaction were significantly related with identity salience. Both of the non-relationship inducing factors were also related significantly to donating behavior. Accordingly, identity salience was significantly related to donating and promoting behaviors. Their results provide support

Figure 2.2 Arnett, German, \& Hunt Identity Salience Model of Relationship Marketing Success

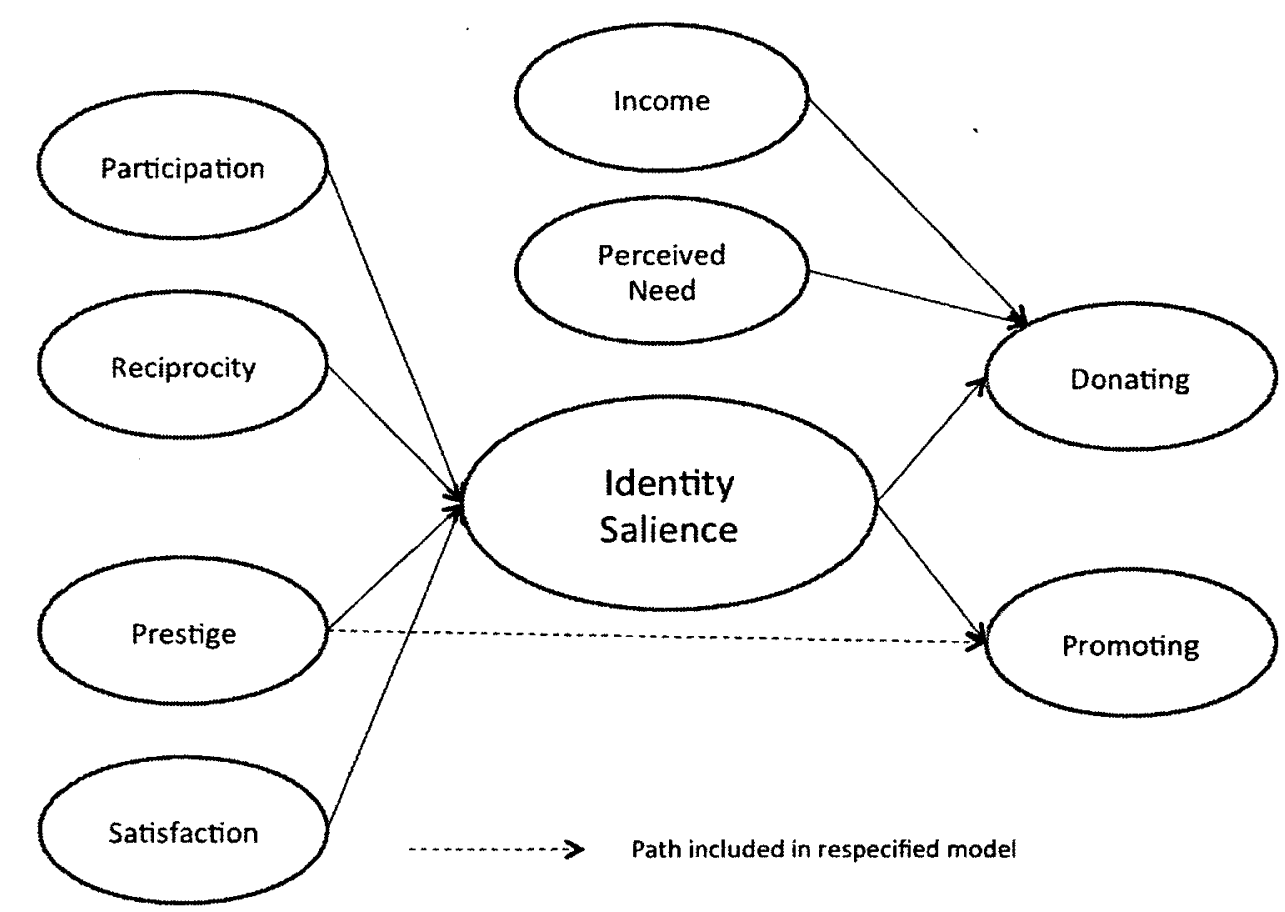

Source: The Identity Salience Model of relationship marketing success: the case of nonprofit marketing by D. B. Arnett, S. D. German, \& S. D. Hunt, (2003). Journal of Marketing, 67 (2) (Apr., 2003), pp. 89-105.

for identity salience playing a central role in nonprofit relationship marketing by mediating the relationships between relationship-inducing factors or charitable giving motivations (participation, prestige, and satisfaction) and supportive behaviors (donating and promoting). 
As such, hypothesis 1 is:

H1:The greater the identity saliency of a donor, the greater the level of charitable giving of the donor.

\section{Relationship marketing}

Relationship marketing is gaining credibility with practitioners and researchers alike, a paradigmatic shift in marketing strategy (Kotler, 1991; Grönroos, 1994; Parvatiyar, Sheth, and Whittington, 1992; Sheth and Parvatiyar, 1995). Practitioners have embraced this shift to the relationship concept, eager to believe every customer interaction, even by direct mail, as part of the "relationship" (Barnes, 2000). While there are several factors that contributed to the paradigm shift from transactional to relational exchange, the relationship focus is a rebirth, or return to pre-industrial age marketing when producers and users engaged each other in the marketplace (Sheth and Parvatiyar, 2000). The definition of marketing has evolved from transactional exchange to a more ubiquitous understanding of marketing as one of delivering value to customers through the building and maintenance of relationships (Payne and Holt, 2001; Polonsky, 1995; Polonsky, Schuppisser, and Beldona, 2002) and on building closer customer connections (Berry, 1983; Barnes, 2000). The implementation of a relationship marketing strategy is an opportunity to develop deep, meaningful relationships with customers (Barnes, 2000; Bhattacharya and Sen, 2003).

The shift in the focus of marketing from transactional exchange to relational exchange originated in the work of MacNeil $(1978,1980)$, the first to consider the longterm impact of relationships in contracts; however, Berry (1983) coined the phrase, "relationship marketing" and gave it meaning. 
Attracting, maintaining and ... enhancing customer relationships. Servicing and selling existing customers is viewed to be just as important to long-term marketing success as acquiring new customers. Getting new customers "is the first step in the marketing process. Cementing the relationship, transforming indifferent customers into loyal ones, serving customers as clients - this is marketing too. (p. 25)

Subsequent understandings of relationship marketing recognize the shift in the exchange component as one moving from mere transactions to long-term relational exchanges. Likewise, Morgan and Hunt (1994, p. 22) referred to relationship marketing as “...all marketing activities directed toward establishing, developing, and maintaining successful relational exchanges." Grönroos (1991) identified and incorporated profitable outcomes for both the buyer and seller by proposing that relationship marketing act to "establish, maintain and enhance relationships with customers and other parties at a profit so that the objectives of the parties involved are met. This is done by mutual exchange and fulfillment of promises (p. 8)." Not only does Grönroos incorporate outcomes in this definition, but he also explicitly described the existence of expectations in the relationship. Thus, relationship marketing is based on the successful execution of a promise between buyer and seller. Furthermore, Grönroos (1991) identified the twosided nature of relationship and incorporated the customer perspective into the marketing definition.

Grönroos' (1991) understanding of relationship marketing is a foundation on which to base this study's proposed relationship marketing framework. All exchange participants and potential partners must be free to identify, establish, maintain, enhance, and terminate a relationship at any given point during the relational experience. The fulfillment of expectations implicitly draws upon some aspects of the two key principles 
within this study - social exchange theory and identity theory. Although the Grönroos definition of relationship marketing is designed to encapsulate a broader stakeholder perspective, it effectively captures the donor-nonprofit bond as relational exchange. Hennig-Thurau and Hansen (2000) described three, distinct theoretical approaches to relationship marketing: behavioral perspective, network approach, and the new institutional economics approach. The behavioral perspective comprises most relationship marketing research including the constructs of trust, commitment, satisfaction, and customer retention. Network theory takes an inter-organizational approach, emphasizing the business-to-business relationship interactions, where firms are engaged in several long-term, complex social arrangements and networks of relationships (Hennig-Thurau and Hansen, 2000; Low, 1996). The new institutional economics approach to relationship marketing uses modern economic theories, such as transactional cost analysis (Adolphs and Büschken 1996; Söllner, 1994) and agency theory (Kleinaltenkamp, 1994; Mishra, Heide and Cort, 1998) to explain the formation and failure of relationships. The behavioral approach to relationship marketing, with its focus on trust, satisfaction, and commitment, best explains the donor-nonprofit relationship.

Early research in relationship marketing stressed the need for constant reselling in services or intangibles (Levitt, 1981), cultivating customer loyalty (Ryans and Wittink, 1977), and for developing the quality of service personnel as means of keeping customers (Berry, 1980; George, 1977). A satisfied customer has no incentive to switch to another competitor if the selling experience is a positive one.

Berry (1983) gave three conditions for relationship marketing: ongoing or periodic desire for service, customer choice of supplier, and an availability of alternative 
suppliers (p. 25). When customers are more likely to do repeat business with a firm and choose one firm over competitors, this creates an opportunity for a relationship to exist and for a firm to differentiate itself among competitive offerings.

In this seminal article, Berry developed five relationship marketing strategies, which have become common practice in firms utilizing a relationship marketing approach:-(1) core service strategy, (2) relationship customization, (3) service augmentation, (4) relationship pricing, and (5) internal marketing. First, a core service strategy draws new customers through a quality experience and opens the door for reselling. Second, the service is tailored to the customer at hand based on in-depth knowledge of the individual needs of customers. Third, organizations should develop meaningful service differentiation; offer the current customer something no other competitor has. Fourth, organizations should encourage customer loyalty by rewarding loyalty with a special relationship price. Lastly, internal marketing strategies should be used to attract and retain the best service personnel. Happy, satisfied employees make the customer experience one they will want to return to. The common thread in all relationship marketing strategies is to give the customer a reason not to switch to a competitor (p. 28).

These strategies are particularly applicable in the nonprofit context as donors are more likely to renew a gift if they are satisfied with the giving experience. Sargeant (2001), in a survey of ten thousand donors in the U.K., found that the role of "quality of service offered to the donor" and donor perceptions about the nonprofit were critical in the retention of donors and that this is an area that effective relationship marketing strategies can positively impact. 
Relationship marketing is considered to be a more profitable marketing strategy by emphasizing customer retention and satisfaction, rather than a focus on sales transactions or the recruitment of new customers. Buchanan and Gilles (1990) gave seven factors that lead to cost savings when marketing emphasizes customer retention. (1) Acquisition costs are incurred at the beginning of a relationship, the longer the relationship, the lower the amortized cost. (2) The cost of managing the account declines as a percentage of total costs or total revenue. (3) Long-term customers are less likely to switch and are less sensitive to price. (4) Long-term customers generate free word of mouth and referral marketing. (5) Long-term customers are more likely to purchase related products. (6) Satisfied customers are less likely to switch to a competitor, thereby reducing competitors' potential market share. (7) And lastly, regular customers need less education about the product or service and know what they want. A "virtuous circle" can be created through increased customer satisfaction, customer retention, and happy employees (Buchanan and Gilles, 1990, p. 524).

Understanding the costs of new customer acquisition, several companies have focused instead on creating exceptionally loyal customers, e.g., Harley Davidson, BMW, Apple, and Southwest Airlines. Attracting new customers is more costly than the retention of current clients (Congram, 1987). Supported by several studies, it is five times more expensive to solicit new customers, as it is to continue relationships with current customers (Harley, 1984; Petersen, 1997). Satisfied customers can be repeat customers as well as a marketing tool for new business.

Also true in the nonprofit sector, the comparison of new donor acquisition and current donor development activities presents a stark contrast. Donor development 
activities generate a 5:1 return on investment (Sargeant and Kaehler, 1998), which means that focusing efforts on growing the current donor base is more profitable.

Morgan and Hunt (1994) developed the commitment-trust theory of relationship marketing where commitment and trust are an integral part of the relational exchange because:

...they encourage marketers to (1) work at preserving relationship investments by cooperating with exchange partners, (2) resist attractive short-term alternatives in favor of the expected long-term benefits of staying with existing partners, and (3) view potentially high-risk actions as being prudent because of the belief that their partners will not act opportunistically. Therefore when both commitment and trust- not just one or the other - are present, they produce outcomes that promote efficiency, productivity, and effectiveness. (p.22)

Commitment and trust are required for relationships that distinguish successful, productive relational exchanges from nonproductive ones. Commitment is defined by Moorman, Zaltman, and Deshpande (1992) as "an enduring desire to maintain a value relationship" (p. 316). Relationship commitment is a central construct in the social exchange body of research (Blau, 1964; Thibaut and Kelley, 1959; Cook and Emerson, 1978); in the marriage literature (McDonald, 1981); in organizational buyer and behavior (Becker, 1960; Reichers, 1985) and of course, commitment has been a central focus in the services relationship marketing literature where relationships are based upon mutual commitment (Berry and Parasuraman, 1991). The exact nature and definition of commitment has been debated in the relationship marketing literature. Measuring commitment by customer retention, repeat purchases, or customer loyalty. The customer's orientation towards the long-term relationship is based on emotional connections, such as affective commitment (Geyskens, Steenkamp, Scheer, and Kumar, 
1996; Moorman et al., 1992) and remaining in the relationship will produce greater benefits than the relationship's termination costs (Geyskens et al.. 1996; Söllner, 1994).

In the donor-nonprofit relationship, donor commitment is more than donor retention and repeat giving. Commitment is about an increasing level of engagement with the nonprofit or as Sargeant (2001) coined it, donor loyalty. Donors want to feel like their gift is making an impact. In his survey of donors in the U.K., Sargeant found that the primary reason for lapsed donors was that the donors found other causes to be more worthy of their support, $26.5 \%$, an indication of donor dissatisfaction with the service quality. In order to increase donor loyalty (commitment), nonprofit organizations "need to improve both the quality of their communications and the choice they offer in that respect" (p. 189).

Trust, as defined by Moorman, Deshpande, and Zaltman (1993, p. 81) is "a willingness to rely on an exchange partner in whom one has confidence." The customer trusts the service provider if the service is reliable and the firm has a high degree of integrity (Moorman et al., 1992; Morgan and Hunt, 1994). Trust is particularly significant in relationship marketing when there is more uncertainty present (Grönroos, 1994) and when there is more risk involved with the transaction (Sheth and Parvatiyar, 1995).

The relationship between trust and commitment is inextricably linked. Sargeant (1999) argued that donors with a higher level of trust in a nonprofit have a greater willingness to become a donor, give more money, and establish a relationship with the nonprofit. Those without trust in the nonprofit, are unlikely to make charitable gifts. Trust is an antecedent to commitment (Sargeant and Lee, 2004). Sargeant et al., (2006) 
found a positive causal link between trust in a nonprofit and the degree of commitment to that organization. These results confirm that trust precedes commitment because people are unlikely to be committed unless a level of trust has been previously established.

As the reigning paradigm in marketing, the large body of research in relationship marketing and its application in the donor-nonprofit relationship has not been fully explored. While trust, commitment, and relationship satisfaction have been investigated in the donor-nonprofit relationship, as Sheth and Parvatiyar (2000) advocated, the focus of the research should be on the factors that induce relationships and the variables that moderate the subtle nuances of trust, commitment, and relationship satisfaction in voluntary association.

\section{Relationship fundraising}

Relationship marketing explains much of the social interaction in the nonprofit sector with internal and external stakeholders. Burnett (1992) was the first to use the phrase, "relationship fundraising" and he advocated for a more holistic approach to relationships with donors that recognized the individual value of each donor, their unique motivations, and their expectations of nonprofits. He argued that fundraising management should take into account the perceived value of the donor relationship. In other words, understanding the value that can be derived from this donor relationship in the future.

The practice of relationship fundraising is widespread, especially when it comes to the solicitation of major gifts. Sargeant and McKenzie (1998) found that nonprofits in the U.K. typically lose about $40-50 \%$ percent of new donors and annually thereafter at a 
rate of $30 \%$. This is also the case in fundraising practice in the U.S. with about $35 \%$ of new donors not renewing. Sargeant (2001) found that communications and organizational performance were strongly correlated with increased donor loyalty. Sargeant et al. (2006) later tested the perceptual determinants of charitable giving in which perceived efficiency and effectiveness of the nonprofit factored heavily in a donor's decision to give.

\section{Relationship satisfaction}

Service quality and customer retention has been a major focus of the for-profit literature. Understanding the significance of service quality (Bitner, 1990; Boulding, Kalra, Staelin, and Zeithaml, 1993) is key to maintaining a long-term relationship with customers. Developed by Parasuraman, Zeithaml, and Berry (1988), SERVQUAL was first used for assessing the perceptions of service quality. Service quality is an abstract construct that is more difficult to measure than the quality of tangible goods (Brown and Swartz, 1989; Carman, 1990; Parasuraman, Zeithaml, and Berry, 1985). The perception of service quality comes from a comparison of customer expectations from the service provider with their perceptions of the actual service performance. Customers assessed service quality in ten dimensions: tangibles, reliability, responsiveness, communication, credibility, security, competence, courtesy, understanding/knowing the customer, and accêss. The SERVQUAL instrument was designed to be used in wide-ranging set of service businesses and the instrument "...can be adapted and supplemented to fit the needs of a particular organization" (Parasuraman et al., 1985, p. 6). 
Cronin and Taylor (1992) explored the relationship between service quality, consumer satisfaction, and purchase intentions and that consumer satisfaction has a significant effect on purchase intentions, more so than service quality, confirming previous research that overall service satisfaction matters (Crosby and Stephens, 1987). Jones and Sasser (1995) measured satisfaction with delivered service quality and found differences in commitment among customer groups. Their research found that very satisfied customers were more likely to be repeat customers than those who were merely satisfied. Application in the nonprofit context would suggest that relationship satisfaction in the donor-nonprofit relationship is very significant in continued charitable giving.

Relationship fundraising success is measured in donor renewal, retention, and donor loyalty. Sargeant (2001) found that more than $26 \%$ of donors lapse because they believe other causes to be more worthy of their support. Nonprofits "need to find ways of improving satisfaction and deepening the bonds that exist between them and their supporters" (p. 188). Sargeant posited that the differentiating factor between lapsed donors and active donors is the quality of the relationship. Using an adaptation of SERVQUAL, for the donor-nonprofit relationship, Sargeant (2001) argued that service satisfaction is as important in the nonprofit sector as it is in the private sector, suggesting that lapsed donors are more dissatisfied with the service quality the nonprofit provides as compared with active donors.

Sargeant (2001) noted that in service relationships, there are only two reasons for defection: natural (finite amount of customer demand) and unnatural (caused by dissatisfaction with service quality). In the nonprofit context, the latter is what can most easily be impacted through the employment of relationship fundraising strategies. 
As such, hypotheses 2 and 3 are:

$\mathrm{H} 2$ :The greater the relationship satisfaction of a donor; the greater the level of charitable giving of the donor.

H3:The greater the identity saliency and the relationship satisfaction, the greater the level of charitable giving of the donor.

\section{Charitable Giving Behavior}

This section reviews the extant literature on the predictors of charitable giving and charitable giving motivations, and incorporates support for these motivations with qualitative data from preliminary focus group interviews. Answering the questions of "who gives" (predictors of charitable giving) and "why they give" (giving motivations) is of critical importance to practitioners, scholars, and public policy makers because the answers to these deceptively simple questions inform decision making in nonprofit marketing strategy, philanthropic research, and public policy making (Bekkers and Wiepking, 2011a). Understanding the characteristics of who gives enables nonprofits to target their solicitations for support and understanding why they give enables them the opportunity to deeply engage donors in their mission; and for scholars to test theories about charitable giving. Understanding the who and why of charitable giving is also important to public policy makers as they endeavor how to best incentivize philanthropy to help solve or address public problems.

\section{Predictors of charitable giving behavior}

Bekkers and Wiepking (2011a) described charitable giving motivations as explaining the pathways or the relationships between the predictors of charitable giving and charitable giving behaviors. Predictors of charitable giving are the individual or 
household characteristics found to correlate with donating behaviors (Bekkers and Wiepking, 2011b); whereas, charitable giving motivations are the possible explanations for an individual's decision to give. Below is a review of the literature investigating these predictive individual and household characteristics of charitable donors beginning with those attributes most frequently studied by scholars: age, income, education, and religiosity.

Age

Overwhelmingly, the literature reveals a positive relationship between age and philanthropy; ${ }^{1}$ finding an age window in which the likelihood of donating increases significantly, above age 40 and decreases after age 65 (Belfield and Beney, 2000; Danesvary and Luksetich, 1997; Landry, Lange, Price and Rupp, 2006; Midlarsky and Hannah, 1989; Wu, Huang, and Kao, 2004). There have been other studies that reveal a

\footnotetext{
${ }^{1}$ See Bekkers and Wiepking, 2011b for an exhaustive discussion of age as a predicting variable of charitable giving behavior (Abrams and Schmitz, 1978; Abrams and Schmitz, 1984; Andreoni, 1988; Andreoni and Miller, 2002; Apinunmahakul and Devlin, 2004; Auten, Cilke, and Randolph, 1992; Auten and Rudney, 1990; Banks and Tanner, 1999; Barrett 1991; Bekkers, 2003; Bekkers, 2006b; Bekkers, 2007b; Bekkers and Schuyt, 2005; Bekkers and Wiepking, 2006; Belfield and Beney, 2000; Bielefeld, Rooney, and Steinberg, 2005; Brooks, 2002; Brooks, 2005; Brown and Lankford, 1992; Carman, 2006; Chang, 2005a; Choe and Jeong, 1993; Chua and Wong, 1999; Clotfelter, 1980; Daneshvary and Luksetich, 1997; Eaton, 2001; Farmer and Fedor, 2001; Feenberg, 1987; Feldstein, 1975a; Feldstein, 1975b; Feldstein and Clotfelter, 1976; Feldstein and Taylor, 1976; Glenday, Gupta, and Pawlak, 1986; Greenwood, 1993; Gruber, 2004; Havens et al., 2007; Hood et al., 1977; Houston, 2006; Hrung, 2004; James and Sharpe, 2007; Jones and Posnett, 1991a; Jones and Posnett, 1991b; Kingma, 1989; Knoke, 1990; Lankford and Wyckoff, 1991; Long, 2000; Lunn et al., 2001; Lyons and Nivison-Smith, 2006; Lyons and Passey, 2005; Marx, 2000; Matsunaga, 2006; McClelland and Kokoski, 1994; Mesch et al., 2006; O'Neill et al., 1996; Okten and Osili, 2004; Okunade and Berl, 1997; Olson and Caddell, 1994; Pharoah and Tanner, 1997; Reece 1979; Reece and Zieschang, 1985; Reece and Zieschang, 1989; Reed and Selbee, 2002; Regnerus et al., 1998; Ricketts and Westfall, 1993; Robinson, 1990; Rooney et al., 2005; Schervish and Havens, 1995a; Schervish and Havens, 1995b; Schervish and Havens, 1998b; Schervish and Havens, 2003; Schiff, 1990; Schlegelmilch et al., 1997a; Schwartz, 1970; Slemrod, 1989; Sokolowski, 1996; Srnka et al., 2003; Sullivan, 1985; Tiehen, 2001; Todd and Lawson, 1999; Van Slyke and Brooks, 2005; Wilhelm et al., 2006; Wu et al., 2004; Yamauchi and Yokoyama, 2005; Yen, 2002).
} 
decrease in charitable giving after age 75 (Andreoni, 2001; Hodgkinson and Weitzman, 1996) and after age 84 (Auten and Joulfaian, 1996).

Life cycle effects and generational differences may explain the relationship between age and philanthropy because older donors have more disposable income (Wilhelm, Rooney, and Tempel, 2007), attend church more regularly (Oslon and Caddell, 1994; Bekkers and Schuyt, 2008; Wilhelm, Rooney, and Tempel, 2007), are less concerned about their children's future and exhibit more altruistic values (Auten and Joulfaian, 1996), and are closer to death than younger donors (Bekkers and Wiepking, 2011b). In survey research, age differences can be partially explained by the life stage or generation to which one belongs (Alwin and Krosnick, 1991). Older people attend church more regularly and have more disposable income as they age. Their children are often well established, alleviating parental concern for their financial future and creating space for the concern for the wellbeing of others or the greater good (Auten and Joulfaian, 1996).

Income

The relationship between level of household income and the amount of charitable donations is positive; however, there is a negative relationship with proportion of income to philanthropy. People with less income give a higher proportionate share of their income than people with higher income. Several scholars have found support for people with higher incomes as more likely to help organizations that help the poor (Regnerus, Smith, and Sikkink, 1998; Banks and Tanner, 1999; McClelland and Brooks, 2004; and Schervish and Havens, 1995a), suggesting that the wealthy have a moral obligation to 
help the less fortunate (Schervish, 2006). The positive relationship between income and charitable giving could also be explained by the cost of giving decreasing as income increases when donations are tax-deductible (Bekkers and Wiepking, 2011b); however, tax deductibility is not a motivation according to most major donors (Panas, 2007). If the psychological benefits of giving, often called "the joy of giving," are in the act of giving; then, giving a higher amount does not necessarily correlate with more joy (Andreoni, 1990; Wiepking and Heijen, 2010). 


\section{Education}

The level of education of charitable donors also has a positive relationship with charitable giving. ${ }^{2}$ Donors with a higher level of education have also been shown to give a higher proportion of income (Schervish and Havens, 1997). There are a number of possible reasons for the positive correlation between education and charitable giving. Brown and Ferris (2007) connected education and giving through additional membership and generalized social trust. "People who are more trusting of others are likely to have more confidence in charitable organisations, suggesting a role for ...efficacy [of nonprofits]" (Bekkers and Wiepking, 2007, p. 35). In addition to generalized social trust and enhanced confidence in nonprofit organizations, Bekkers (2006a) also found that higher education is related to giving through higher verbal intelligence and higher income.

\section{Religiosity}

Bekkers and Wiepking (2011b, p. 5) describe religious involvement as "the first ubiquitous correlate of charitable giving" with studies finding support for church membership and church attendance in both secular and religious philanthropy. ${ }^{3}$

\footnotetext{
${ }^{2}$ See Bekkers and Wiepking, (2011b) for an exhaustive discussion of education as a predicting variable of charitable giving (Apinunmahakul and Devlin, 2004; Banks and Tanner, 1999; Bekkers, 2003; Bekkers, 2006b; Bekkers and De Graaf, 2006; Bielefeld et al., 2005; Brooks, 2004; Brown, 2005; Brown and Ferris, 2007; Brown and Lankford, 1992; Carroll, McCarthy, and Newman, 2006; Chang, 2005; Chua and Wong, 1999; Duncan, 1999; Eschholz and Van Slyke, 2002; Feldman, 2007; Gruber, 2004; Houston, 2006; Jones and Posnett, 1991 a; Kingma, 1989; Lyons and Nivison-Smith, 2006; Lyons and Passey, 2005; Matsunaga, 2006; McClelland and Kokoski, 1994; Mesch, Rooney, Steinberg, and Denton, 2006; Olson and Caddell, 1994; Pharoah and Tanner, 1997; Reece and Zieschang 1985; Reed and Selbee, 2002; Rooney, Steinberg, and Schervish, 2001; Schiff, 1990; Schlegelmilch, Diamantopoulos, and Love, 1997a; Sokolowski, 1996; Tiehen, 2001; Todd and Lawson, 1999; Van Slyke and Brooks, 2005; Wiepking and Maas, 2006; Wilhelm, Brown, Rooney, and Steinberg, 2006; Yamauchi and Yokoyama, 2005; Yavas, Riecken, and Parameswaran, 1981).

3 (Bekkers, 2003; Bekkers and Schuyt ,2005; Bennett and Kottasz, 2000; Bielefeld et al., 2005; Brooks, 2003; Brooks, 2004; Brown and Ferris, 2007; Bryant, Slaughter, Kang, and Tax, 2003; Chang, 2005;
} 
However, there are mixed results in the relationship between charitable giving and religious socialization, denomination, and religious beliefs. Not all religious faiths have been considered in charitable giving research; although, in several studies, Protestants give more than Catholics in the U.S., Canada, and Netherlands (Bekkers and Schuyt, 2008; Chaves, 2002; Forbes and Zampelli, 1997, Hoge and Yang, 1994; Reed and Selbee, 2001; and Zaleski and Zech, 1992, 1994). Bekkers and Wiepking (2011b) suggested the following as possible influencing factors in the connection between religiosity and charitable giving: the religious give to uphold their reputation; to support their religious values (Bekkers and Schuyt, 2008; Lunn et al., 2001; Sullivan, 1985; Bekkers and Wiepking, 2010a), to be socially responsible (Bekkers and Schuyt, 2008), and in response to different solicitation methods such as tithing, annual pledges, and collections baskets (Hoge and Yang, 1994; Zaleski and Zech, 1994; Zaleski et al., 1994).

In this study, a focus group participant discussed the influence of religion that confirms the previous research in charitable giving and religion:

"I've been given so much in my life, in my life, [sic] that I need to give back. And because I'm a Christian and that's what I have been taught in my church."

Other predictors of charitable giving include gender, marital status, having children, employment, home ownership, perceived financial position, and ethnicity/race. These are not included in the proposed model due to their confounding relationships to the previous, more salient predictors of charitable giving - age, income, education, and religion (Bekkers and Wiepking, 2011a).

Chaves, 2002; Davidson and Pyle, 1994; Eckel and Grossman, 2003; Eschholz and Van Slyke, 2002; Feldman, 2007; Forbes and Zampelli, 1997; Hoge and Yang, 1994; Hunter, Jones, and Boger, 1999; Jackson and Mathews, 1995; Lee and Farrell, 2003; Lunn, Klay, and Douglass, 2001; Lyons and NivisonSmith, 2006; Lyons and Passey, 2005; Olson and Caddell, 1994; Park and Park, 2004; Reed and Selbee, 2001; Reed and Selbee, 2002; Regnerus et al., 1998; Schiff, 1990; Schlegelmilch et al., 1997a; Sokolowski, 1996; Sullivan, 1985; Tiehen, 2001; Van Slyke and Brooks, 2005; Zaleski and Zech, 1992; Zaleski and Zech, 1994) 


\section{Charitable giving motivations}

Bekkers and Wiepking (2011a) stated that while the knowledge gained by exploring the common characteristics of "who gives" is useful information, it has limited value in testing theories about philanthropy because knowledge about who gives does not investigate the underlying motivations for giving - "why they give." "Few studies have included measures of the mechanisms [motivations] that may explain relationships between predictors and charitable giving. Without these measures, we are often left with several possible explanations that are not mutually exclusive" (Bekkers and Wiepking, 2011a, p. 928). This study heeds their call to explore more fully why some give more than others, why they continue to give, and the distinct nature of the relationship between donors and nonprofit organizations.

As demonstrated thus far in the literature, a great deal of progress has been made in understanding the characteristics of who gives and important theoretical steps have been made in understanding why they give - motivations. Lindahl and Conley (2002) submitted that nonprofit strategy must be based on "informed inquiry," which Bekkers and Wiepking (2011a) argued can only be achieved through the comprehensive investigation of charitable giving motivations and moderating variables; thereby, yielding an elegant model of charitable giving.

Research on charitable giving motivations thus far has produced an overwhelming number of reasons why individuals make charitable gifts and the motivations have been organized in a number of different ways: mechanisms or motivations, altruistic and nonaltruistic, psychological motivations and sociological influences, emotional and economic, and extrinsic and intrinsic. In the exhaustive review of empirical research on 
charitable giving by Bekkers and Wiepking (2011a), they developed eight 'mechanisms' of charitable giving behavior. The term, 'mechanisms' is used as a synonym for motivations, focusing on how motivations can influence charitable giving support. The following section reviews the literature on charitable giving motivations and is supported by the preliminary focus group interviews. ${ }^{4}$

Trust

Trust is very important in sectors, such as the nonprofit sector, requiring individual trust and support to succeed (Gaskin, 1999). Due to the nature of the relationship between nonprofits and individual donors, the relationship, in most cases, is not based on a formal contract between individuals, but rather an implied social contract based upon trust. From this perspective, trust is the foundation for voluntary association within the nonprofit sector (Tonkiss and Passey, 2001). Sargeant et al. (2006, p. 156) define trust as referring "to the extent of donor belief that a charity will behave as expected and fulfill its obligations."

Tonkiss and Passey (2001) describe three key factors to building and maintaining individual donor trust in the nonprofit sector. (1) Unlike the private sector, nonprofits must identify themselves as such, so that relationships are not defined by contract; but instead, are secured by trust. (2) Trust is established through shared values between the nonprofit and donors. These shared values form the basis of trust and should be exhibited in the daily operations of the nonprofit. (3) Relationships based on trust in the nonprofit

\footnotetext{
${ }^{4}$ Two focus groups were held in September 2011 to investigate, qualitatively, the variables in the proposed model. The results of these focus group interviews confirm and corroborate previous studies in charitable giving and provide empirical support for the proposed model. Results from these focus group interviews are used in Chapter II to provide support for the hypotheses and the development of the proposed model. Additionally, in Chapter IV, the results are used to illustrate the statistical results.
} 
sector are different from confidence-based relationships from the private sector. Many nonprofit organizations must balance the need for greater efficiency (confidence-based) and maintaining donor trust. Increased provision of public goods and services by the nonprofit sector has put increased attention on private sector values like efficiency. Tonkiss and Passey (2001, p. 272) posit that this balance is the most challenging for nonprofits because of the shift in focus from "wider outcomes (trust relations based on shared evaluations of social good) to specific outputs (confidence relations based on target-driven contracts).",

There are two types of trust in social exchange: transactional trust and relational trust. Transactional trust involves a single, short-term exchange over a specific period of time. Many interactions involving transactional trust are infrequent; more formal in nature, and where emotions are less significant (Gundlach and Murphy, 1993). Relational trust builds over time based on repeated exchanges, the history of interactions, and on the nonprofit meeting a donor's expectations (Rousseau, Sitkin, Burt, and Camerer, 1998). In contrast with transactional trust, relational trust has a long-term, strategic orientation, involves large investments with high switching costs, and complex outcomes.

Sargeant et al. (2006) found that the degree of trust in a charitable organization is causally linked to the level of commitment and commitment is causally linked to the average charitable donation. They tested drivers of trust in charitable organizations: responsiveness, performance of the charity, and communications. Both the organizational performance and the communications from the charity were causally 
linked as drivers of trust whereas the relationship between responsiveness of the charity and trust was not significant.

As such, hypothesis 4 is:

H4:Donors with a higher level of trust in a nonprofit organization will be more satisfied with the relationship with the nonprofit organization.

\section{Perceptions of charities}

Perceptions of charities have been found to impact charitable giving behavior (Sargeant et al., 2006). Several factors create an individual's perception of a nonprofit organization and are used in the making the decision to donate. Several studies (Sargeant et al., 2004; Sargeant and Woodcliffe, 2005; Bennett and Savani, 2003; and Schlegelmilch et al., 1997b) have revealed perceived need, organizational efficiency, organizational effectiveness, and perceived benefits, as major factors influencing the formation of individual perceptions of charities and subsequently, charitable giving.

\section{Perceived need}

Donors must first become aware of the need for support before making a charitable gift and this can happen through solicitation communications, personal experience, familial connection, coverage in mass media, and charity brand awareness. Tangible, social, or psychological needs of people are met through people asking for help and nonprofit organizations making the case for support. Social psychology has documented the effects of perceived need in which prosocial behaviors were studied (Berkowitz, 1968; Berkowitz and Daniels, 1964; Schwartz, 1975). Largely, the 
perception of need is positively related to the likelihood that help will be given (Levitt and Kornhaber, 1977; Schwartz, 1974; Staub and Baer, 1974).

Subjective perceptions of need relate positively to increased donations (Wagner and Wheeler, 1969). Accordingly, those who give more generously perceive a higher need for support (Diamond and Kashyap, 1997; Weerts and Ronca, 2007); those who volunteer believe that there is a greater demand for volunteers (Unger, 1991); those who perceive the need for support of panhandlers give more money (Lee and Farrell, 2003); and those who know someone in need, similarly; give to others in need (Small and Simonsohn, 2006). These subjective. perceptions of need could be related to the development of pro-social values and empathy.

Consequently, having knowledge of need personally inspires donations (Polonsky, Shelley, and Voola, 2002; Radley and Kennedy, 1995). The perception of need is higher when donors have a personal experience with it through family members or beneficiaries of the organization. In United Way workplace giving campaigns, people who know someone who has benefitted from a United Way agency are more probable donors (Pitts and Skelly, 1984), which makes a strong case for the employee giving campaign fundraising strategy employed. The link between familial connection, perceived need, and charitable giving is most obvious in giving to disease related organizations. People who have a relative with that disease are more likely to donate to nonprofits working in those areas (Bekkers, 2008; Burgoyne, Young, and Walker, 2005). More common diseases demonstrate more common need, affect more people, and subsequently generate more support (Olsen and Eidem, 2003). 
Nonprofit communications are designed to increase the perception of need. As nonprofits build awareness of their "brand," and a network of volunteers, donors, and beneficiaries, the increased perception of need generates donations. In a study of Spanish development aid organizations, Marcuello and Salas, $(2000,2001)$ found that newer organizations receive far less support and volunteers than older ones, which have a larger volunteer base.

The perception of need is also heightened by extended coverage by the mass media, especially in disaster and relief appeals (Simon, 1997). The strength of this association between extended media coverage, perceived need, and charitable giving is dependent on the number of people affected, and the identification between donors and the people affected (Adams, 1986; Simon, 1997). Interestingly, Bennett and Kottasz (2000) find that increased television watching is positively related to relief donations. When the perception of need is more salient, people are motivated to give.

In the preliminary focus groups, the perception of need was a primary motivation for giving that confirms the previous research in charitable giving and perceived need:

"[one participant said she gives because] ...there's a need and because my needs... are taken care of."

As such hypotheses 5 and 6 are:

H5:The greater the perceived financial need of the nonprofit organization, the higher the identity salience for the donor.

H6:The greater the perceived financial need of the nonprofit organization, the higher the relationship satisfaction for the donor. 


\section{Perceived organizational performance}

Perceived performance of the charitable sector and of individual organizations is also a motivating factor for charitable giving. When donors perceive that their contributions make a difference to the cause they are supporting, they perceive the organization to be more effective. Sargeant, West, and Ford (2004) define effectiveness as "the extent to which charities achieve useful goals for society and are thus seen to be fulfilling their mission" (p.23). Conversely, when people perceive that their donation will not make an impact, they are less likely to donate (Radley and Kennedy, 1992; Mathur, 1996; Diamond and Kashyap, 1997; Duncan, 2004; Arumi, Wooden, Johnson, Farkas, Duffett, and Ott, 2005; and Smith and McSweeney, 2007).

Nonprofit communications relating to organizational performance influence donor perceptions of efficacy. In experimental studies, communications demonstrating the impact of donations had a positive influence on charitable giving (Jackson and Mathews, 1995; Parsons, 2003, 2007); as well as the disclosure of financial data in organization communications (Parsons, 2007). As discussed earlier, communications and organizational performance are drivers of trust in nonprofits, when donors have trust they increase their commitment to the organization (Sargeant et al., 2006). The role of communications and organizational performance in charitable giving was supported in the focus groups for this study that confirms the previous research in charitable giving and perceived organizational performance:

"I mean I feel like what they're doing is effective and it's making a difference. And one of the things that they do, is they do a good job of keeping me updated on what they are doing and how my donations are being utilized." 
Leadership giving is affected by perceived efficacy (List and Lucking-Reiley, 2002; Bac and Bag, 2003; List and Rondeau, 2003; Andreoni and Petrie, 2004; Potters, Sefton, and Vesterlund, 2005; Chen, Li, and MacKie-Mason, 2006; Landry, Lange, List, Price, and Rupp, 2006). Leadership gifts or endorsement by a person with high status help to legitimize nonprofit organizations and inspire confidence and trust in the perceived efficacy of a particular nonprofit (Bryan and Test, 1967; Lincoln, 1977; Reingen, 1982). This is supported by field experiments in which solicitations signed by a professor in health research raised donations by $2.4 \%$ (Vriens, Scheer, Hoekstra, and Bult, 1998) and in a lab experiment which linked high status donors to leading others to give (Kumru and Vesterlund, 2005).

Perceptions of efficacy are associated with "charitable confidence and perceptions of overhead and fundraising costs" (Bekkers and Wiepking, 2007, p. 36). Confidence and trust in nonprofit organizations and beliefs about their effectiveness promote charitable giving (Bekkers, 2006a; Bennett, 2003; Bennett and Gabriel, 2003; Bowman, 2006; Keyt, Yavas, and Riecken, 2002; Parsons, 2003; Sargeant et al., 2006; Schervish and Havens, 2002; Schlegelmilch et al., 1997a; Yavas, Riecken, and Parameswaran, 1981). Donors who have more confidence in general about nonprofit organizations believe their donations are less likely to be spent on administrative overhead (Bekkers, 2006a; Sargeant et al., 2006) and have a higher perceived efficacy of the nonprofit sector. The perception of a nonprofit's efficiency also influences charitable giving (Callen, 1994; Sargeant, 2004; Trussell and Parsons, 2007). Being efficient with resources is a significant factor in the decision to donate (Glaser, 1994; Harvey and McCrohan, 1988). Likewise, perceived inefficiencies (Bennet and Savani, 2002) and 
perceived mismanagement (Sargeant, 2000) can impact charitable giving. Perceptions of a nonprofit organization's management and fundraising efficiency can significantly influence a donor's overall perception of the organization as well as their-willingness to give (Sargeant, 2000).

Several studies show that donors are acutely aware of expensive marketing and fundraising materials (Sargeant and Woodliffe, 2005; Schervish and Havens, 2002; Bekkers and Crutzen, 2007). While well designed fundraising materials are noticed by donors (Diamond and Gooding-Williams, 2002), in field experiments, more plainly and thriftily designed materials actually generated increased charitable giving (Warwick, 2001; Vriens et al., 1998; Bekkers and Crutzen, 2007).

As such hypotheses 7 and 8 are:

H7: The greater the perceived organizational performance, the greater the identity salience of the donor.

H8: The greater the perceived organizational performance, the greater the relationship satisfaction of the donor.

\section{Perceived benefits}

Social exchange theory explains charitable giving that is motivated by an anticipated return from donation efforts (Amos, 1982; Bar-Tel, 1976; Krebs, 1982). Sargeant et al. (2006) discuss three categories of benefits: demonstrable, emotional, and familial.

Demonstrable benefits are the tangible benefits received as a result of the process of giving with "selfish economic considerations" suggesting that individual donors are motivated by benefits received previously or promised in the future (Sargeant et al., 2006, p. 3). Charitable raffles or lotteries are the most obvious example of demonstrable 
benefits, where individual donors purchase a ticket for the chance to win prizes.

Charitable donations through sponsorship, special events, performances, special access, or other "selective incentives" are also motivated by demonstrable (tangible) benefits in the exchange.

Donors often receive demonstrable benefits for different levels of giving, which increase giving levels overall (Buraschi and Cornelli, 2002; Andreoni and Petrie, 2004). For instance, a $\$ 5,000$ gift at a regional professional theatre will gain the donor access to the artistic process during the production of the play or musical. They dine with the production staff and give their opinion on the artistic product, ultimately feeling ownership in the end product, which in turn results in donor renewal and retention or as Sargeant (2001) described it, “donor loyalty.” Offering special access or tangible items can be characterized as "consumption philanthropy" because motivations are based in consumption and cloaks buying in the disguise of charitable giving.

Consumption philanthropy turns helpfulness and prosocial behaviors into exchange where donors expect value for money. Eikenberry (2009) argues that the shortterm benefits of consumption philanthropy contradict the long-term hidden costs "individualizing solutions to collective problems; replacing virtuous action with mindless buying; and hiding how markets create many social problems..." (p. 51).

Desmet (1998) found that charities offering products for sale encounter lower donations. Other examples of demonstrable benefits are gifts included with donation (Alpizar et al., 2007; Chen et al., 2006; Edlund, Sagarin, and Johnson, 2007; Harris, Liguori, and Stack, 1973), personal profit from exchange (Marr, Mullin, and Siegfried, 
2005; Schervish and Havens, 2002), and donations in anticipation of need for the nonprofit's services in the future (Burgoyne et al., 2005).

In this study's focus groups, participants made note of the tangible benefits and special treatment they receive:

"... and each time you go up, you know, you get certain extra things."

One of the more pervasive motivations for charitable giving is the perceived emotional benefit of donating (Andreoni, 2001), yielding both social and psychological benefits of emotional association. Social benefits include recognition (Kottasz, 2004), reputation, respect and prestige (Kotler and Andreasen, 1991; Haggberg, 1992; Komter, 1996), in some cases donors feel social pressure to contribute. Psychological benefits include, warm feeling or glow (Andreoni, 1990), empathy, sympathy, guilt, fear, pity (Feldman, 1985; Fultz et al., 1986), a desire to bring about social change (Radley and Kennedy, 1995), self-esteem (Mathur, 1996), and diffusion of negative feelings (Cialdini, 1987). Several focus group participants made note of the psychological benefits of giving:

"[the more you donate, gives you]... a status, like you feel like more important in a way, even though it's kind of, you know, it's false in a way, and it's kind of silly, but you do feel like more important because you are like in the director's circle now."

One participant noted the social pressure to donate as an executive in a Fortune 500 company,

"I can tell you that there are corporate influences that come into play too...there's nobody saying you have to do this but you can't help but notice in the companyif you join certain Boards, or you're asked to do certain things, that you're expected as a component of that, to be heavily involved in the gifting process and that's associated with your role at the corporation. So I want to be careful to say 
that no one has ever said to me, that you have to do this, but it just kind of comes along with it -corporate pressure is an element of how the process works."

Emotional utility is often referred to as "personal mood management" where donors have an emotional experience resulting from the giving process (Andreoni, 2001; Bendapudi et al., 1996; Cialdini et al., 1987; Wegener and Petty, 1994). Even in purely altruistic motivations, there exists some form of emotional utility as a result of the giving process.

Familial utility can be described as a personal familial connection or experience that inspires (Bruce, 1998; Sargeant, 1999) a "need to assist or demonstrate an affinity with one's friends or loved ones" (Sargeant et al., 2006, p. 3). Healthcare and disease related nonprofits are particularly adept at maximizing donations from personal familial linkages to a cause (Kotler and Clarke, 1987). For example, a focus group participant for this study said:

\footnotetext{
"My father has Alzheimer's, so I've been a contributor to the Alzheimer's Association for the last eight years and I will continue until he passes and probably well onto that. You know, just because there 's that direct connection, it's influencing me, and so I will do anything, I will give as much as I can for research."
}

Sargeant et al. (2006) developed these three categories of perceived benefits in the social exchange of charitable giving, suggesting that nonprofits able to supply the appropriate combination of benefits for donors are able to build trust and commitment with the donors. Their study found that emotional and familial utilities are significant in developing donor commitment and trust does not mediate the relationship. In fact, their study concluded that trust is unrelated to the direct donor benefits and in the nonprofit 
context is built through providing service to beneficiaries of the nonprofit and through communications with the donors $(2006$, p. 9).

The following hypotheses are therefore offered:

H9: Reciprocity in demonstrable utility will relate positively to charitable giving mediated by identity saliency and relationship satisfaction.

H10: Reciprocity in emotional utility will relate positively to charitable giving mediated by identity saliency and relationship satisfaction.

H11: Reciprocity in familial utility will relate positively to charitable giving mediated by identity saliency and relationship satisfaction.

\section{Solicitation}

One of the most significant factors that influence charitable giving motivations is solicitation, the experience of being asked to donate. Studies reveal that most donations are received after being asked (Bryant et al., 2003) and usually occur within two weeks of being asked to give (Bekkers, 2005a). Increased giving is associated with donors who are directly solicited as opposed to being presented with passive opportunities to donate (Bekkers, 2005a; Lee and Farrell, 2003; Simmons and Emanuele, 2004; Tiehen, 2001).

The frequency of solicitations can have an adverse effect on charitable giving. There is marginal utility in repeat solicitations; studies have found that the average gift decreases and asking too frequently can cause donor fatigue (Leslie and Ramey, 1988; Van Diepen, Donkers, and Franses, 2009; Wiepking, 2008). The relationship between repeat solicitations and charitable giving was discussed in the focus groups for this study:

"... in addition to getting a letter thanking me, and having the statement for your IRS tax purposes, there's a follow up almost immediately, like within a week or month, of additional solicitations. And it's, that to me is a sign of inefficiency. If you - I understand why they would solicit, but you would think that if someone just gave you a gift, you would wait at least, I would think, make it an annual request, right?" 
Larger donors report receiving more fundraising appeals (Bekkers, 2005a; Van Diepen et al., 2009). Once they make a gift or two in response to solicitations, it attracts new solicitations. Supported in this study's focus groups, a donor noted, "once your name gets out there as having given to, well then your name gets out there. And then that...creates problems...more solicitations from all over the place...I would prefer it [his name] not be in there [symphony program]."

The manner or mode in which donors are asked also influences the effectiveness of the solicitation. Generally, people try to thwart solicitations (Pancer, McMullen, Kabatoff, Johnson, and Pond, 1979) and because of growing number and frequency of "asks for contributions," most people tend to reject the solicitation (Diamond and Noble, 2001).

In the focus groups held for this study, repeat solicitations and gifts with donation were seen as wasteful:

"...that money could be better spent on what the organization is."

Also figuring prominent in the focus group discussion was the use of telemarketing and professional call centers providing additional support for the previous research on charitable giving and the experience of being solicited for support:

"The amount of money that they collected, most of it went to the collection people, or the marketing agents. And they [nonprofits] have to do that to an extent, but ... it really puts you off when they call, it does decrease your motivation to give...because you know those people don't have any stake in that [in the cause]. It decreases your trust in that charity." 
As such, hypotheses 12 and 13 are:

H12: The greater the satisfaction with the solicitation process, the greater the identity saliency of the donor.

H13: The greater the satisfaction with the solicitation process, the greater the relationship satisfaction of the donor.

Parental socialization and youth participation

Few studies have investigated the influence of parental socialization or modeling of prosocial behaviors and subsequent charitable giving; however, it is likely that the influence of parental modeling does impact future charitable giving behavior of children. Prosocial behaviors can be defined as "voluntary actions that are intended to help or benefit another individual or group of individuals" (Eisenberg and Mussen, 1989, p. 3). Along with volunteering, helping, sharing, and cooperating, charitable giving is considered a prosocial behavior (Batson, 1998).

The modeling of parental volunteering and charitable giving and its influence on future charitable giving by children has produced ambivalent results. Concurrent charitable giving by parents and children in the U.S. are strongly related (Wilhelm, Brown, Rooney, and Steinberg, 2008). Bekkers (2005) found that higher levels of parental education, parental religious involvement, and parental volunteering are related to higher amounts donated by children. Logically, the financial situation and stability of families also has an impact on charitable giving; lower income and family instability in childhood is related to lower charitable giving in adulthood (Bandy and Wilhelm, 2007). Schervish and Havens (1997) found no relationship between parental volunteering and the proportion of income donated. Bryant et al. (2003) also found no relationship between prosocial behaviors and charitable giving; whereas, Feldman (2007) did find that 
prosocial behaviors and the likelihood of donating to be related. Eisenberg (2000) finds that parental encouragement of prosocial values leads to charitable giving. Having a positive relationship with parents who modeled altruistic behaviors was significantly related to volunteer commitment (Clary and Miller, 1986). Bekkers (2005) found that "charity begins at home" where, parental modeling of philanthropic behaviors encouraged giving and volunteering of children as adults; youth participation in nonprofit organizations is positively related to current giving and volunteering; parental modeling and youth participation foster charitable giving because they support the development of prosocial behaviors and values and build social capital.

A focus group participant discussed the role of parental socialization and youth participation, providing corroboration for the previous research on charitable giving and parental socialization and youth participation:

"The other reason why, I think a lot of us have this tendency to be generous is because of our home life. And circumstances were that we weren't, we're very middle class, is what I came from. But we always saw, either through my family, like my mom and dad, or with the school, because the school had a big influence, elementary school, I didn't go to a preschool, in which we were asked, you know, pass the hat, so to speak. So this really was sort of brought to me by our culture, our society, as well as family values."

And another participant referred to the role of parental modeling,

"When I was growing up, we had very little money... however, like both my parents were in education, they were teachers, and they were very passionate about trying to help others... and doing some volunteering."

As such, hypotheses 14 and 15 are:

H14: The greater the parental socialization and youth participation, the greater the identity saliency of the donor.

H15: The greater the parental socialization and youth participation, the greater the relationship satisfaction of the donor. 


\section{Proposed Model}

Based on the literature discussed above and the preliminary data from the focus groups in this study, the charitable giving motivations examined in this research are trust, perceived need, perceived organizational performance, perceived benefits, solicitation, and parental socialization and youth participation; and the mediating factors are identity saliency and relationship satisfaction. The proposed model of charitable giving behavior adds to the literature on charitable giving by: (1) including both identity saliency and relationship satisfaction as mediating variables in a random sample of charitable donors and (2) exploring and testing a selection of charitable giving motivations. Figure 2.3 depicts the proposed model.

Figure 2.3 Proposed Model of Individual Charitable Giving

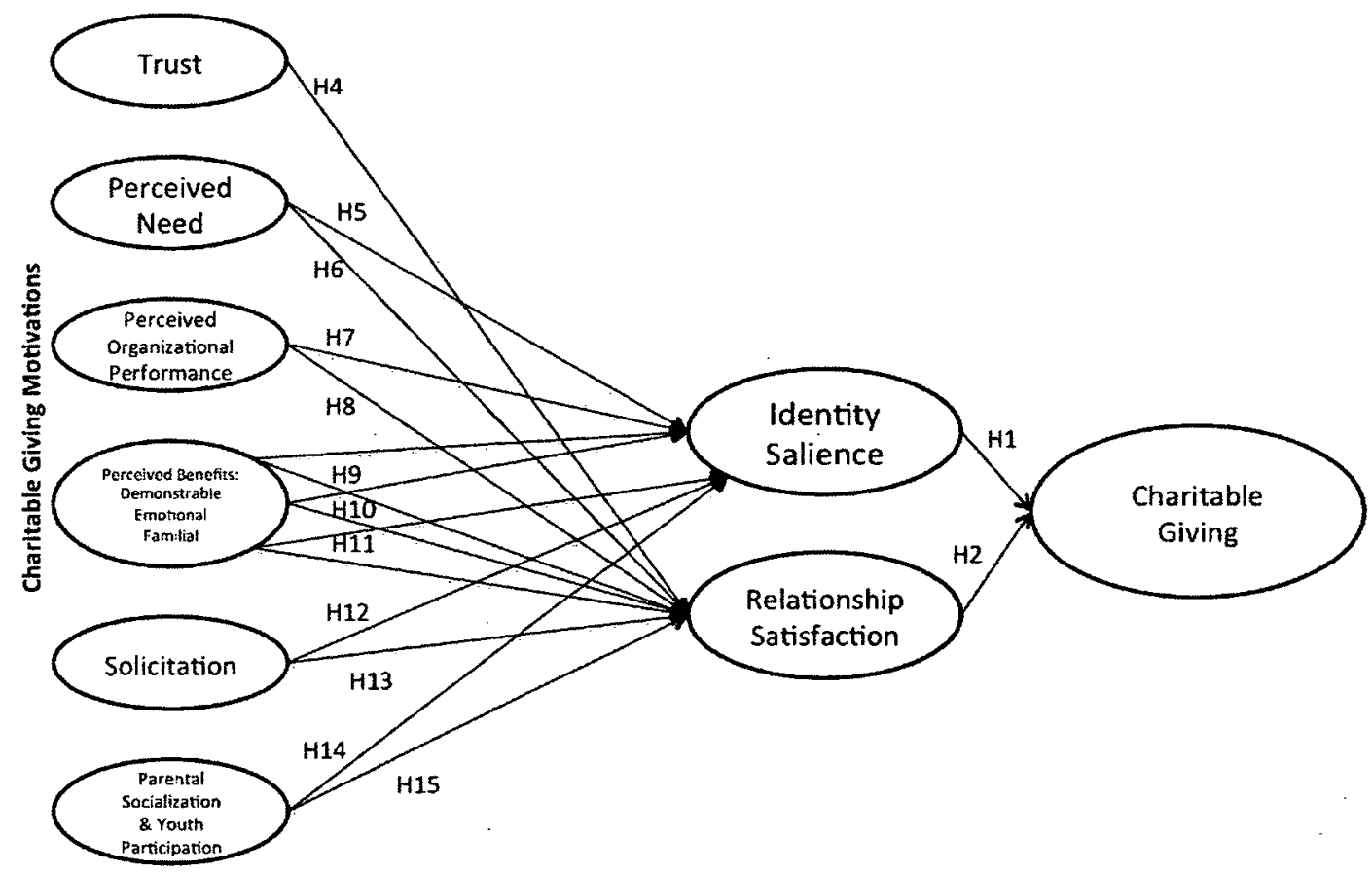




\section{Conclusion}

This dissertation is built on the premise that the extant relationship marketing and charitable giving literature, while rich in theoretical and empirical contributions, is still limited in its ability to capture the full nature and scope of donor-nonprofit relationships. Nonprofits have to know who to ask, when to ask, and how to ask donors for support, which necessitates a deep knowledge of and a relationship with individual donors.

\section{Hypotheses}

As depicted in Figure 2.3 above, this new model of Individual Charitable Giving will test the following hypotheses:

H1: The greater the identity saliency of a donor, the greater the level of charitable giving of the donor.

H2: The greater the relationship satisfaction of a donor, the greater the level of charitable giving of the donor.

H3: The greater the identity saliency and the relationship satisfaction, the greater the level of charitable giving of the donor.

H4: Donors with a higher level of trust in a nonprofit organization will be more satisfied with the relationship with the nonprofit organization.

H5: The greater the perceived financial need of the nonprofit organization, the higher the identity salience for the donor.

H6: The greater the perceived financial need of the nonprofit organization, the higher the relationship satisfaction for the donor.

H7: The greater the perceived organizational performance, the greater the identity salience of the donor.

H8: The greater the perceived organizational performance, the greater the relationship satisfaction of the donor.

H9: Reciprocity in demonstrable utility will relate positively to charitable giving mediated by identity saliency and relationship satisfaction. 
H10: Reciprocity in emotional utility will relate positively to charitable giving mediated by identity saliency and relationship satisfaction.

H11: Reciprocity in familial utility will relate positively to charitable giving mediated by identity saliency and relationship satisfaction.

H12: The greater the satisfaction with the solicitation process, the greater the identity saliency of the donor.

H13: The greater the satisfaction with the solicitation process, the greater the relationship satisfaction of the donor.

H14: The greater the parental socialization and youth participation, the greater the identity saliency of the donor.

H15: The greater the parental socialization and youth participation, the greater the relationship satisfaction of the donor. 


\section{CHAPTER III}

\section{METHODOLOGY}

\section{Introduction}

Chapter I of this dissertation presented an introduction to identity saliency theory and relationship marketing theory and provided justification for the importance of this research study. The literature review and theory development in Chapter II then provided insight into the findings of past research on charitable giving behavior, explicating past research on the predictors of charitable giving and the motivations for charitable giving and offered a theoretical foundation for the model which is tested in this study. This chapter will present the methodology, the data collection, the instrument and associated constructs, and the analytical procedures utilized to answer the two research questions and test the 15 research hypotheses in the research design.

This chapter begins with a discussion of the research questions and purpose of the research, the design and methodology, and then explains the sampling frame and mechanisms for each stage of the data collection. The qualitative phase of data collection is reviewed, followed by a presentation of the quantitative data collection; including, the survey instrument and the scales measuring the various constructs. Finally, the method of quantitative data analysis will be reviewed and a summary section presented.

\section{Research Questions}

The purpose of this research is to examine charitable giving motivations, and to test and extend recent nonprofit relationship marketing research, which has sought to explain the antecedents to successful relationships with nonprofit donors and to clarify 
the role of identity saliency and donor relationship satisfaction in nonprofit relationship marketing success. The thesis of this research is that two key relational factors, "identity saliency," drawn from social psychology and organizational behavior, and "relationship satisfaction," drawn from social exchange theory, mediate relational exchange in the nonprofit context (See Figure 1.1). This study explores relationship marketing in the nonprofit context by (1) positing that identity saliency and relationship satisfaction mediate relational exchange in the nonprofit context and (2) investigating several charitable giving motivations that influence identity saliency and relationship satisfaction.

\section{Research Design}

This study examines the relationship between charitable giving motivations and charitable giving behavior, mediated by identity saliency and relationship satisfaction. Eight constructs are examined as charitable giving motivations and two mediating constructs (identity saliency and relationship satisfaction) are tested. The constructs and scales used to measure them are discussed in more detail later in this chapter. The study employed a sequential mixed methods research design, chosen for this research because of its ability to strengthen the proposed individual charitable giving model and the survey instrument design.

Using mixed methods is more than the simple combination of qualitative and quantitative methods. It involves the use of both approaches to inquiry in a manner that strengthens the study overall, given that the use of only qualitative or quantitative research is less effective (Plano Clark, 2007). There are three general strategies for mixing methods: sequential, concurrent, and combined (Creswell, 2009). This study 
employed sequential mixed methods because, as described by Tashakkori and Teddlie (2003), the first data collection method (focus group interviews) has informed the development of the second data collection method (survey instrument). Similarly, the transcripts from the focus group interviews are used to support the proposed model (Creswell and Plano Clark, 2007). A pragmatic approach to research, the mixed methods logic of inquiry uses "induction (or discovery of patterns), deduction (testing of theories and hypotheses), and abduction (uncovering and relying on the best of a set of explanations for understanding one's results)" (Onwuegbuzie and Johnson, 2004, p.17). In this research, the sequencing of preliminary focus group interviews followed by a cross-sectional survey of a larger sample allowed the researcher to find descriptive data about the charitable giving motivations, perceptions about nonprofit organizations, relationship satisfaction, and charitable giving behavior and to develop the proposed model and survey instrument. Gilbert Churchill (1979) proposed a procedure, Table 3.1, for validating constructs that embraces a multi-method approach to inquiry and it has guided the structure of this dissertation.

Table 3.1

Procedure for Validating Constructs

\section{Stage 1}

1. Specify the domain of the

Literature search constructs.

Construct definition

2. Generate the initial sample of items.

Literature search

Initial item sample

In-depth interviews

Expert input

Refined item sample 
3. Collect data - pre-test. Collect qualitative data

- Qualitative focus group interviews

- Survey design

\section{Stage 2}

4. Purify the measures.

Reliability analysis

Confirmatory factor analysis

Revised item sample

5. Collect the data.

Collect quantitative data

6. Assess the reliability.

Reliability analysis

7. Assess validity.

Confirmatory factor analysis

Test construct validity

- Convergent

- Discriminant

8. Develop norms.

Test nomological validity

Note. Adapted from "A Paradigm for Developing Better Measures of Marketing Constructs," by G. A. Churchhill, 1979, Journal of Marketing Research 16 (February), p. 66.

\section{Stage One Qualitative}

After reviewing the literature on charitable giving, two focus groups were convened for the purpose of exploring charitable giving motivations and charitable giving behavior using a semi-structured interview protocol and techniques. A snowball sample of individual donors, within the geographic area of Hampton Roads, was interviewed in two small groups. A moderator's guide (Appendix C) structured the interviews somewhat and freedom to deviate and return to the guide as the discussion progressed was allowed. An outside observer, also an Old Dominion University doctoral student from the Urban Studies and Public Administration Department, was used to take detailed 
field notes during the focus groups. Both an audit trail and the use of member checking were used as strategies to ensure the accuracy of the data collected.

Participation in the focus groups was completely voluntary and the participants in the focus groups were asked to keep the discussion confidential within the members of the group and by participating; they agreed to hold the information confidential. The participants provided informed consent (Appendix D).

Participants for the focus groups were recruited using a snowball technique, which is a type of purposive sampling where referrals for the focus groups were initiated through social networks (Patton, 2002). First, area corporations (two Fortune 500 corporations and a large local realty) were contacted for solicitation as potential sites for focus groups. One of the Fortune 500 corporations declined to participate due to a lack of interest in the research topic by the company liaison. Next, a meeting was scheduled with each company liaison in which the details of the research were discussed and their commitment to participate, by helping with the recruitment of participants and provision of a space, secured. Third, the two company liaisons were given a flyer (Appendices E, F) summarizing the research activity to distribute as needed to potential participants. The company liaison contacted potential participants by telephone, in person, and by email, extending an invitation to participate in the focus groups. To qualify to participate in the focus groups, participants must have made a charitable donation, cash or in-kind, in the last 24 months. The focus groups were conducted in September 2011. The data collected was considered sensitive because it had been obtained from identified participants; however, any identifiers at the beginning of the focus group were deleted and discarded from the analysis. The focus groups were recorded via digital audio and downloaded by 
the principal investigator. The presence of audio recording of the discussion was acknowledged both in the informed consent and verbally, at the beginning of each focus group by the facilitator. Group members who were uncomfortable with being recorded were given the opportunity to leave without embarrassment, although none did. The transcripts for the focus groups were reviewed and coded by the principal investigator.

Moving from the general to the specific, the donors were asked a series of questions followed by group discussion on giving motivations, repeat giving, barriers or deterrents to giving, and attitudes about giving. Finally, the group members were asked to share anything that might not have already been covered but that they felt was relevant to the discussion. The interviews were designed to produce keywords and concepts and provide insight in the proposed individual giving model, Figure 2.3. Recurring themes and concepts, including variable additions/deletions and support for the variable linkages in the proposed model were identified. The results of the qualitative stage were largely supportive of the proposed model and an additional construct was added as a charitable giving motivation. The models presented in Figures 1.1 and 2.3 were evaluated in terms of the results of those interviews and discussions, as was the survey instrument (Appendix A). A more detailed presentation of the qualitative stage of inquiry and results is presented in Chapter IV.

\section{Stage Two Quantitative}

This study focuses on the charitable giving behaviors of individuals, and as such, data was collected from individual donors to nonprofit organizations (those people who have donated to charity in the last 24 months). A cross sectional web survey of an online 
consumer panel was employed to gather information on a population at a single point in time (Babbie, 1990). The survey instrument (Appendix A) tested 15 research hypotheses through 83 questions.

The use of the Internet for surveys is increasing due to technological and cultural changes in survey methods (Dillman et al., 2009; Couper, 2000). More people are using the Internet and email as a primary workplace and communication tool. A new survey by the Pew Research Center's Internet and American Life Project found that $75 \%$ of all adults in the U.S. actively participate in a voluntary group or organization and of those, Internet users are more likely to be active participants than those who do not use the Internet (Rainie, Purcell, and Smith, 2011). Using a web-administered survey is an appropriate choice for this target population.

Issues and Answers, Inc., a market research firm, was contracted to provide a random sample of individual donors from the three largest MSAs in Virginia (ArlingtonAlexandria ${ }^{5}$, Richmond, and Virginia Beach-Norfolk-Newport News). Use of a random sample reduces the risk of sample bias in the survey results. The firm was asked to provide a wide mix of demographic profiles as well as a mix of the type of charitable organizations that the money was donated to and the donation amount.

Issues and Answers, Inc. secures its sample from a national online consumer panel. In contrast to telephone surveys and random sample email surveys, online consumer panels have been shown to produce more reliable results and are an acceptable alternative to telephone surveys that produce high-quality research (Braunsberger et al., 2007). The vast majority of the U.S. population can be reached by telephone, $98 \%$

${ }^{5}$ In this study, Arlington-Alexandria refers to the Virginia residents of the WashingtonArlington-Alexandria MSA that encompasses residents from Maryland, Virginia, and the District of Columbia. 
(Smith, 2011) and the use of telephone survey methods has increased significantly (Link and Oldenick 1999). Nevertheless, telephone surveys have several weaknesses that can be overcome by the use of an online consumer panel in web surveys. The increase in telemarketing, telemarketing fraud, and deceitful fundraising practices via telephone has negatively impacted the response rate on telephone surveys (Council for Marketing and Opinion Research, 2003; Fowler, 2009). Fraudulent fundraising practices via telephone have made donors wary of discussing charitable giving over the telephone (Federal Trade Commission, 2011). As such, more affluent households and those with older children are screening telephone calls, utilizing Caller ID and other "gatekeeper technologies" (Tucker and Oldenick, 1999). Telephone interviewers experience more hang-ups if the call is perceived to be a telemarketer (Elving, 2000; Council for Marketing and Opinion Research, 2003). Thus, response rates for telephone surveys are very low (Keeter et al., 2000; Council for Marketing and Opinion Research, 2003) and the generalizability of telephone survey results is often questionable (Strieber et al., 1986; Tucker and O'Neill, 2002).

The employment of web survey methods has made surveying potential respondents quick and inexpensive. A web survey using an online consumer panel can generate results very quickly. The costs associated with web surveys are significantly less than telephone and traditional mail methods (Krasilovsky, 1996) and the pool of potential respondents is higher (Couper, 2000). However, nonresponse rates can be equally as high as telephone surveys and the coverage error may also be high (Couper, 2000). Web survey respondents may not be truthful in demographic information, which can make the survey results inaccurate, and any conclusions drawn invalid (Braunsberger 
et al., 2007). However, James (2003) suggested that the use of consumer panels specifically enlisted for online research, like that, which is used in this study, could overcome these limitations.

Some sources of potential error to consider in survey research are coverage error, sampling error, non-response error, and measurement error. Coverage error occurs when all members of the target population do not have a probable chance of being included in the sample causing the results to not accurately reflect the target population (Fowler, 2009). Sampling error, or standard error, gives the researcher an understanding about the precision of the statistical estimate generated from the survey results. Acquiring a large, probability sample and inferring their responses to the population reduces sampling, or standard error. Non-response error, the sample bias that occurs when a segment of the population is not surveyed, is overcome by the use of a web-administered survey. Measurement error is the bias or error that occurs when surveys do not measure the intended construct due to problems with the survey instrument, question wording and order, and response options (Fowler, 2009). Using previously validated construct scales and pre-testing the final survey instrument has reduced the amount of measurement error in this study. Finally, Fowler (2009) advocates that researchers use a level of rigor appropriate to the project goals, deviating as necessary while maintaining, "precision, accuracy, and credibility of survey estimates" (p. 175). 


\section{Survey Instrument}

The survey instrument (Appendix A) contains 83 questions that test the 15 hypotheses of the proposed individual giving model. A complete table of how the variables are operationalized is provided in Appendix B.

The unit of analysis is the individual respondent to the survey, drawn from a random sample of charitable donors from the three largest MSAs in Virginia. In the social sciences, the individual is the most typical unit of analysis (Babbie, 1990). Current research on charitable giving guided the selection of the unit of analysis. Charitable giving behavior is considered a household activity because the resources of a household are pooled, and as such, is most often measured at the household level (Burgoyne et al., 2005). However, because this study investigates individual charitable giving motivations, an individual's identity saliency, and an individual's satisfaction with the nonprofit relationship, it makes sense to then measure the dependent variable, charitable giving, also at the individual level.

\section{Charitable giving}

Relationship fundraising success is measured by increased and renewed donations and promoting behaviors (Arnett et al., 2003; Mael and Ashworth, 1992; Sargeant, 2001). As such, the dependent variable of interest in this study is a measure of the level of charitable giving. To test the dependent variable, charitable giving, Questions 4 - 9 asked about donations in the past as well as the intention to donate in the future. (Table 3.2, 3.3) Two large panel studies from the Netherlands and the United States use a series of selfreport questions about past charitable giving that focus on the details of the donations in 
order to minimize error. Rooney et al. (2001) found that asking detailed questions about donation history increases the frequency and amount of self-report data on charitable donations. The method of questioning, however, does not apply in studies focusing on gifts to one nonprofit organization.

In this study, respondents are asked to first identify the nonprofit organization with which they have a relationship, the type of organization it is, and to estimate its size (Questions 1-3). They are asked how much they gave in total with prompts for the different kinds giving opportunities found in many nonprofits. The following questions ask about the frequency of gifts and the length of time they had been a donor of the organization (Table 3.2).

To measure intention to donate and promote, a four-item intention to donate scale is used. Ranganathan and Henley (2007) adapted the Coyle and Thorson (2001) behavioral intention scale (Table 3.3) to charitable giving intentions in a survey of 214 individuals with a Cronbach's alpha reliability coefficient of .89 . This was adapted for use in this study.

Table 3.2

Charitable giving

How much did you donate to $(\mathrm{X})$ in the past year? Please include donations through direct mail, online, tickets to special events, raffles, sponsorships, and team fundraising events.

How frequent are your donations to $(X)$ in the 2 or $3 \quad 4$ to 8 past year?

Once times / times/ Monthly Weekly

How long have you been a Less than 1-3 years 3-5 years More than 5 donor of $(\mathrm{X})$ ? 1 year $\quad$ years

Note. The nonprofit's name is inserted at $\mathrm{X}$ throughout the questionnaire. 
Table 3.3

Intention to donate

"Completely disagree" to "Completely agree", seven-point scale

I am likely to donate to the charity in question.

I will donate the next time.

I will definitely donate.

I will recommend the charity to others to donate

Note. Adapted from Ranganathan, S. and Henley, W.H. (2007). Determinants of charitable donation intentions: A structural equation model. International Journal of Nonprofit and Voluntary Sector Marketing, 13(1), 1-11.

\section{Identity salience}

Identity salience refers to the self-relevance of role identities in an individual.

Identity saliency was measured using a seven-point scale $(1=$ strongly disagree to $7=$ strongly agree) developed and tested by Callero (1985) with a Cronbach's alpha

reliability coefficient of .81 . The extent to which the donor role-identity is a part of the donor's self is operationalized by adapting the blood donor salience scale (Callero, 1985)

to charitable giving (Table 3.4).

Table 3.4

Identity Saliency

"Strongly disagree" to "Strongly agree", seven-point scale

Donating to $(\mathrm{X})$ is something I rarely think about.

I would feel a loss if I were forced to give up donating to (X).

I really don't have clear feelings about (X) donation.

For me, being a donor means more than just giving money.

Donating to $(\mathrm{X})$ is an important part of who I am.

Note. The nonprofit name is inserted throughout the survey at X. Callero, P. L. (1985).

Role identity salience. Social Psychology Quarterly, 48(3), 203-215.

\section{Relationship satisfaction}

Donors were asked to assess the quality of the relationship with the nonprofit organization in question and the quality of the service offered using a measurement instrument, SERVQUAL (Parasuraman et al., 1988), which was adapted to charitable 
giving by Sargeant (2001) using a seven-point Likert scale $(1=$ strongly disagree, $7=$ strongly agree) (Table 3.5 ).

Table 3.5

Relationship Satisfaction "Strongly disagree" to "Strongly agree", seven-point scale

I feel confident that $\mathrm{X}$ is using my monies appropriately.

$X$ 's communications are always courteous.

$X$ 's employees have the best interests of society at heart.

$\mathrm{X}$ is the charity most likely to have an impact on this cause.

When $\mathrm{X}$ promises to provide a service to society, it does so.

I feel safe in my transactions with $X$.

Their communications are visually appealing.

$\mathrm{X}$ keeps me informed about how my monies are being used.

Employees in $\mathrm{X}$ are always courteous

$\mathrm{X}$ 's communications are always timely.

The behavior of X's employees instills confidence.

Employees in $\mathrm{X}$ have the knowledge to answer my questions.

$X$ 's employees have the best interests of their supporters at heart.

$\mathrm{X}$ makes me feel that it is always willing to help me if I have a query.

Employees at $\mathrm{X}$ are never too busy to speak with me.

$\mathrm{X}$ always responds promptly to requests $\mathrm{I}$ might have for information.

$\mathrm{X}$ gives me individual attention.

$\mathrm{X}$ writes to me at the times of the year I find most convenient.

Employees of $X$ seem to understand my specific needs.

When $I$ have a problem, $X$ shows an interest in solving it.

Note. The name of the nonprofit is inserted at $\mathrm{X}$ throughout the questionnaire. Sargeant, A. (2001). Relationship Fundraising: How to Keep Donors Loyal. Nonprofit Management and Leadership, 12(2), 177.

Trust

Trust was measured using a scale developed by Sargeant and Lee (2004) and

subsequently used again in charitable giving behavior research by Sargeant et al. (2006).

Trust is defined as "the extent of donor belief that a charity will behave as expected and

fulfill its obligations" (Sargeant and Lee, 2004). The researchers measure trust in a five-

item measure designed to capture the degree of trust in a nonprofit organization.

Respondents were asked to what extent they agreed with statements in a seven-point 
Likert scale from "strongly disagree" to "strongly agree." This was tested among 334 respondents by Sargeant and Lee (2004)) and was found to exhibit a Cronbach's alpha coefficient reliability of 0.96 for trust in a nonprofit to which a donation has been made (Table 3.6).

Table 3.6

Trust

"Strongly disagree" to "Strongly agree", seven-point scale

I would trust this nonprofit to always act in the best interest of the cause.

I would trust this nonprofit to conduct their operations ethically.

I would trust this nonprofit to use donated funds appropriately.

I would trust this nonprofit not to exploit their donors.

I would trust this nonprofit to use fundraising techniques that are appropriate and sensitive.

Source: Sargeant A, and Lee S. (2004). Donor trust and relationship commitment in the U.K. charity sector: The impact on behavior. Nonprofit Voluntary Sector Quarterly, $33(2), 185-202$.

\section{Perceived need}

Perceived need was measured using a scale developed by Arnett et al. (2003) in a survey on alumni charitable giving behavior and relationship marketing. While a subjective construct, the perception of need can be described as donors being aware of the nonprofit organization's need for support. Arnett et al. (2003) measured perceived need using three statements measured on a seven-point scale ("strongly disagree" to "strongly agree"). This was tested among 953 respondents and was found to exhibit a Cronbach's alpha coefficient reliability of 0.86 for perceived need of a nonprofit to which a donation has been made. (Table 3.7) 
Table 3.7

Perceived Need

"Strongly disagree" to "Strongly agree", seven-point scale

(Nonprofit name)'s need for financial support from its donors will be even greater in the future.

Nonprofit organizations that receive some public funding need the financial support of their donors just as much as those nonprofits that do not.

(Nonprofit name) presently needs strong financial support from its donors.

Note. Arnett, D. B., German S. D., and Hunt, S. D. (2003). The identity salience model of relationship marketing success: The case of nonprofit marketing. Journal of Marketing, 67(2), 89-105.

\section{Perceived organizational performance}

Perceived organizational performance was measured using a scale developed by Sargeant et al. (2006) in a survey of charitable giving behavior in the U.S. Perceived organizational performance can be described as donors understanding of the efficiency and efficacy of a nonprofit organization's operations. Sargeant et al. (2006) measured perceived organizational performance using two statements measured on a seven-point scale ("strongly disagree" to "strongly agree"). This was tested among 1,355 respondents and was found to exhibit a Cronbach's alpha coefficient reliability of 0.83 for perceived organizational performance of a nonprofit to which a donation has been made. (Table

\section{8)}

Table 3.8

Perceived Organizational Performance

"Strongly disagree" to "Strongly agree", seven-point scale

This nonprofit is the nonprofit most likely to have an impact on this cause.

This nonprofit spends a high proportion of its income on this cause.

Note. Sargeant, A., Ford, J. B., and West, D. C. (2006). Perceptual determinants of nonprofit giving behavior. Journal of Business Research, 59, 155-165. 
Perceived benefits

Perceived benefits were measured using three scale scales developed by Sargeant et al. (2006) in a survey of charitable giving behavior in the U.S. They divided perceived benefits, or anticipated returns from charitable giving, into three constructs: demonstrable utility, emotional utility, and familial utility. Demonstrable benefits are the tangible benefits received as a result of the process of giving with "selfish economic considerations" suggesting that individual donors are motivated by benefits received previously or promised in the future (Sargeant et al., 2006, p. 3). They measured demonstrable utility using five statements measured on a seven-point scale ("strongly disagree" to "strongly agree"), which was found to have a Cronbach's alpha coefficient reliability of .71. (Table 3.9) Emotional utility is often referred to as "personal mood management" where donors have an emotional experience resulting from the giving process (Andreoni, 2001; Bendapudi et al., 1996; Cialdini et al., 1987; Wegener and Petty, 1994). They measured emotional utility using two statements measured on a seven-point scale ("strongly disagree" to "strongly agree"), which was found to have a Cronbach's alpha coefficient reliability of .68. (Table 3.10) Familial utility can be described as a personal familial connection or experience that inspires (Bruce, 1998; Sargeant, 1999) a "need to assist or demonstrate an affinity with one's friends or loved ones (Sargeant et al., 2006, p. 3). They measured familial utility using three statements measured on a seven-point scale ("strongly disagree" to "strongly agree"), which was found to have a Cronbach's alpha coefficient reliability of .72. (Table 3.11) 
Table 3.9

Perceived Benefits: Demonstrable Utility

"Strongly disagree" to "Strongly agree", seven-point scale

When I give to this nonprofit I receive some benefit in return for my donation.

I give to this nonprofit to gain local prestige.

I donate money to this nonprofit to receive their publications.

Contributing to this nonprofit enables me to obtain recognition.

I may one day benefit from the work this organization undertakes.

Source: Sargeant, A., Ford, J. B., and West, D. C. (2006). Perceptual determinants of nonprofit giving behavior. Journal of Business Research, 59, 155-165.

Table 3.10

Perceived Benefits: Emotional Utility

"Strongly disagree" to "Strongly agree", seven-point scale

I often give to this nonprofit because I would guilty if I didn't.

If I never gave to this nonprofit I would feel bad about myself.

Source: Sargeant, A., Ford, J. B., and West, D. C. (2006). Perceptual determinants of nonprofit giving behavior. Journal of Business Research, 59, 155-165.

Table 3.11

Perceived Benefits: Familial Utility

"Strongly disagree" to "Strongly agree", seven-point scale

I give money to this nonprofit in memory of a loved one.

I felt that someone I know might benefit from my support.

My family had a strong link to this nonprofit.

Source. Sargeant, A., Ford, J. B., and West, D. C. (2006). Perceptual determinants of nonprofit giving behavior. Journal of Business Research, 59, 155-165.

\section{Solicitation}

Solicitation was measured using a scale developed by Sargeant (2001) in a survey

of ten thousand individual donors in the U.K. In this study, solicitation is defined as the

degree of satisfaction with the solicitation process. This differs from relationship

satisfaction as it directly assesses the experience of being asked to donate. Sargeant

(2001) measured this using nine statements measured on a seven-point scale ("strongly

disagree" to "strongly agree"). (Table 3.12) 
Table 3.12

Solicitation

Asking for appropriate levels of support.

Leaving it to me how much to donate.

Thanking me for my support.

Responding quickly when I contact them.

Demonstrating they care about their supporters.

Being polite in all their communications.

Informing me about how money is spent.

Not asking me for support too often.

Making me feel important.

Note. Sargeant, A. (2001). Relationship fundraising: How to keep donors loyal. Nonprofit

Management and Leadership, 12(2), 177.

\section{Parental Socialization and Youth Participation}

Parental socialization and youth participation were measured using a scale developed by Perry (1997) in a survey testing the antecedents to public service motivation. Perry (1997) adapted a parental socialization and youth participation scale from Clary and Miller (1986), using eleven of the original fifteen statements with a Cronbach's alpha coefficient reliability at .78. Parental modeling of pro-social behaviors and youth participation, in particular volunteering and donating to charity, have been shown to be strongly correlated to altruistic behavior in adulthood (Clary and Miller, 1986; Rosenhan, 1970; Bekkers, 2005). (Table 3.13)

Table 3.13

Parental Socialization and Youth Participation "Strongly disagree" to "Strongly agree", seven-point scale My parents rarely donated money to charitable causes.

My father treated his job as one in which he tried to help other people.

My parents actively participated in volunteer organizations (such as the Red Cross, March of Dimes, etc.)

My mother treated her job (in home an/or out-of home) as one in which she helped other people.

In my family, we always helped one another. 
My parents very frequently donated money to people who collected money door to door (Such as March of Dimes, Heart Fund, etc.)

Concerning strangers experiencing distress, my parents generally thought that it was more important to "not to get involved."

My parents frequently discussed moral values with me (values like the "Golden Rule," etc.)

When I was growing up, my parents told me I should be willing to "lend a helping hand." My parents often urged me to donate money to charities.

When I was younger, my parents very often urged me to get involved with volunteer projects for children (for example, UNICEF, walkathons, etc.)

Note. Perry, J. (1997). Antecedents of public service motivation. Journal of Public Administration Research and Theory, 7(2), 181-197.

\section{Data Analysis}

The raw data was downloaded, formatted, and coded for transfer to SPSS and AMOS for analysis.

Step 1: $\quad$ Sample Profile

The survey sample was profiled for age, sex, race, education and income. While the sample was skewed towards female and Caucasian, this is not inconsistent with charitable giving. The sample was scrutinized for donor behaviors. The intent of this is to reconfirm that the data is distributed widely.

Step 2: $\quad$ Measurement Model

Confirmatory factor analysis (CFA) was conducted for all of the constructs using AMOS. Next the modification indices were run which revealed any problematic items and construct cross loadings. Items with low loadings were dropped and the fit of the model was examined. Reliability for the latent constructs was determined using Cronbach's alpha (SPSS). 


\section{Step 3: $\quad$ Structural model}

Once the CFA worked after refinements, structural equation modeling was conducted using AMOS under the advisement of the methodologist member of the committee. The model fit indices were analyzed along with the variance explained for the endogenous constructs. The regression weights for the hypothesized links were tested for statistical significance.

\section{Step 4: $\quad$ Data summarizing}

The results of the sample profile analysis, the final list of scale items with the standardized loadings, the fit indices of the measurement model, the standardized weights, and statistical significance of the links in the structural model were summarized in the form of tables and figures. The results of these analyses are presented in Chapter IV.

\section{Limitations}

There are some limitations in survey research and specifically, charitable giving research that should be addressed. While every attempt to has been made to strengthen the research design, the use of a random sample from a consumer research panel may present a threat to internal validity, selection bias, as the members of the panel have agreed to membership for the purpose of surveys. However, it has been requested that the random sample be reflective of the populations in those MSAs. Additionally, since the population is limited to Virginia, the results cannot be generalized to other populations. A limitation commonly found in charitable giving research is social desirability (Hall, 2001). Some people may not want to admit how little they give or that they do not give at all. In order to be perceived more socially desirable, they give more 
socially desirable answers, such as reporting higher or more frequent charitable donations. Dillman (2007) suggests that using a survey method that minimizes interpersonal communication such as mail or web surveys reduces socially desirable responses.

\section{Summary}

This chapter explained the proposed methodology for this research project, which utilizes a sequential mixed methods research design using focus group interviews and a cross sectional survey on a random sample of charitable donors in Arlington-Alexandria, Richmond, and Virginia Beach-Norfolk-Newport News MSAs. The purpose of the study is to examine charitable giving motivations, and to test and extend recent nonprofit relationship marketing research, which has sought to explain the antecedents to successful relationships with nonprofit donors and to clarify the role of identity saliency and donor relationship satisfaction in nonprofit relationship marketing. The next chapter presents the collection and analysis of the data to answer the previously discussed research questions. 


\section{CHAPTER IV}

\section{RESULTS OF THE STUDY}

\section{Introduction}

Chapter III explained the data collection method for this study, introduced the sample utilized in the study, recounted the hypotheses for the variables of interest, described the survey instrument, and reviewed the analytic approaches. This chapter presents the results of the sequential mixed methods study, presenting first the results of the qualitative stage and second, the results of the quantitative stage. The hypotheses and the resulting analytics are presented in numerical order according to the presentation for the conceptual framework within the literature review in Chapter II.

\section{Stage One - Qualitative}

The qualitative stage of this study was comprised of two one-hour focus group interviews for the purpose of exploring charitable giving motivations and charitable giving behavior using a semi-structured interview protocol and techniques. The review of the focus group transcripts generated several key findings that informed the development of the survey instrument which are described below in terms of commonalities with the semi-structured interview topics: charitable giving motivations, barriers or deterrents to charitable giving, and repeat giving.

In-depth analysis of the transcripts for the two one-hour focus groups was completed using a qualitative analysis worksheet. The researcher coded the transcripts and then counted the frequencies to the qualitative worksheet. Keywords, statements, and concepts were identified from the focus groups and similarities and differences were 
noted between the two focus groups. The researcher was sensitive to interwoven relationships of topics and constructs.

Among charitable giving motivations, the most prevalent reason noted by participants as a reason for giving was identification with the cause of the nonprofit organization. Almost all of the participants discussed how they understood the mission of the nonprofit and that they felt a close connection with the cause and the organizations they support. They shared personal stories of familial closeness to the cause and how they might have been helped in the past, even expressing feelings of guilt if they did not support the nonprofit.

Other charitable giving motivations discussed in order of their prevalence were: perceived need, perceived organizational performance, giving back, parental socialization and youth participation, recognition, altruism, perceived benefits, ease of giving, religious influence, communications, making a difference, economic ability to give, peer pressure, familial connection, spousal influence, tax deductibility, status, and prestige (Table 4.1). The pursuit of prestige or societal status through charitable giving was not very important to the focus group participants. In fact, several participants denied it as a motivation for giving directly when the topic was brought up. Examples of those responses included "I don't - I don't personally know anyone that gives for any of those reasons" to "most of the people I know aren't going to donate enough to have a plaque." However, when asked about donor recognition and expressions of thanks for their gifts, there was general agreement that there are tangible and intangible benefits to giving: examples of those included "each time you go up, you know, you get certain extra things" and "they send quarterly newsletters" to "when you go to the symphony, that's 
the first thing you do is go to the back of the program and look for your name and I feel good when my name is in there."

Several participants noted the influence of past life experiences such as parental modeling of pro-social behaviors like giving and volunteering and the participation in charitable fundraising drives in their youth:

"When I was growing up, we had very little money, however, like both my parents were in education, they were teachers, and they were very passionate about trying to help others, and doing some volunteering, and so I saw that, and that kept building and I expect my children, who will see me doing things, will be the same way."

The focus group participants also discussed barriers and deterrents to charitable giving. Mismanagement, scandal, and wasteful spending, especially in the fundraising solicitation process were noted as major deterrents to giving. Regarding the experience of being asked to donate, participants were turned off to telefunding campaigns, "notes to neighbors," and direct mail solicitation that included a gift, such as return address labels, stationary, magnets, or desk items etc. These methods were perceived as both annoying and wasteful. Also, participants preferred to make charitable gifts to local organizations that were perceived as more likely to make an impact in their community: "we tend to give more of our giving to local organizations that we know specifically impact people in this area."

Repeat giving among the participants was primarily motivated by knowing that their gift was making an impact, most often communicated in publications, letters, and newsletters from the nonprofit. Encouraged by the demonstration of the usefulness of their donations, they indicated repeat giving: "one of the things that they do, is they do a good job of keeping me updated on what they are doing and how my donations are being 
utilized." However, what discouraged repeat giving was additional "asks" so quickly and often after the first gift was made: "there's a follow up almost immediately, like within a week or month, of additional solicitations...it's a sign of inefficiency."

The results of the focus groups and the review of the previous research in charitable giving behavior informed the design of the survey instrument. Several constructs from the literature review were confirmed in the focus groups as necessary for inclusion: trust, perceived financial need, perceived organizational performance, and perceived benefits (demonstrable utility, emotional utility, and familial utility). Two more constructs emerged from the focus groups, directly informing the survey instrument design and proposed model: satisfaction with the solicitation process and parental socialization and youth participation. Table 4.1 present the keywords listed in order of prevalence in the transcripts.

Table 4.1

Keywords \& Statements in Focus Groups

Identification

Way in which asked and/or authenticity of ask

Perceived need

Organizational efficiency

Giving back

Parental socialization

Organizational effectiveness

Recognition

Altruism

Perceive benefits

Easy to give

Religion

Communications

Making a difference

Economic situation

Other cause

Peer pressure

Familial

Spouse

Tax deduction

Status

Prestige

Note: Listed in order of descending prevalence. 


\section{Stage Two - Quantitative}

\section{Data Collection Process}

Issues and Answers Network, Inc., located in Virginia Beach, was contracted to collect the survey data from an online consumer panel. They were asked to provide 500 completed surveys from U.S. consumers located in the three largest metropolitan statistical areas in the Commonwealth of Virginia (Arlington-Alexandria, Richmond, and Virginia Beach-Norfolk-Newport News) who had made two or more donations to the same nonprofit organization in the last two years. Designed to be reflective of the U.S. Census, the online consumer panel in these geographic areas contained 13,945 members.

The research agency utilized the following process for data collection. The total panel was divided by the required sample size (500) to create a selection interval. Records were chosen according to the selection interval. Once the end of the sampling frame was reached, the software went back to the beginning for additional records to fulfill the needed sample size. The resulting target sample was sorted randomly before emailing, using a standard Oracle ${ }^{\mathrm{Tm}}$ random sorting algorithm. When samples were emailed, each group represented a smaller version of the entire sample, similar in demographics and geography to other groups. For the current project 1,274 respondents answered the first screening question and then $719(56 \%)$ qualified as having donated two or more times to the same charity in the last 2 years and completed the entire survey. The invitations to participate in the study were sent to members of the panel sharing these demographics: 18 years and older, mostly with annual household income over $\$ 30,000$, and representing a geographic spread over the three largest metropolitan statistical areas in the Commonwealth of Virginia. The agency returned completed responses from 719 
donors who made two or more donations to the same charity in the last two years. The data was received in SPSS format.

\section{Profile of survey respondents}

The survey respondents were charitable donors from the three largest MSAs in Virginia who had made two or more charitable donations of money to the same nonprofit. within the past two years. The total number of online surveys started was 1,274 of which 719 were utilized in analysis $(\mathrm{N}=719)$. No surveys were excluded due to missing data. Each question had the same number of valid responses. As mentioned earlier, the total sampling frame is 13,945 and this survey captured about 5 percent of the sampling.

The data was checked for inconsistencies and frequencies for all scale items were analyzed. The review indicated that there were no major issues, no missing data, and it appeared to be balanced. The demographic profile of the respondents was also scrutinized for representativeness and balance.

Tables $4.2-4.8$ present the demographic profile of the respondents and 2010 census data for the Commonwealth of Virginia is also provided for comparison. A detailed analysis of the respondents showed that there was a balanced break down on age. (Table 4.2). The average age of the respondents was 48 years. Gender was skewed more towards female (Table 4.3). The racial profile of the respondents was skewed more towards Caucasians (Table 4.4). All income groups were represented in the sample (Table 4.5). The respondents in the sample were educated, with $94.7 \%$ having completed some college education or more (Table 4.6 ) and $57.2 \%$ of respondents had a military affiliation, where someone in their immediate family is currently on active duty in the 
U.S. Military or is a veteran, or retired military $^{6}$ (Table 4.7). The respondents in the sample were also evenly spread among avid churchgoers to non-church goers (Table 4.8).

Table 4.2

Age

\begin{tabular}{lcc} 
& Survey & Virginia \\
\hline Mean & 48 years old & 38.7 years old \\
Standard Deviation & 14.515 years & \\
Minimum & 19 years old & \\
Maximum & 91 years old & \\
\hline
\end{tabular}

Source: U.S. Census Bureau, 2009 American Community Survey, "Age" Retrieved online at http://factfinder.census.gov.

Table 4.3

Gender

\begin{tabular}{lccc}
\hline & $\mathrm{N}$ & Percentage & Virginia \\
\hline Male & 272 & 37.8 & 49.1 \\
Female & 447 & 62.2 & 50.9 \\
\hline
\end{tabular}

Source: U.S. Census Bureau, 2009 American Community Survey, "Gender" Retrieved online at $\mathrm{http}: / /$ factfinder.census.gov.

Table 4.4

Race

\begin{tabular}{lccc}
\hline & $\mathrm{N}$ & Percentage & Virginia \\
\hline White & 583 & 81.1 & 71.5 \\
Black or African American & 57 & 7.9 & 19.7 \\
American Indian or Alaskan Native & 2 & .3 & .5 \\
Asian & 50 & 7.0 & 5.6 \\
Native Hawaiian or other Pacific Islander & 4 & .6 & .3 \\
From multiple races & 23 & 3.2 & 2.4 \\
\hline
\end{tabular}

Source: U.S. Census Bureau, 2009 American Community Survey, "Race" Retrieved online at http://factfinder.census.gov.

\footnotetext{
${ }^{6}$ While this might be initially perceived as high or skewed, this is representative of the estimated number of veterans living in Virginia, 819,490 and includes all immediate family members ("State summary," 2010).
} 
Table 4.5

Annual Household Income

\begin{tabular}{lccc}
\hline & $\mathrm{N}$ & Percentage & Virginia \\
\hline Under $\$ 25,000$ & 60 & 8.3 & 19.4 \\
$\$ 25,000$ to $\$ 49,999$ & 106 & 14.7 & 22.8 \\
$\$ 50,000$ to $\$ 74,999$ & 120 & 16.7 & 18.4 \\
$\$ 75,000$ to $\$ 99,999$ & 147 & 20.4 & 12.8 \\
$\$ 100,000$ to $\$ 149,999$ & 149 & 20.7 & 14.1 \\
$\$ 150,000$ or more & 137 & 19.1 & 12.2 \\
\hline
\end{tabular}

Source: U.S. Census Bureau, 2009 American Community Survey, B19001, "Household Income in the Past 12 Months" and B19013, "Median Household Income in the Past 12 Months (In 2009 Inflation-Adjusted Dollars)," Retrieved online at http://factfinder.census.gov.

Table 4.6

Educational Attainment Level

\begin{tabular}{lccc}
\hline & N & Percentage & Virginia \\
\hline Less than high school & 3 & .4 & 12.4 \\
High school graduate or equivalent & 35 & 4.9 & 30.7 \\
Some college & 129 & 17.9 & 26.5 \\
Bachelor's degree & 258 & 35.9 & 19.5 \\
Master's degree & 206 & 28.7 & 7.9 \\
Professional degree (for example: M.D., D.D.S., & 56 & 7.8 & 1.5 \\
D.V.M., L.L.B., J.D.) & & & \\
Doctoral degree (for example: Ph.D., Ed.D.) & 32 & 4.5 & 1.5 \\
\hline
\end{tabular}

Source: U.S. Census Bureau, 2011 Current Population Survey, "Table 1. Educational Attainment of the Population 18 Years and Over, by Age, Sex, Race, and Hispanic Origin: 2011 retrieved online at http://www.census.gov/hhes/socdemo/education/data/cps/2011/tables.html.

Table 4.7

Amount of Family Members with a Military Affiliation

\begin{tabular}{lcc}
\hline & $\mathrm{N}$ & Percentage \\
\hline 1 & 194 & 27.0 \\
2 & 109 & 15.2 \\
3 & 53 & 7.4 \\
4 & 31 & 4.3 \\
5 & 13 & 1.8 \\
6 or more & 11 & 1.5 \\
None & 308 & 42.8 \\
\hline
\end{tabular}


Table 4.8

Attendance at religious services, church, or other place of worship

\begin{tabular}{lccc}
\hline & N & Percentage & Virginia \\
\hline More than once per week & 61 & 8.5 & 3.9 \\
Once a week & 166 & 23.1 & 29.2 \\
A couple of times per month & 64 & 8.9 & 11.3 \\
Once a month & 26 & 3.6 & 41.6 \\
Less than once a month & 44 & 6.1 & 2.7 \\
A couple of times a year & 174 & 24.2 & 4.5 \\
Never & 184 & 25.6 & 6.7 \\
\hline
\end{tabular}

Source: The Gallup Organization, 2011 Religion and Social Trends, "Church Attendance Lowest in New England, Highest in South. Retrieved online at

http://www.gallup.com/poll/22579/church-attendance-lowest-new-england-highestsouth.aspx

\section{Data Preparation}

Prior to analyzing the data, some of the measures needed to be refined. Age was calculated by subtracting the year of birth from the current calendar year (2012). Four questions were reverse coded (questions 8 and 10 in identity salience; question 73 in parental socialization and youth participation; question 65 in solicitation). Church attendance was recoded so that higher values equal higher church attendance. The first observed variable in the charitable giving latent construct was normalized because the donation amount was positively skewed towards the lower range of charitable giving amounts. Lastly, "not applicable" responses in parental socialization and youth participation were recoded to "neither agree nor disagree."

\section{Descriptive statistics}

The following section presents the descriptive statistics for the type and size of nonprofit organization and the dependent variables related to charitable giving. 
Giving to health related nonprofit organizations was the most prevalent in this study $(23.8 \%)$, followed by giving to human services (19.1\%), religious giving $(15.9 \%)$, public society-benefit-relief $(9.2 \%)$, other $(7.0 \%)$, education $(6.4 \%)$, military support organizations (6.3\%), environment/animals (4.6\%), foundation (4.2\%), arts, culture, and humanities $(2.9 \%)$, and international affairs (.8\%) (Table 4.9$)$. The size of nonprofit organizations was also well balanced with respondents reporting giving to large $(53.8 \%)$, medium (23.2\%), and small (22.9\%) nonprofit organizations (Table 4.10). In summary, there was a good mix of types and sizes of nonprofit organizations in the sample.

Table 4.9

Type of Nonprofit Organization

\begin{tabular}{lcc}
\hline & $\mathrm{N}$ & Percentage \\
\hline Religious & 114 & 15.9 \\
Education & 46 & 6.4 \\
Foundation & 30 & 4.2 \\
Human services & 137 & 19.1 \\
Health & 171 & 23.8 \\
Public-society-benefit (relief) & 66 & 9.2 \\
Arts, culture, and humanities & 21 & 2.9 \\
International affairs & 6 & .8 \\
Environment/animals & 33 & 4.6 \\
Military support organizations & 45 & 6.3 \\
Other & 50 & 7.0 \\
\hline
\end{tabular}

Table 4.10

Size of Nonprofit Organization

\begin{tabular}{lcc}
\hline & $\mathrm{N}$ & Percentage \\
\hline Small & 165 & 22.9 \\
Medium & 167 & 23.2 \\
Large & 387 & 53.8 \\
\hline
\end{tabular}

Charitable giving amounts were skewed to the lower range of gifts; the mean gift amount was $\$ 864.43$, the median was $\$ 200.00$, and the mode was $\$ 100$, with $44.6 \%$ of 
the respondents indicating donations of less than $\$ 100$ and $14 \%$ with relatively large amounts (more than $\$ 1,000$ ) (Table 4.11). The frequency of those charitable gifts were given two to three times per year (43\%), once per year $(27.4 \%)$, monthly $(15.9 \%)$, four to eight times per year (10.4\%), and weekly (3.3\%) (Table 4.12). In terms of the length of time the respondents had been donating to that charitable organization, also referred to as donor tenure, $47.4 \%$ of the respondents in the sample indicated that they had been giving to that charitable organization for more than five years (Table 4.13). This implies that they had a relationship over time with the charitable organization. This mix of types and sizes of nonprofit organizations, donation amount, frequency of charitable giving, and length of time as a donor also enhances the generalizability of the study's findings.

Table 4.11

Self-reported Estimate of Annual Charitable Giving in U.S. Dollars

\begin{tabular}{lc}
\hline Mean & $\$ 864.43$ \\
Standard Deviation & $\$ 2,683.35$ \\
Median & $\$ 200.00$ \\
Mode & $\$ 100.00$ \\
Minimum & $\$ 10.00$ \\
Maximum & $\$ 30,000.00$ \\
\hline
\end{tabular}

Table 4.12

Frequency of Charitable Giving

\begin{tabular}{lcc}
\hline & N & Percentage \\
\hline Once & 197 & 27.4 \\
2 to 3 times per year & 309 & 43.0 \\
4 to 8 times per year & 75 & 10.4 \\
Monthly & 114 & 15.9 \\
Weekly & 24 & 3.3 \\
\hline
\end{tabular}


Table 4.13

Length of time having been a donor

\begin{tabular}{lcc}
\hline & $\mathrm{N}$ & Percentage \\
\hline Less than 1 year & 36 & 5.0 \\
1 to 3 years & 190 & 26.4 \\
3 to 5 years & 152 & 21.1 \\
More than 5 years & 341 & 47.4 \\
\hline
\end{tabular}

\section{Data Analysis}

\section{Confirmatory factor analysis}

An evaluation of the proposed theoretical model was performed using confirmatory factor analysis (CFA) and hypothesis testing using AMOS 19.0 structural equation modeling (SEM) software. First, using confirmatory factor analysis, the proposed measurement model was evaluated and revised in order to gain a better model fit, understanding how the observed variables relate to the latent constructs or factors (Tabachnick and Fidell, 2001). Next, structural equation modeling (SEM) was performed which provides an understanding of how well the structural relationships between the latent constructs fit the data in the sample.

All of the eleven constructs measured in this study are unobservable or latent constructs that may account for variation in the data or correlations between the observed variables. These latent variables are constructed by observed variables that can be directly measured (Dodge, 2003). Latent variables "represent 'shared' variance, or the degree to which variables 'move' together" (Tabachnick and Fidell, 2001, p. 655). Confirmatory factor analysis is a statistical method to measure the degree to which the variables move together or co-vary.

The results from the confirmatory factor analysis of the proposed measurement 
model were assessed following the guidance of Kline (2005) and Hooper, Coughlin, and Mullen (2008), utilizing six fit indices in a thorough assessment strategy. All the utilized model fit indices' recommended thresholds are summarized in Table 4.14. Threshold values of the fit indices should be flexible enough to accommodate changes in sample size, model complexity, and degrees of freedom in model specification to examine how accurately various fit indices performed (Hair et al., 2010). More complex models and larger samples should not be subject to as strict an evaluation than more simple models and smaller samples.

Table 4.14

Model Fit Indices Recommended Thresholds

\begin{tabular}{|c|c|c|}
\hline Fit Indices & Threshold & Source \\
\hline Normed Chi Square (Chi Square/df) & $2.0-5.0$ & $\begin{array}{l}\text { Wheaton et al., 1977; } \\
\text { Tabachnick and Fidell, } 1977\end{array}$ \\
\hline Goodness of Fit (GFI) & $>.90$ & Hu and Bentler, 1999 \\
\hline Tucker-Lewis Index (TLI) & $>.95$ & Hu and Bentler, 1999 \\
\hline Comparative Fit Index (CFI) & $>.95$ & $\mathrm{Hu}$ and Bentler, 1999 \\
\hline Incremental Fit Index (IFI) & $>.95$ & Hu and Bentler, 1999 \\
\hline Root Mean Squared Error (RMSEA) & $.06-.07$ & Hu and Bentler, 1999; Steiger, 2007 \\
\hline
\end{tabular}

In order to evaluate the measurement properties of the endogenous and exogenous variables used in the study, a confirmatory factor analysis (CFA) was undertaken with all eleven constructs evaluated simultaneously in a single CFA model with 72 items -trust (5 
items), perceived need (3 items), perceived organizational performance ( 2 items), demonstrable utility (4 items), emotional utility ( 3 items), familial utility ( 3 items), solicitation ( 9 items), parental socialization and youth participation (11 items), identity saliency (5 items), relationship satisfaction (20 items), and charitable giving ( 7 items).

The standardized regression weights were studied and a note was made of all the items that had a standardized loading less than 0.50 . For samples under 1,000 , the minimum acceptable loading is .70 ; however, for samples over 1,000 , the commonly used cut off is .32 (Tabachnick and Fidell, 2001). Modification indices were also run and those error terms that had a high covariance (modification index $>20$ ) with other error terms were identified and noted. However, at this juncture no items were deleted from any of the scales.

Several of the parental socialization and youth participation variables had very low standardized values. All of the remaining indicator variables loaded successfully onto their constructs - trust, perceived financial need, perceived organization performance, demonstrable utility, emotional utility, familial utility, and solicitation; although none were significant. The proposed measurement model did not show very many positive correlation coefficients between the variables. The chi-square values and fit indices are summarized in Table 4.15. The proposed measurement model shows a mediocre fit $\left(x^{2}(2280)=8120, x^{2} / \mathrm{df}=3.562, \mathrm{CFI}=0.84, \mathrm{IFI}=0.84, \mathrm{TLI}=0.83, \mathrm{GFI}=\right.$ 0.69 , RMSEA $=0.06$ ). 
Table 4.15

Chi Square and Goodness of Fit Indices for the Proposed Measurement Model

\begin{tabular}{lc}
\hline Index & Proposed \\
\hline Chi Square & 8120.437 \\
Degrees of Freedom & 2280 \\
Significance & 0.00 \\
Normed Chi Square (Chi Square/df) & 3.562 \\
Goodness of Fit (GFI) & .69 \\
Tucker-Lewis Index (TLI) & .83 \\
Comparative Fit Index (CFI) & .84 \\
Incremental Fit Index (IFI) & .84 \\
Root Mean Squared Error (RMSEA) & .06 \\
\hline
\end{tabular}

\section{Revised Measurement Model}

Since the proposed measurement model did not fit the data well, the measurement model was modified based on two criteria. First, only indicator variables with standardized factor loadings above .50 were retained (Hair, Black, Babin, and Anderson, 2010); but indicator variables with loadings below .50 were retained if the construct would have less than three indicator variables (as Kline, 2005, noted instability with twoindicator constructs). Second, indicator variables with high modification indices (MI) were deleted, as this was an indication that the variables were cross loading onto other constructs (Byrne, 2001). As such, standardized factor loadings less than .50 were SAL1 (.36), SAL3 (.40), CG2 (.18), and CG3 (.27). In the identity saliency construct, it is important to note that SAL1 (Donating to $(\mathrm{X})$ is something I rarely think about) and SAL3 (I really don't have clear feelings about (X) donation) were negatively worded statements. Two of the seven indicator variables from the dependent variable of 
charitable giving, CG2 (frequency of donations) and CG3 (donor tenure) did not load successfully onto the construct and were also dropped from the model.

Next, items with high modification indices were dropped from the model.

Relationship satisfaction, solicitation, and parental socialization and youth participation were large scales with the number of scale items ranging from 9 to 20 items. The error term of RSAT19 is highly correlated with error term of RSAT17 (MI = 103.79). RSAT19 loaded on highly to RSAT17 $(\mathrm{MI}=46.06)$. The error term of RSAT18 highly correlated with error term of RSAT19 $(\mathrm{MI}=103.64)$. RSAT18 loaded on highly to RSAT19 $(\mathrm{MI}=$ 45.97). The error term of RSAT16 highly correlated with error term of RSAT17 (MI = 75.97). RSAT16 loaded on highly to RSAT17 $(\mathrm{MI}=28.92)$. The error term of RSAT15 highly correlated with error term of RSAT16 $(\mathrm{MI}=139.22)$. RSAT15 loaded on highly to RSAT16 $(\mathrm{MI}=48.40)$. The error term of RSAT8 highly correlated with error term of RSAT10 $(\mathrm{MI}=82.27)$. RSAT8 loaded on highly to RSAT10 $(\mathrm{MI}=41.78)$. The error term of RSAT7 highly correlated with error term of RSAT8 $(\mathrm{MI}=47.84)$. RSAT7 loaded on highly to RSAT8 $(\mathrm{MI}=24.63)$. The error term of RSAT6 highly correlated with error term of RSAT5 $(\mathrm{MI}=157.16)$. RSAT6 loaded on highly to RSAT5 $(\mathrm{MI}=$ 61.20). The error term of RSAT5 highly correlated with error term of RSAT3 (MI = 110.82). RSAT5 loaded on highly to RSAT3 $(\mathrm{MI}=36.78)$. The error term of RSAT4 highly correlated with error term of RSAT5 $(\mathrm{MI}=125.02)$. RSAT4 loaded on highly to RSAT5 $(\mathrm{MI}=65.39)$. The error term of RSAT2 highly correlated with error term of RSAT3 $(M I=76.11)$. RSAT2 loaded on highly to RSAT3 $(M I=31.73)$. The error term of RSAT1 highly correlated with error term of RSAT5 $(M I=145.68)$. RSAT1 loaded on highly to RSAT5 $(\mathrm{MI}=56.30)$. The error term of SOL2 highly correlated with error 
term of SOL3 $(\mathrm{MI}=35.73)$. SOL2 loaded on highly to SOL5 $(\mathrm{MI}=5.10)$. The error term of SOL4 highly correlated with error term of RSAT16 $(\mathrm{MI}=42.75)$. SOL4 loaded on highly to RSAT16 $(\mathrm{MI}=19.29)$. The error term of SOL7 highly correlated with error term of RSAT8 $(\mathrm{MI}=164.43)$. SOL7 loaded on highly to RSAT8 $(\mathrm{MI}=94.05)$. The error term of PSYP3 highly correlated with error term of PSYP5 (MI = 53.66). PSYP3 loaded on highly to PSYP5 (MI = 11.98). The error term of PSYP5 highly correlated with error term of PSYP8 (MI = 33.14). PSYP5 loaded on highly to PSYP8 $(\mathrm{MI}=$ 18.19). The error term of PSYP11 highly correlated with error term of PSYP10 (MI = 58.60). PSYP11 loaded on highly to PSYP10 $(\mathrm{MI}=30.10)$.

The composite reliability and the average variance extracted were used to measure the convergent validity of constructs. Constructs have convergent validity when the composite reliability exceeds the criterion of .70 (Hair, et al., 2010) and the average variance extracted is above .50 (Bagozzi, 1994). Familial utility had limited reliability: although its average variance extracted (AVE) was .60 , its composite reliability was only .63.

Discriminant validity was assessed by comparing the absolute value of the correlations between the constructs and the square root of the average variance extracted by a construct. When the correlations are lower than the square root of the average variance extracted by a construct, constructs are said to have discriminant validity (Fornell and Larcker, 1981). The findings reveal that the square roots of the average variance extracted for all the constructs (except perceived organizational performance) were higher than their correlations with other constructs. Thus, except for the construct of perceived organizational performance, all constructs had discriminant validity. 
Table 4.16

Chi Square and Goodness of Fit Indices for the Revised Measurement Model

\begin{tabular}{lc}
\hline Index & Proposed \\
\hline Chi Square & 2674.533 \\
Degrees of Freedom & 1016 \\
Significance & .000 \\
Normed Chi Square (Chi Square/df) & 2.632 \\
Goodness of Fit (GFI) & .86 \\
Tucker-Lewis Index (TLI) & .92 \\
Comparative Fit Index (CFI) & .93 \\
Incremental Fit Index (IFI) & .93 \\
Root Mean Squared Error (RMSEA) & .05 \\
\hline
\end{tabular}

As shown in Table 4.16, the revised measurement model demonstrates reasonable levels of fit $\left(x^{2}(1016)=2674, x^{2} / \mathrm{df}=2.632, \mathrm{CFI}=0.93, \mathrm{IFI}=0.93, \mathrm{TLI}=0.92, \mathrm{GFI}=\right.$ 0.86, RMSEA $=0.05$ to the data. Based on the recommended thresholds in Table 4.14, the model fit for the complete measurement model is acceptable.

\section{Structural Model and Hypothesis Testing}

After refining the measurement model, structural equation modeling was performed using AMOS 19.0 (Figure 4.1). The structural paths were defined as per the conceptual model presented in Chapter II. The structural model shows a reasonably good fit $\left(x^{2}(899)=2146, x^{2} / \mathrm{df}=2.388, \mathrm{CFI}=0.94, \mathrm{IFI}=0.94, \mathrm{TLI}=0.94, \mathrm{GFI}=0.88\right.$, RMSEA $=0.04)$. Based on the criteria recommended by Hair et al. (2010), Bollen (1989) and $\mathrm{Hu}$ and Bentler (1999), these measures of the model fit are acceptable. However, not all of the path coefficients were statistically significant. 
The key constructs were evaluated in terms of the squared correlations to assess the amount of variance explained for each of the constructs in the model (Table 4.17). Cohen (1992) states that in models using multiple independent variables, an effect size of $2 \%$ is considered small, around $15 \%$ is considered medium and $35 \%$ or more is considered large. The results of the proposed structural model are summarized in Figure 4.1. This model explains $23.8 \%$ of the variance in charitable giving/intention to donate and $12.3 \%$ of the variance in the charitable giving/amount donated. The model explains $58.1 \%$ of the variance in identity saliency and $67.4 \%$ in relationship satisfaction. Therefore, it means that the exogenous variables (such as trust, perceived financial need, perceived organizational performance, demonstrable utility, emotional utility, familial utility, solicitation, and parental socialization and youth participation) that lead to identity saliency and relationship satisfaction together explain $23.8 \%$ of the variance of donors future intentions to donate and $12.3 \%$ of their past, self-reported donations (amount donated). Since, the primary objective of this study is not to explain all the variables that influence charitable giving but rather to explain the role of identity saliency and relationship satisfaction, this is a medium effect size and is acceptable (Kline, 2005; Cohen, 1992). This also means that there are other factors that influence charitable giving which have not been modeled in this study and can be opportunities for future research. This model explains $58.1 \%$ of the variance in identity saliency and $67.4 \%$ of the variance of relationship satisfaction, which are both very large effects. This means that the variance of the exogenous variables (like trust, perceived financial need, perceived organizational performance, demonstrable utility, emotional utility, familial utility, solicitation, and parental socialization and youth participation) and endogenous variables 
(like identity saliency and relationship satisfaction) in this model explain a reasonable amount of the variance of the dependent variable in this study, charitable giving. The model performs satisfactorily. Table 4.18 displays the model fit indices of the proposed structural model.

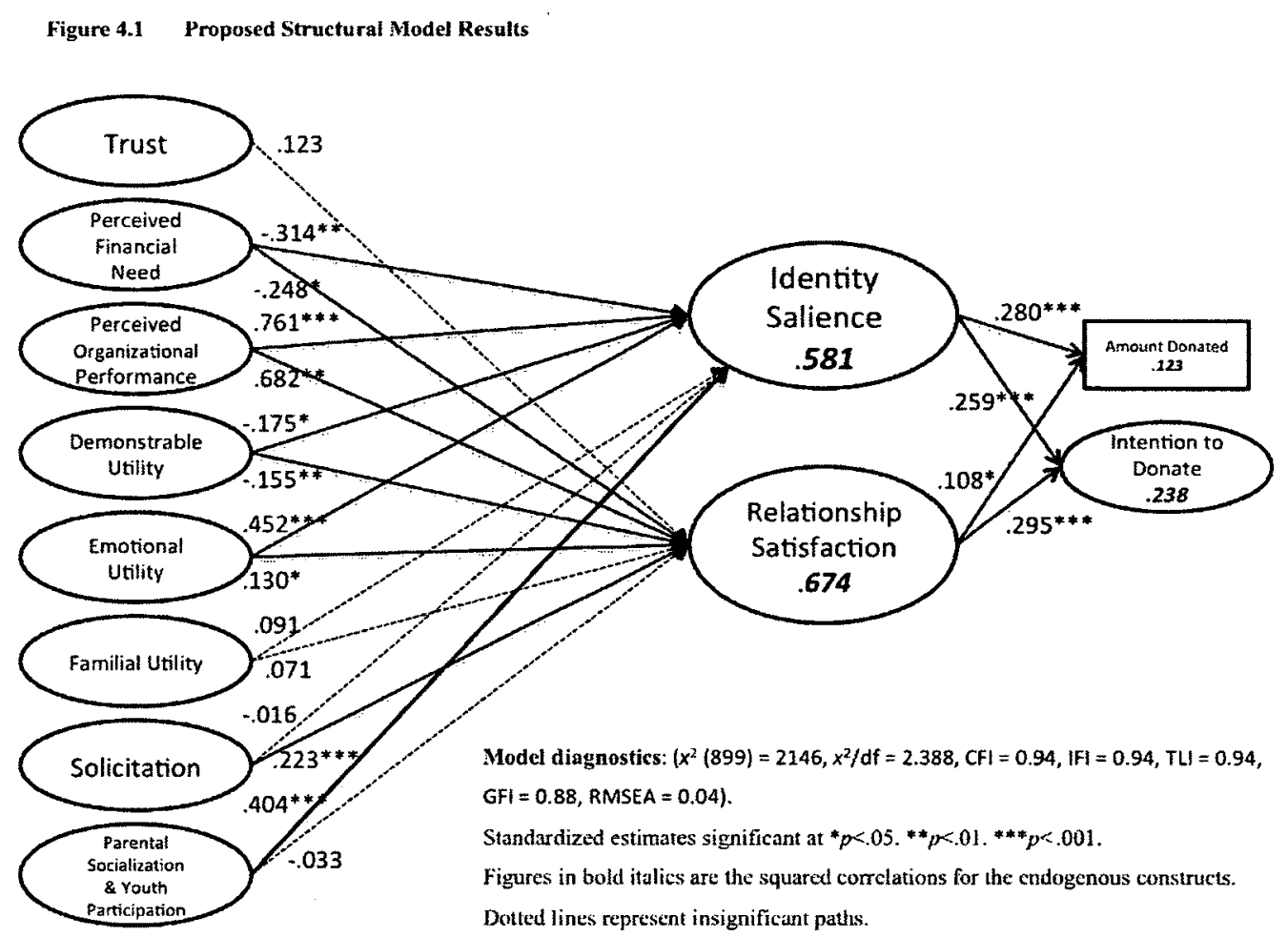

Table 4.17

Variance Explained by Endogenous Constructs

\begin{tabular}{lc} 
& Squared Correlations \\
\hline Charitable Giving (Intention to Donate) & .238 \\
Charitable Giving (Amount Donated) & .123 \\
Identity Saliency & .581 \\
Relationship Satisfaction & .674 \\
\hline
\end{tabular}


Table 4.18

Chi Square and Goodness of Fit Indices for the Proposed Structural Model

\begin{tabular}{lc}
\hline Index & Proposed \\
\hline Chi Square & 2146.453 \\
Degrees of Freedom & 899 \\
Significance & .000 \\
Normed Chi Square (Chi Square/df) & 2.388 \\
Goodness of Fit (GFI) & .88 \\
Tucker-Lewis Index (TLI) & .94 \\
Comparative Fit Index (CFI) & .94 \\
Incremental Fit Index (IFI) & .94 \\
Root Mean Squared Error (RMSEA) & .04 \\
\hline
\end{tabular}

All but one of the hypotheses were tested using the path coefficient. Hypothesis 3's mediation tests are presented at the end of this section.

H1:The greater the identity saliency of a donor, the greater the level of charitable giving of the donor.

This hypothesis states that there is a positive causal link between identity saliency and charitable giving. The path coefficient to charitable giving/intention to donate $=$ $0.259, \quad(t=5.284)$ is significant at $\mathrm{p}<0.001$ (Figure 4.1) and the path coefficient to charitable giving/amount donated $.280(\mathrm{t}=5.644)$ is significant at the $\mathrm{p}<.001$.

Therefore, $\mathbf{H 1}$ is supported. As hypothesized, this means that as a donor's identity salience rises, their level of charitable giving increases. This finding builds on the work of Amett, German, and Hunt (2003) who had studied this relationship in alumni giving in higher education. 
H2: The greater the relationship satisfaction of a donor, the greater the level of charitable giving of the donor.

This hypothesis states that there is a positive causal link between relationship satisfaction and charitable giving. The path coefficient to charitable giving/intention to donate $=0.295,(t=6.336)$ is significant at $p<0.001$ and the path coefficient to charitable giving/amount donated $.108(\mathrm{t}=2.358)$ is significant at the $\mathrm{p}<.05$ (Figure 4.1). Therefore, $\mathbf{H} 2$ is supported. As hypothesized, this means that as a donor's relationship satisfaction rises, their level of charitable giving increases. This finding contributes to previous research in the donor nonprofit relationship satisfaction (Sargeant, 2001).

H4: Donors with a higher level of trust in a nonprofit organization will be more satisfied with the relationship with the nonprofit organization.

This hypothesis states that there is a positive causal link between trust and relationship satisfaction. The path coefficient $=0.123,(t=.829)$ is not significant (Figure 4.1). Therefore, $\mathbf{H} 4$ is not supported. As hypothesized, this means that as a donor's trust in an organization rises, their level of relationship satisfaction increases; however, the results do not support this hypothesis. This finding is contrary to previous research in trust and commitment in donor nonprofit relational exchange (Sargeant et al., 2006). This finding could be the result of trust being directly related to charitable giving and not mediated by identity saliency and relationship satisfaction.

H5: The greater the perceived financial need for the nonprofit organization, the higher the identity salience for the donor. 
This hypothesis states that there is a positive causal link between perceived financial need and identity saliency. The path coefficient $=-3.14,(t=-2.765)$ is significant at $\mathrm{p}<0.01$ (Figure 4.1). As hypothesized, this means that as a donor's perceived financial need rises, their level of identity saliency increases; however, the results do not support this hypothesis because the relationship is significant in the reverse direction. This negative relationship would be denoted by the case in which the greater the perceived financial need for a nonprofit organization, the lower the level of identity saliency or the less a person identifies with a nonprofit. This finding could be the result of donors being less motivated by financial crisis and being less likely to give to and identify with a nonprofit in a financial crisis.

H6: The greater the perceived financial need for the nonprofit organization, the higher the relationship satisfaction for the donor.

This hypothesis states that there is a positive causal link between perceived financial need and relationship satisfaction. The path coefficient $=-.248,(t=-2.479)$ is significant at $\mathrm{p}<.05$. (Figure 4.1). As hypothesized, this means that as a donor's perceived financial need rises, their level of relationship satisfaction increases; however, the results do not support this hypothesis because the relationship is significant in the reverse direction. This negative relationship would be denoted by the case in which the greater a person's relationship satisfaction, the lower his perceived financial need for the nonprofit organization. This finding could be the result of donors being less motivated by financial crisis and being more likely to give to and be satisfied with a nonprofit on more firm financial footing. The primary reason for giving to charity is to have an impact on 
the cause, and an organization that is financially healthy is more likely to be able to make an impact.

H7:The greater the perceived organizational performance, the greater the identity salience of the donor.

This hypothesis states that there is a positive causal link between perceived organizational performance and identity saliency. The path coefficient $=0.761,(t=$ 6.198 ) is significant at $\mathrm{p}<0.001$ (Figure 4.1). Therefore, $\mathbf{H 7}$ is supported. As hypothesized, this means that as a donor's perceived organizational performance rises, their level of identity saliency increases.

H8:The greater the perceived organizational performance, the greater the relationship satisfaction of the donor.

This hypothesis states that there is a positive causal link between perceived organizational performance and relationship satisfaction. The path coefficient $=0.682,(t$ $=3.003$ ) is significant at $p<0.01$ (Figure 4.1). Therefore, $\mathbf{H 8}$ is supported. As hypothesized, this means that as a donor's perceived organizational performance rises, their level of relationship satisfaction increases. This finding builds on the work of Sargeant et al. (2006).

H9:Reciprocity in demonstrable utility will relate positively to charitable giving mediated by identity saliency and relationship satisfaction.

This hypothesis states that there is a positive link between demonstrable utility and charitable giving. The path coefficient to identity saliency is $=-.175,(t=-2.499)$ and is significant at $\mathrm{p}<.05$. The path coefficient to relationship satisfaction is $=-.155,(\mathrm{t}=-$ 
2.646 ) is significant at $p<0.01$ (Figure 4.1). As hypothesized, this means that as a donor's demonstrable utility rises, their level of charitable giving increases mediated by identity saliency and relationship satisfaction; however, the results do not support this hypothesis because the relationship is significant in the reverse direction. This negative relationship would be denoted by the case in which the greater a person's identity saliency and relationship satisfaction, the lower his demonstrable utility. This finding could be the result of the sample only being constructed of repeat donors as opposed to a mix of first time donors and repeat donors. Because the study focuses on relational exchange, exchange over time, the sample was restricted to repeat donors. It is possible that demonstrable utility is only significant in first time gifts and not in continued giving.

H10: Reciprocity in emotional utility will relate positively to charitable giving mediated by identity saliency and relationship satisfaction.

This hypothesis states that there is a positive link between emotional utility and charitable giving. The path coefficient to identity saliency $=.452,(\mathrm{t}=5.196)$ and is significant at $\mathrm{p}<.001$. The path coefficient to relationship satisfaction $=.130(t=2.101)$ is significant at $\mathrm{p}<0.05$ (Figure 4.1). Therefore, $\mathbf{H 1 0}$ is supported. As hypothesized, this means that as a donor's emotional utility rises, their level of identity saliency, relationship satisfaction, and charitable giving increases. The results indicate that there is a much stronger relationship between emotional utility and identity saliency than emotional utility and relationship satisfaction.

H11: Reciprocity in familial utility will relate positively to charitable giving mediated by identity saliency and relationship satisfaction. 
This hypothesis states that there is a positive link between familial utility and charitable giving. The path coefficients are $=.091,(\mathrm{t}=1.111)$ and $.071,(\mathrm{t}=1.134)$ and are not significant at $\mathrm{p}<.05, \mathrm{p}<.01$, or $\mathrm{p}<.001$ (Figure 4.1). Therefore, $\mathrm{H11}$ is not supported. As hypothesized, this means that as a donor's familial utility rises, their level of charitable giving increases mediated by identity saliency and relationship satisfaction; however, the results do not support this hypothesis. This finding could be related the smaller sample size or the types of nonprofit organizations in the sample. Perhaps if the sample were restricted to disease related nonprofits, in which familial utility plays a more larger role as a giving motivation, the findings would then be more significant.

H12: The greater the satisfaction with the solicitation process, the greater the identity saliency of the donor.

This hypothesis states that there is a positive causal link between satisfaction with the solicitation process and identity saliency. The path coefficient $=-.016,(t=-.272)$ is not significant at $\mathrm{p}<.05, \mathrm{p}<.01$, or $\mathrm{p}<.001$ (Figure 4.1). Therefore, $\mathrm{H12}$ is not supported. As hypothesized, this means that as a donor's satisfaction with the solicitation process rises, their level of identity saliency increases; however, the results do not support this hypothesis.

H13: The greater the satisfaction with the solicitation process, the greater the relationship satisfaction of the donor.

This hypothesis states that there is a positive causal link between satisfaction with the solicitation process and relationship satisfaction. The path coefficient $=0.223$, $(t=4.250)$ is significant at $\mathbf{p}<0.001$ (Figure 4.1). Therefore, H13 is supported. As hypothesized, this means that as a donor's satisfaction with the solicitation process rises, 
their level of relationship satisfaction increases. This finding builds on the work of Sargeant (2001).

H14: The greater the parental socialization and youth participation, the greater the identity saliency of the donor.

This hypothesis states that there is a positive causal link between parental socialization and youth participation and identity saliency. The path coefficient $=0.404$, $(t=3.085)$ is significant at $p<0.001$ (Figure 4.1). Therefore, H14 is supported. As hypothesized, this means that as a donor's parental socialization and youth participation rises, their level of identity saliency increases.

H15: The greater the parental socialization and youth participation, the greater the relationship satisfaction of the donor.

This hypothesis states that there is a positive causal link between parental socialization and youth participation and relationship satisfaction. The path coefficient = $.033,(t=-.894)$ is not significant at $\mathrm{p}<0.001$ (Figure 4.1). Therefore, H15 is not supported. As hypothesized, this means that as a donor's parental socialization and youth participation rises, their level of relationship satisfaction increases; however, the results do not support this hypothesis. This finding could be the result of parental socialization and youth participation being more directly related to bonding or identifying with an organization rather than a condition of relationship satisfaction.

While not every path was statistically significant at $\mathrm{p}<.001$ in the model, when the less significant $(\mathrm{p}<.05, \mathrm{p}<.01)$ and statistically insignificant paths were dropped from the model, the model fit was poorer. As such, the proposed structural model was not revised. 


\section{Mediating Role of Identity Saliency and Relationship Satisfaction}

Under the guidance of Holmbeck (1997) and McKinnon, Lockwood, and

Hoffman (2002), the mediating role of identity salience and relationship satisfaction was tested by first dropping both constructs from the model. The revised model with nine latent constructs was then run and the results of this model are found in Table 4.19. The structural model shows reasonably good fit $\left(x^{2}(484)=1084, x^{2} / d f=2.240, \mathrm{CFI}=0.96\right.$, $\mathrm{IFI}=0.96, \mathrm{TLI}=0.95, \mathrm{GFI}=0.92, \mathrm{RMSEA}=0.04)$. This model explains $28.6 \%$ of the variance in charitable giving/intention to donate and $8.4 \%$ of the variance in the charitable giving/amount donated. Therefore, it means that the exogenous variables (such as trust, perceived financial need, perceived organizational performance, demonstrable utility, emotional utility, familial utility, solicitation, and parental socialization and youth participation) together explain $28.6 \%$ of the variance of donors' future intentions to donate and $8.4 \%$ of their past, self-reported donations (amount donated). There are less significant paths than the proposed structural model as only the following paths were significant: emotional utility to charitable giving (intention to donate) significant at $\mathrm{p}<.05$, demonstrable utility to charitable giving (intention to donate) significant at $\mathrm{p}<.05$, trust to charitable giving (intention to donate) significant at $\mathbf{p}<.05$, and parental socialization and youth participation to charitable giving (amount donated) significant at $\mathrm{p}<.05$. 
Table 4.19

Chi Square and Goodness of Fit Indices for the Structural Model without Identity Saliency and Relationship Satisfaction

\begin{tabular}{lc}
\hline Index & Revised, No Mediation \\
\hline Chi Square & 1084 \\
Degrees of Freedom & 484 \\
Significance & .000 \\
Normed Chi Square (Chi Square/df) & 2.240 \\
Goodness of Fit (GFI) & .92 \\
Tucker-Lewis Index (TLI) & .95 \\
Comparative Fit Index (CFI) & .96 \\
Incremental Fit Index (IFI) & .96 \\
Root Mean Squared Error (RMSEA) & .04 \\
\hline
\end{tabular}

Next the model was run with only identity saliency as the mediating variable. The results of the revised model with ten latent constructs are found in Table 4.20. The structural model indicates a poor fit $\left(x^{2}(916)=8155, x^{2} / \mathrm{df}=8.903, \mathrm{CFI}=0.67, \mathrm{IFI}=\right.$ $0.67, \mathrm{TLI}=0.64, \mathrm{GFI}=0.51, \mathrm{RMSEA}=0.11$ ). This model explains $22.5 \%$ of the variance in charitable giving/intention to donate and $12.7 \%$ of the variance in the charitable giving/amount donated. The model explains $55.5 \%$ of the variance in identity saliency. Therefore, it means that the exogenous variables (such as trust, perceived financial need, perceived organizational performance, demonstrable utility, emotional utility, familial utility, solicitation, and parental socialization and youth participation) that lead to identity saliency and relationship satisfaction together explain $22.5 \%$ of the variance of donors' future intentions to donate and $12.7 \%$ of their past, self-reported donations (amount donated). There are less significant paths than the proposed structural 
model as only the following paths were significant: emotional utility to identity salience significant at $\mathrm{p}<.001$, identity salience to charitable giving (intention to donate) and charitable giving (amount donated) significant at $\mathrm{p}<.001$, and perceived organization performance to identity saliency significant at $\mathrm{p}<.05$.

Table 4.20

Chi Square and Goodness of Fit Indices for the Structural Model with only Identity Saliency

\begin{tabular}{lc}
\hline Index & Revised with only Identity Saliency \\
\hline Chi Square & 8155 \\
Degrees of Freedom & 916 \\
Significance & .000 \\
Normed Chi Square (Chi Square/df) & 8.903 \\
Goodness of Fit (GFI) & .51 \\
Tucker-Lewis Index (TLI) & .64 \\
Comparative Fit Index (CFI) & .67 \\
Incremental Fit Index (IFI) & .67 \\
Root Mean Squared Error (RMSEA) & .11 \\
\hline
\end{tabular}

Next the model was run with only relationship satisfaction as the mediating variable. The results of the revised model with ten latent constructs are found in Table 4.21. The structural model shows reasonably good fit $\left(x^{2}(783)=1908, x^{2} / d f=2.437, \mathrm{CFI}\right.$ $=0.95, \mathrm{IFI}=0.95, \mathrm{TLI}=0.92, \mathrm{GFI}=0.88, \mathrm{RMSEA}=0.045)$. This model explains $20.3 \%$ of the variance in charitable giving/intention to donate and $7.7 \%$ of the variance in the charitable giving/amount donated. The model explains $62.6 \%$ of the variance in relationship satisfaction. Therefore, it means that the exogenous variables (such as trust, perceived financial need, perceived organizational performance, demonstrable utility, 
emotional utility, familial utility, solicitation, and parental socialization and youth participation) that lead to identity saliency and relationship satisfaction together explain $20.3 \%$ of the variance of donors' future intentions to donate and $7.7 \%$ of their past, selfreported donations (amount donated). There are less significant paths than the proposed structural model as only the following paths were significant: trust to relationship satisfaction significant at $\mathrm{p}<.001$, solicitation to relationship satisfaction significant at $\mathrm{p}<.001$, and relationship satisfaction to charitable giving (intention to donate) and charitable giving (amount donated) significant at $\mathrm{p}<.001$.

Table 4.21

Chi Square and Goodness of Fit Indices for the Structural Model with only Relationship Satisfaction

\begin{tabular}{lc}
\hline Index & Revised, with only Relationship Satisfaction \\
\hline Chi Square & 1908 \\
Degrees of Freedom & 783 \\
Significance & .000 \\
Normed Chi Square (Chi Square/df) & 2.437 \\
Goodness of Fit (GFI) & .88 \\
Tucker-Lewis Index (TLI) & .94 \\
Comparative Fit Index (CFI) & .95 \\
Incremental Fit Index (IFI) & .95 \\
Root Mean Squared Error (RMSEA) & .045 \\
\hline
\end{tabular}

A mediated model is one that seeks to explain some or all of the relationship between independent variables and dependent variables through the inclusion of an intervening variable or mediating variable. Instead of a direct causal link between the independent and dependent variables, the mediated model hypothesizes that the independent variable causes the mediating variable thus causing a change in the 
dependent variable. Mediation can account for some (partial mediation) or all (full mediation) of the observed relationship between variables. Partial mediation indicates that there are significant relationships between the mediator and the dependent variable and there remains a significant relationship between the independent variables and the dependent variable. In this study, there were significant relationships between identity saliency, relationship satisfaction and charitable giving (intention to donate and amount donated). Excluding both mediating variables explained less of the variance in the dependent variable and had less significant paths than the inclusion of both identity saliency and relationship satisfaction; thus indicating, a partially mediated relationship between the independent variables and the dependent variables of charitable giving.

\section{Summary of Chapter IV}

This chapter presented the results of this mixed methods study in two sequential stages: qualitative focus group interviews and a quantitative survey of a random sample of individual donors to nonprofit organizations. It included the presentation of the focus group data results, the descriptive statistics of the sample profile and dependent variable of interest - charitable giving, confirmatory factor analysis of the eleven constructs, and structural equation modeling, analysis of the data, and testing of the hypothesized relationships. The results of the data analysis generated a wealth of information supporting the individual charitable giving model. Confirmatory factor analysis was

utilized to test the reliability of the survey instrument. Next fifteen hypotheses were formulated to test the relationships between charitable giving motivations (independent variables), identity saliency and relationship satisfaction (mediating independent variables) and charitable giving (dependent variable). 
Then, structural equation modeling was undertaken to test the proposed individual charitable giving model using data obtained from a survey of charitable donors from the three largest MSAs in the Commonwealth of Virginia and to test the hypotheses. Structural equation modeling was used in the data analysis because of its ability to generate a better assessment of model fit of the data, incorporating observed variables, latent constructs, and measurement error. The fifteen hypotheses were tested and of the fifteen hypothesized relationships between the independent variables and charitable giving, six hypotheses were unsupported. Familial utility and solicitation did not have statistically significant relationships with identity saliency. Demonstrable utility and identity saliency were significantly negatively related. Trust, familial utility, and parental socialization and youth participation did not have statistically significant relationships with relationship satisfaction. Demonstrable utility and relationship satisfaction were significantly negatively related. Satisfaction with the solicitation process was significantly related to relationship satisfaction. Emotional utility was significantly related to identity saliency and relationship satisfaction in which the linkage with identity saliency had a significantly stronger relationship. Of particular note is the strength of the relationship between perceived organizational performance and identity saliency and relationship satisfaction, the second most significant findings. Finally, both identity saliency and relationship satisfaction were statistically significant related to charitable giving and were evaluated as partially mediating the relationship between charitable giving motivations and charitable giving. In the structural model, the charitable giving motivations (perceived organizational performance, emotional utility, solicitation, parental socialization and youth participation), identity saliency, relationship satisfaction, 
all significantly predict charitable giving (past donated amounts and future intention to donate) levels in the individual donors. 


\section{CHAPTER V}

\section{CONCLUSIONS AND IMPLICATIONS}

This research focused on explaining the antecedents to successful relationships with nonprofit donors and the influence of identity saliency and relationship satisfaction on individual charitable giving behavior in a sample of charitable donors in Virginia. The review of the extant literature and previous research on identity saliency, relationship marketing, and charitable giving, revealed that charitable giving behavior is influenced by a number of different charitable giving motivations, identity saliency, and relationship satisfaction. While previous research has tested the effects of identity saliency and relationship satisfaction independently, the model used in this study tested both constructs as mediating variables between charitable giving motivations and the level of charitable giving behavior. Next, Chapter $\mathrm{V}$ presents a discussion of the findings, managerial implications, suggestions for future research, limitations of the study, and some closing remarks.

\section{Discussion of the Findings}

While previous researchers have studied identity saliency (Callero, 1985; Callero et al., 1987; Lee et al., 1999, Arnett et al., 2003) and relationship satisfaction (Sargeant, 2001) in charitable giving, these constructs were tested for the first time simultaneously as mediators between charitable giving motivations and charitable giving behavior. The goal of this study is to understand more fully the roles that identity saliency and relationship satisfaction play in individual charitable giving and to explore the charitable 
giving motivations that drive these mediating constructs. This section discusses the findings for the proposed structural model and for each of the research questions.

The proposed structural model fit the data well. Identity saliency and relationship satisfaction significantly predicted charitable giving; although the link between relationship satisfaction and charitable giving (amount donated) was not as strong as its relationship with charitable giving (intention to donate) and identity saliency and charitable giving (intention to donate) and charitable giving (amount donated) (Figure 4.1). This suggests that asking donors about their future intentions as opposed to their self-reported amount donated might be more reflective of their perceptions of the nonprofit. The latent constructs of perceived organizational performance, emotional utility, and parental socialization and youth participation significantly predicted higher identity salience in the donors. Perceived organizational performance, emotional utility, and solicitation, all significantly predicted relationship satisfaction in the donors. The SEM analysis supports Sargeant's (2001) research on relationship fundraising, with regard to the importance of satisfaction with the solicitation process and perceived organizational performance and relationship satisfaction. The structural model also supports Sargeant et al.'s (2006) original research on the perceptual determinants of charitable giving, specifically in the significance of perceptions of organizational performance and emotional utility. Lastly, the structural model supports the research of Arnett et al. (2003) that linked identity saliency to charitable giving as a mediating construct.

Several of the latent constructs resulted in insignificant and negative or inverse relationships with identity salience and relationship satisfaction: perceived financial need, 
demonstrable utility, and solicitation with identity salience, and parental socialization and youth participation with relationship satisfaction. In the mediation testing where the mediating variables were removed individually and together and the models were run again, some of these relationships were significantly and directly related to charitable giving. The hypothesized relationship between trust and relationship satisfaction was significant when identity salience was removed from the model. Demonstrable utility, while inversely related to identity saliency and relationship satisfaction, was significantly related to charitable giving (intention to donate). Lastly; parental socialization and youth participation was still significantly related to identity salience when relationship satisfaction was removed from the model.

The scale items, data, and factor analysis were thoroughly reviewed to ensure the accuracy of the findings. It is important to note that the sample and data reflect repeat giving and not first time charitable donations; therefore, resulting negative paths indicate a possible theoretical explanation.

\section{Research Question One}

To what extent do identity saliency and relationship satisfaction mediate relational exchange between nonprofits and donors?

The findings resulting from research question one indicate a positive, significant, and partially mediating relationship between identity saliency, relationship satisfaction and charitable giving. This finding extends previous research that found that identity saliency influences pro-social behaviors like blood donation (Callero, 1985), helping behaviors (Callero et al., 1987) and charitable giving (Lee et al., 1999; Arnett et al., 2003), and that relationship satisfaction also increases charitable giving levels (Sargeant, 
2001). This study represents the first time that these two constructs were measured simultaneously as mediating variables and, together, they explain a significant proportion of the variance in individual charitable giving. This finding speaks to the importance of donor cultivation and stewardship strategies in nonprofit relationship marketing. The more a donor identifies with an organization, the higher the level of charitable giving. The more satisfied a donor is with the relationship with a nonprofit, the higher the level of charitable giving. Also, this finding also speaks to the importance of getting to know the donor base, on an individual basis, understanding that each donor identifies in some manner to the nonprofit they are supporting.

In practice and research, the focus has been on identifying who gives and why they give but very few practitioners and even fewer researchers have asked why donors continue to give a particular nonprofit. Exploring this question more fully might provide practitioners with detailed knowledge of what communication and solicitation strategies work best and the potential impact of donor perceptions of the organization. Moreover, by getting to know donors better, the opportunity exists for a deeper level of engagement with donors, in which the nonprofit develops passionate and engaged donors, who may also desire more interaction with the nonprofit and the cause through volunteering or advocacy efforts.

\section{Research Question Two}

What are the charitable giving motivations that influence identity saliency and relationship satisfaction in relational exchange between nonprofits and donors?

The findings resulting from research question two indicate several interesting relationships in the charitable giving motivations tested in this model: trust, perceived 
financial need, perceived organizational performance, demonstrable utility, emotional utility, familial utility, solicitation, and parental socialization and youth participation. Perceived organizational performance, emotional utility, and parental socialization and youth participation had a positive and significant relationship with identity saliency. Perceived organizational performance, emotional utility, and solicitation had a positive and significant relationship with relationship satisfaction. In this study, not all charitable giving motivations were drivers of identity saliency and relationship satisfaction. Some charitable giving motivations, like demonstrable utility and trust, were directly related to charitable giving and not mediated by identity saliency and relationship satisfaction.

Trust

Trust was hypothesized to have a significant relationship with relationship satisfaction; although, in this study the relationship was insignificant. However, during the mediation tests for identity saliency and relationship satisfaction, trust was found to have a positive and significant relationship with charitable giving (intention to donate) but not charitable giving (amount donated) in the absence of the mediating variables. This indicates that trust is not an antecedent of identity saliency but does play a role in future intentions to donate to a nonprofit (Sargeant and Lee, 2004; Tonkiss and Passey, 2001; Rousseau et al., 1998). Trust is critically important in relationships between donors and nonprofits and is the foundation for voluntary association within the nonprofit sector (Tonkiss and Passey, 2001). In this study, trust was found to be a significant driver of relationship satisfaction when identity saliency was removed from the model in the mediation testing. This finding regarding trust in individual charitable giving behavior provides further empirical evidence of its significance in donor nonprofit relationships 
and extends the limited research on perceived trust (Tonkiss and Passey, 2001, Sargeant and Lee, 2004; Sargeant et al., 2006).

\section{Perceived financial need}

With regard to perceived financial need, charitable donors want to be a part of successful nonprofits making an impact on a cause they care about. More often than not, donors who are repeat givers are less motivated by an organization's financial crisis and view their donations as an investment in their community.

A donation to a nonprofit organization is an investment in the community the organization serves.... The philanthropic sector has an opportunity to build stronger communities through boldness, innovations, and new models for action that are based on results, not needs, on investment opportunities not institutional financial urgency...Donors do not give to organizations because organizations have needs, they give because organizations meet needs (Sprinkel Grace, 1997).

While Arnett et al. (2003) found that perceived financial need was significantly related to donating, the sample was limited to the university fundraising context and included both first time donors and repeat donors. Additionally, the dependent variables in the study were amount donated, derived from the organization's donor database, as well as self-reported promoting behaviors; whereas this study's dependent variables reflect self-reported donation amounts over time and intention to donate in the future. Sargeant (2001) found that more than 26 percent of lapsed donors stop giving because they perceive that other causes are more deserving. Donors who give based on perceived financial need are usually first time donors, not repeat donors. He concludes that nonprofits can retain this type of donor if they can find ways of deepening the bond [identity salience] and improving the satisfaction [relationship satisfaction] between the 
organizations and their supporters. In this study's results, the stronger an individual donor's identity salience and relationship satisfaction, the lower the perceived financial need. This negative path provides empirical support for Sargeant's (2001) managerial suggestion that donors, who perceived the financial need of another cause to be greater, generally shift their support to that more deserving cause unless they have higher identity salience and relationship satisfaction with the first nonprofit.

Perceived organizational performance

Perhaps the most compelling finding in this study, perceived organizational performance of the nonprofit was found to be a significant antecedent of identity salience and relationship satisfaction and represents a key contribution to the literature. How a nonprofit's performance is perceived by the donor strongly influences how much they identify with an organization as a donor and how satisfied they are in their relationship, and consequently these donors have higher levels of charitable giving. This finding supports the work of Sargeant et al. (2006) in which perceived organizational performance was found to be a significant predictor of charitable giving levels and Sargeant (2001) in which he found that communicating the impact of the nonprofit to donors on an ongoing basis influenced their perception of organizational performance and made it less likely that donors would lapse or switch their support to a more deserving organization. 


\section{Demonstrable utility}

This study's lack of support for the hypothesized relationship between demonstrable utility and identity salience, relationship satisfaction, and charitable giving provides further empirical support for the work of Sargeant et al. (2006) where personal benefits did not drive the relationship variables tested - trust or commitment. It is important to reiterate that respondents in this study were repeat donors, not first time donors. So while previous research (Amos, 1982; Beatty et al., 1991; Frisch and Gerrard, 1981, Buraschi and Cornelli, 2002; Andreoni and Petrie, 2004; Alpizar et al., 2007; Chen et al., 2006; Edlund, Sagarin, and Johnson, 2007; Harris, Liguori, and Stack, 1973; Marr, Mullin, and Siegfried, 2005; Schervish and Havens, 2002) suggests demonstrable utility as a driver of charitable giving, this study's results indicate that demonstrable utility should only be understood as such in first time donations and not long-term relationships between donors and nonprofit organizations. The results indicate that demonstrable utility is not related to identity salience and relationship satisfaction in a sample of repeat donors.

During the mediation tests, demonstrable utility was found to be directly related to charitable giving (intention to donate) when both identity saliency and relationship satisfaction were removed from the model. This suggests that in a sample of repeat donors, demonstrable utility was only significant in discussing future charitable giving behaviors. This finding could be related to how recent their first time gift to the nonprofit organization. If they had made their first charitable gift relatively recently, the value provided in demonstrable utility could be more significant than if they had been giving to the organization for quite some time. 


\section{Emotional utility}

In this study, emotional utility was found to be a significant driver of both identity saliency and relationship satisfaction and consequently charitable giving. This supports previous research that has confirmed emotional utility as a ubiquitous motivation for charitable giving (Andreoni, 2001; Kottasz, 2004; Kotler and Andreasen, 1991; Haggberg, 1992; Komter, 1996; Andreoni, 1990; Feldman, 1985; Fultz et al., 1986; Radley and Kennedy, 1995; Mathur, 1996; Cialdini, 1987; Bendapudi et al., 1996; Cialdini et al., 1987; Wegener and Petty, 1994). Arnett et al. (2003) also found emotional utility to be drivers of identity saliency, where self-identity and emotions play a significant role. This study is the first time that emotional utility has been linked to relationship satisfaction in the nonprofit sector and represents a key contribution to the literature.

The decision to make a charitable gift to a nonprofit organization and to continue that giving in a relationship over time, is an intensely personal decision. Emotions play a role in first time gifts and as demonstrated in this study, they are also significant in maintaining the relational exchange. Nonprofit organizations should continue to develop solicitation strategies that appeal to donors' emotions and should be able to connect that solicitation with making an impact on the cause they represent. The more donors feel good about their charitable giving, the more likely they are to continue the relationship and are more likely to desire a deeper connection or level of engagement with the organization. 


\section{Familial utility}

While previous research has linked familial utility to charitable giving (Bruce, 1998; Sargeant, 1999; Sargeant et al., 2006; Kotler and Clarke, 1987), in this study familial utility was not a driver of identity saliency and relationship satisfaction or directly related to charitable giving. Like demonstrable utility, perhaps the sample of repeat donors influenced this finding. In the mediation testing, familial utility was only significantly related to identity saliency and subsequently charitable giving; however, this was not the case in the full model. In the full model, the standardized regression weights for familial utility were less significant as compared to emotional utility suggesting that this could matter more in first time donations.

\section{Solicitation}

The experience of being asked to donate is one of the most significant factors that influence charitable giving and the process of being solicited for support was examined using the scale developed by Sargeant (2001). In this study, satisfaction with the solicitation process was a significant driver of relationship satisfaction and consequently charitable giving. This finding supports previous studies that indicated donor fatigue (Sargeant, 2001; Leslie and Ramey, 1988; Van Diepen et al., 2009; Wiepking, 2008; Diamond and Noble, 2001) and dissatisfaction with the manner or mode of being asked (Pancer et al., 1979) decreased charitable giving levels. The importance of the satisfaction with the solicitation process also represents a key contribution to the literature. 


\section{Parental socialization and youth participation}

Parental socialization and youth participation was found to have an insignificant relationship with relationship satisfaction, and a significant relationship with identity saliency, which is contrary to the hypothesized paths. Previous research on parental modeling of pro-social behaviors and participation as youth indicated that having these youthful experiences make people more likely to exhibit these behaviors as adults (Wilhelm et al., 2008; Feldman, 2007; Bekkers, 2005; Eisenberg, 2000). In this study, the results indicate that parental socialization and youth participation only as a driver to identity salience and subsequently, charitable giving. In the repeat giving context, donors with higher parental modeling and youth participation are more likely to have higher identity salience and give at higher levels.

This finding supports efforts to develop pro-social behaviors in youth through parental modeling and youth participation. Connecting parental modeling and youth experience with nonprofit identification contributes to a theoretical foundation for nurturing a more caring society, populated with citizens who continue to exhibit these pro-social behaviors as adults.

\section{Managerial Implications and Suggestions for Future Research}

As the evolution of the definition of marketing has evolved from value in exchange toward value cocreation (value for all stakeholders), so too must the theoretical and managerial understanding of the relationship between donors and nonprofit organizations evolve toward value cocreation where value is created together for all stakeholders to make transformational change (Figures 5.1 and 5.2). Support for this 
evolutionary shift in understanding fundraising from the transactional exchange to the relational exchange to the transformational exchange is found in the data from this charitable giving study with important managerial implications and suggestions for future research.

In the nonprofit context, as the understanding of fundraising evolves from transactional exchange to value creation to value cocreation, the nonprofit organizations shift their focus from the immediate and short-term to a more strategic perspective in creating value together (Figure 5.2). In the transactional exchange, nonprofit organizations focus on donor acquisition, raising more money, special events, and fundraising programs (such as raffles, car wash, product sales). The variables of interest are demonstrable utility and perceived financial need. Donors in the transactional exchange are thinking about what they get from giving (tangible benefits) and the financial need of the nonprofit organization.

In the relational exchange, nonprofits begin to manage relationships with donors over time. The variables of interest are identity salience, relationship satisfaction, trust, familial utility, parental socialization and youth participation, and solicitation. Donor perceptions of the nonprofit become more significant in the relational exchange. Donors are more influenced by relationship satisfaction, trusting the nonprofit, personal identity and connections to the cause, and satisfaction with the solicitation process. From the organizational perspective, the focus begins to shift to communications, donor renewal, stewardship, and major gift campaigns.

In the transformational exchange, nonprofits understand donors as individuals and endeavor to create value together to make transformational change in the world. The 
variables of interest are identity salience, relationship satisfaction, perceived organizational performance, emotional utility, parental socialization and youth participation, and solicitation. In the transformational exchange, donors give because they want to have an impact on a cause that they care passionately about. They continue to give because they perceive the organization as being efficient and effective, and making a difference, an impact. Finally, they continue to give to a particular organization because they are satisfied with the solicitation process and in the relationship. Donors feel valued by the organization and that their donations are having an impact on the cause they care passionately about. In the transformational exchange, donors may also take on other roles in the nonprofit, like volunteering or advocacy efforts representing a dramatically increased level of engagement with high switching costs. Donors could also be providing direct services, serving in leadership positions within the nonprofit, and engaging external people and organizations to join the philanthropic effort.

Figure 5.1 An evolving understanding of marketing

\begin{tabular}{|c|c|c|}
\hline Exchange & Value Creation & Value Cocreation \\
\hline $\begin{array}{c}\text { Each party gess } \\
\text { somathing } \\
\text { of value }\end{array}$ & $\begin{array}{l}\text { Value in use \& } \\
\text { relationship marketing }\end{array}$ & $\begin{array}{l}\text { Creation watue together } \\
\text { for all statenolers }\end{array}$ \\
\hline
\end{tabular}

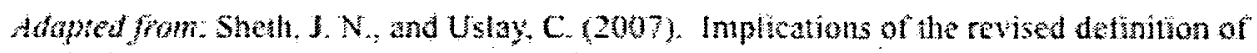

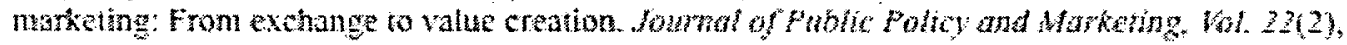
302.307 


\begin{tabular}{|c|c|c|}
\hline Exchange & Value Creation & Value Cocreation \\
\hline TRANSACTIONAL & RELATIONAL EXCHANGE & TRANSFORMATIONAL \\
\hline $\begin{array}{l}\text { EXCHANGE } \\
\text { Nonprofits focus }\end{array}$ & $\begin{array}{l}\text { Nonprofits begin to } \\
\text { manage relationships }\end{array}$ & $\begin{array}{c}\text { EXCHANGE } \\
\text { Nonprofits understand }\end{array}$ \\
\hline $\begin{array}{l}\text { Nonprotits focus } \\
\text { on donor } \\
\text { acquisition and }\end{array}$ & with donors. & $\begin{array}{l}\text { donors as individuals and } \\
\text { create value together to }\end{array}$ \\
\hline $\begin{array}{l}\text { raising more } \\
\text { money. }\end{array}$ & $\begin{array}{l}\text { VARIABLES OF INTEREST } \\
\text { Identity Salience } \\
\text { Relationship Satisfaction }\end{array}$ & $\begin{array}{l}\text { make transformational } \\
\text { change in the world. }\end{array}$ \\
\hline $\begin{array}{l}\text { VARIABLES OF } \\
\text { INTEREST }\end{array}$ & $\begin{array}{c}\text { Trust } \\
\text { Familial Utility }\end{array}$ & $\begin{array}{l}\text { VARIABLES OF INTEREST } \\
\text { Identity Salience }\end{array}$ \\
\hline Demonstrable & Solicitation & Relationship Satisfaction \\
\hline Utility & Parental Socialization \& & Perceived Organizational \\
\hline Perceived Financial & Youth Participation & Performance \\
\hline Need & & $\begin{array}{c}\text { Emotional Utility } \\
\text { Solicitation } \\
\text { Parental Socialization \& } \\
\text { Youth Participation }\end{array}$ \\
\hline
\end{tabular}

Very recently, multiple conceptions of value cocreation in philanthropy have emerged: high impact philanthropy, social entrepreneurship, and venture philanthropy. These conceptions of philanthropy, while similar to this idea of value cocreation in the donor nonprofit relationship, have a quite different understanding of philanthropic action.

High impact philanthropy is defined as "the practice of making charitable contributions with the intention of maximizing social good" (Center, 2012). High impact philanthropy is most often practiced in the U.S. at the community foundation level and is almost solely focused on outcome measurement. Tangentially related to value cocreation in the nonprofit sector, social entrepreneurship has several meanings, which are perspective dependent (Dees, 1998). Mair and Marti (2004) describe three variations of the definition of social entrepreneurship: nonprofits finding new revenue streams to create social value (Austin, Stevenson, \& Wei-Skiller, 2003; Boschee, 1998); private 
businesses involved in cross-sector partnerships (Sagawa \& Segal, 2000; Waddock, 1988); and a process of alleviating social problems and creating social change (Alvord et al, 2004, Ashoka Innovators, 2000). Venture philanthropy is influenced broadly by venture capital finance and technology business management with the goal of achieving philanthropic or social change. Also known as "involved grantmaking" - venture philanthropy is characterized by experimental approaches, measurable results, a more strategic, long-term perspective, capacity building, multi-year funding, and high involvement by donors (Stanford, 2012). The primary difference between high impact philanthropy, social entrepreneurship, venture philanthropy and the value cocreation put forth in these closing remarks is the unit of analysis. The change [value] is implemented by the organization whereas in transformational exchange, value is co-created.

This study has many implications for practitioners of nonprofit marketing strategy in understanding the donor relationship, charitable giving motivations, and the potential impact of identity saliency and relationship satisfaction. Sargeant and Shang (2011, p. 3) call for a path forward in growing philanthropy by enhancing the quality of donor relationships. In practice, nonprofits have focused too heavily on the tangible benefits of membership or as defined in this study, demonstrable utility. Demonstrable utility is the value derived from tangible benefits received as a result of the process of giving with "selfish economic considerations" suggesting that individual donors are motivated by benefits received previously or promised in the future (Sargeant et al., 2006, p. 3). Demonstrable utility was found to be of little significance to repeat donors and was inversely related to a donor's identity salience and relationship satisfaction. The more a donor identified with an organization and the more satisfied a donor was with their 
relationship with an organization, the less importance they gave to tangible benefits of charitable giving.

If nonprofit organizations want to deepen their level of engagement with donors, they must first understand donors as unique individuals with individual charitable giving motivations or reasons for giving. By understanding those motivations and giving donors more opportunities to engage with the mission in a manner that suits them, nonprofits can maximize a donor's identity saliency and relationship satisfaction. Nonprofits "need to find ways of improving satisfaction and deepening the bonds that exist between them and their supporters" (p. 188). Sargeant posited that the differentiating factor between lapsed donors and active donors is the quality of the relationship. Perhaps the quality of the relationship can be improved by turning those repeat donors into zealots, those donors who are extremely passionate about the cause who donate not only their money; but also their time in volunteering and advocacy efforts.

When a nonprofit organization shifts their strategy from the transactional exchange to the transformational exchange, they are really shifting the organization's approach to fundraising management and measuring its success from the very short-term to the more strategic, long-term view. New fundraising strategies should focus on donor retention, donor loyalty, integrating donors into the organization, and encouraging more collaboration between programs, governance, and development.

Several scholars have pointed to the need for approaching the acquisition of resources for the nonprofit organization in more strategic way, which necessitates a new conceptualization of the individual donor as Brudney and Meijs (2009) propose, “a natural resource" that is both sustainable and renewable, as well as, versatile in the roles 
they play in nonprofits. Sargeant and Shang (2011) ask practitioners to consider donors as potential volunteers and advocates. Given the managerial implications from this study and recent practical suggestions from other scholars, the common constructs in charitable giving should be developed and further refined to include other pro-social behaviors like volunteering and advocacy. The role of and relationships between volunteering, advocacy, and charitable giving behaviors of supporters should be explored as a potential nonprofit engagement ladder of participation which would provide empirically based evidence for building donor sustainability and versatility.

The findings in this study also suggest a need for a deeper exploration of charitable giving motivations among types of donors: first time and renewing donors. As proffered in this research, the motivations for giving differ among these groups and a universal approach to developing charitable giving models is not applicable.

Moreover, the findings related to the perceptions of organizational performance, present the opportunity to investigate the efficacy of nonprofit communications and methods of communicating with donors. By refining organizational performance messaging, how best to develop positive donor perceptions of organizational performance, the frequency and methods of communication can be clarified. In this study, perceived organizational performance was strongly related to donor identification with the nonprofit and also in their levels of relationship satisfaction and represents a critical area of future research.

Additionally, this study has implications for the public sector as governments use volunteers to assist in the delivery of public goods and services and seek to engage citizens in the governance process. Understanding their motivations for pro-social 
behaviors and the impact of identity saliency and relationship satisfaction may help to enable them to make more effective use of their resources and deepen their relationship with citizens.

\section{Limitations of the Study}

This study is limited by some threats to internal validity including selection bias, social desirability, and instrumentation. While every attempt has been made to strengthen the research design, the use of a random sample from a consumer research panel did present a threat to internal validity, selection bias, as the members of the panel have agreed to membership for the purpose of surveys. Additionally, since the population is limited to charitable donors in Virginia, the results cannot be generalized to other populations. As discussed earlier, a frequent limitation of charitable giving research and survey research, as a whole, is social desirability (Hall, 2001). Respondents may not want to admit their level of charitable giving, as it is an intensely personal decision. In order to be perceived more socially desirable, they give more socially desirable answers, such as reporting higher or more frequent charitable donations. As recommended by Dillman (2007), social desirability was minimized by using a survey research method that minimized interpersonal communication and emphasized the confidentiality of their responses.

In this study, instrumentation is also a threat to internal validity. Relying predominantly on validated scales from Arnett et al. (2003), Sargeant (2001), and Sargeant et al. (2006), the survey instrument was developed from several sources and the reliability scores for Cronbach's Alpha were recalculated to minimize the threat to the validity of the survey instrument. 
Charitable giving in this study was measured in two ways: actual self-reported charitable giving and intention to donate. The use of self-report data in charitable giving research can be inaccurate, as the ability of respondents to recall accurate details during the course of a completing a survey is not reliable (Bekkers and Weipking, 2010). This limitation was overcome by also asking about their future intention to donate; thus capturing another facet of charitable giving that can be more reflective of future charitable giving behavior. In this study, more of the variance in charitable giving was explained by the donor's intention to donate as opposed to the self-reported charitable giving (amount donated).

\section{Closing Remarks}

The goal of this research is to provide nonprofit organizations with a means to evaluate their marketing strategy and make adjustments to streamline and focus their efforts with a more strategic approach to developing donor engagement and support. The study's findings provide nonprofit organizations with a framework for nurturing existing donor relationships, as well as attracting new donors. Greater and deeper knowledge of the donor base allows for more targeted strategies to attract and retain supporters, making the most efficient and effective use of limited organizational resources.

The findings of this study expanded the work of previous researchers in the areas of identity saliency, relationship satisfaction, and charitable giving motivations and it revealed that both identity saliency and relationship satisfaction significantly predict charitable giving behavior and partially mediate the paths between charitable giving 
motivations and charitable giving behavior. Perceived organizational performance, emotional utility, and parental socialization and youth participation were significant drivers of identity saliency. Perceived organizational performance, emotional utility, and satisfaction with the solicitation process significantly predicted relationship satisfaction levels in donors. A further assessment of the results revealed that perceived financial need, demonstrable utility, and familial utility are not antecedents of identity saliency and relationship satisfaction and parental socialization and youth participation is not an antecedent of relationship satisfaction.

Previous research in charitable giving behavior has investigated in a . comprehensive manner, who gives, and this body of research has given us a better understanding of why they give; however, what has not been fully explored is why they continue to give and what else would they do if asked. Giving volunteers and donors the opportunity to do more, to have a greater impact on the things they care so much about is not really about getting more out of them but is more about the organization fulfilling their mission by giving them the opportunity to create change in the world.

The nonprofit sector provides what governments and markets fail to provide, and these organizations tackle, in many cases, the most complex problems, in which a transformational approach is warranted. The more we know about the factors that influence pro-social behaviors, and act on that knowledge, the more likely we are to nurture and grow a more caring society, a society that is capable of partnership, compromise, collaboration, and comprehensive approaches to addressing societal needs. Nonprofits are in a unique position, to be the bridge between governments and markets, and citizens and consumers, with the rare ability to tap into the individual passions in our 
citizenry and move them to action. Deepening the level of engagement with volunteers and donors can only make it better and make us better. 


\section{REFERENCES}

Abrams, B. A., and Schmitz, M. D. (1978). The "crowding-out" effect of governmental transfers on private charitable contributions. Public Choice, 33(1), 29-39.

Abrams, B. A., and Schmitz, M. D. (1984). The "crowding-out" effect of governmental transfers on private charitable contributions: Cross-section evidence. National Tax Journal, 37, 563-568.

Adams, W. C. (1986). Testing geographical bias in international news whose lives count? TV coverage of natural disasters. Journal of Communication 36(2), 113-123.

Alderson, W. (1957). Marketing behavior and executive action. Homewood, IL: Irwin.

Alpizar, F., Carlsson, F., and Johansson-Stenman, O. (2007). Anonymity, reciprocity and conformity: Evidence from voluntary contributions to a natural park in Costa Rica. Journal of Public Economics, 92(5-6), 1047-1060.

Alwin, D. F., and Krosnick, J. A. (1991). The reliability of survey attitude measurement: The influence of question and respondent attributes. Sociological Methods and Research, 20, 139-181.

Amos, O. M. (1982). Empirical analysis of motives underlying individual contributions to charity. Atlantic Economic Journal, 10(4), 45-52.

Anderson, J. and Narus, J. A. (1990). A model of distributor firm and manufacturer firm working partnerships. Journal of Marketing. 54(1): 42-58.

Andreoni, J. (1988). Privately provided public goods in a large economy: The limits of altruism. Journal of Public Economics 35, 57-73.

Andreoni, J. (1990). Impure altruism and donations to public goods: A theory of warmglow giving. Economic Journal, 100, 464-477.

Andreoni, J. (2001). The economics of philanthropy. In International Encyclopedia of the Social and Behavioral Science, N. J. Smelser and P.B. Baltes, (Eds.) 11369-76. London: Elsevier.

Andreoni, J., and Miller, J. (2002). Giving according to GARP: An experimental test of the consistency of preferences for altruism. Econometrica, 70, 737-753.

Andreoni, J., and Petrie, R. (2004). Public goods experiments without confidentiality: A glimpse into fund-raising. Journal of Public Economics, 88, 1605-1623.

Apinunmahakul, A., and Devlin, R. A. (2004). Charitable giving and charitable gambling: An empirical investigation. National Tax Journal, LVII(1), 67-88.

Aristotle (1999, 1162a34-1163a24). Nichomachean ethics, Indianapolis.

Arnett, D. B., German S. D., and Hunt, S. D. (2003). The identity salience model of relationship marketing success: The case of nonprofit marketing. Journal of Marketing, 67(2), 89-105.

Arumi, A. M., Wooden, R., Johnson, J., Farkas, S., Duffett, A., and Ott, A. (2005). The charitable impulse. New York: Public Agenda. 
Association of Fundraising Professionals. (2011). The AFP fundraising dictionary online. In B. Levy (Ed.), Arlington, VA: Association of Fundraising Professionals. Retrieved from http://www.afpnet.org/files/ContentDocuments/AFP Dictionary A-Z final 6-903.pdf

Auten, G. E., and Joulfaian, D. (1996). Charitable contributions and intergenerational transfers. Journal of Public Economics, 59, 55-68.

Auten, G. E., Cilke, J., and Randolph, W. (1992). The effects of tax reform on charitable contributions. National Tax Journal, 45, 267-290.

Auten, G.E., and Rudney, G. (1990). The variability of individual charitable giving in the U.S. Voluntas $1,80-97$.

Bac, M., and Bag, P. K. (2003). Strategic information revelation in fund-raising. Journal of Public Economics, 87, 659-679.

Backhaus, K., Adolphs, M., and Büschken, J. (1996). The paradox of unsatisfying but stable vertical relationships, In J. Sheth, and A. Söllner, (Eds.): Development, Management and Governance of Relationships. International Conference on Relationship Marketing, 29-31.

Bacon, F., and Pitcher, J. (1985). The essays. Harmondsworth, UK: Penguin.

Bagozzi, R. P. (1974). Marketing as an organized behavioral system of exchange. Journal of Marketing, 38(4), 77-81.

Bagozzi, R. P. (1975). Marketing as exchange. Journal of Marketing, 39(4), 32-39.

Banks, J., and Tanner, S. (1999). Patterns in household giving: Evidence from UK data. International Journal of Voluntary and Nonprofit Organizations, 10, 167-178.

Bar-Tel, D. (1976). Prosocial behavior: Theory and research. New York, NY: John Wiley and Sons, Inc.

Barnes, J. G. (2000). Closeness in customer relationships: Examining the payback from getting closer to the customer. In T. Hennig-Thurau and U. Hansen (Eds.). Relationship marketing: Gaining competitive advantage through customer satisfaction and customer retention. Berlin: Springer-Verlag.

Barrett, K. S. (1991). Panel-data estimates of charitable giving: A synthesis of techniques.

Barrett, P. (2007). Structural equation modeling: Adjudging model fit. Personality and Individual Differences, 42(5), 815-24.

Barrett, P. (2007). Structural equation modeling: Adjudging model fit. Personality and Individual Differences, 42(5), 815-24.

Batson, C. D. (1998). Altruism and prosocial behavior. In D. T. Gilbert (Ed.), Handbook of social psychology (Vol. 2, pp. 282-316). New York: Random House.

Becker, H. S. (1960). Notes on the concept of commitment. American Journal of Sociology, 66(1), 32-40. 
Bekkers, R. (2003). Trust, accreditation, and philanthropy in the Netherlands. Nonprofit and Voluntary Sector Quarterly, 32, 596-615.

Bekkers, R. (2005a). It's not all in the ask. Effects and effectiveness of recruitment strategies used by nonprofits in the Netherlands. Paper presented at the 34rd Annual ARNOVA-Conference, Washington, D. C.

Bekkers, R. (2006a,). Keeping the faith: Origins of confidence in charitable organizations and its consequences for philanthropy. Paper presented at the NCVO/VSSN Researching the Voluntary Sector Conference 2006, Warwick University, UK.

Bekkers, R. (2006b). Traditional and health related philanthropy: The role of resources and personality. Social Psychology Quarterly, 68, 349-366.

Bekkers, R. (2007b). Measuring altruistic behavior in surveys: The all-or-nothing dictator game. Survey Research Methods, 1(3).

Bekkers, R. (2008). Straight from the heart. In S. Chambré and M. Goldner (Eds.), Advances in medical sociology, Volume 10: Patients, consumers and civil society: US and international perspectives, 197-221. UK: Emerald Group.

Bekkers, R. and Wiepking, P. (2007). Generosity and philanthropy: A literature review. Report commissioned by the John Templeton Foundation. Available at SSRN: http://ssrn.com/abstract $=1015507$

Bekkers, R., and Crutzen, O. (2007). Just keep it simple: A field experiment on fundraising letters. International Journal of Nonprofit and Voluntary Sector Marketing, 12, 371-378.

Bekkers, R., and De Graaf, N. D. (2006). Education and prosocial behavior. Manuscript, Utrecht University, The Netherlands.

Bekkers, R., and Schuyt, T. (2008). And who is your neighbor? Explaining denominational differences in charitable giving and volunteering in the Netherlands. Review of Religious Research, 50(1), 74-96.

Bekkers, R., and Schuyt, T.N. (2005). And who is your neighbor? Explaining the effect of religion on charitable giving and volunteering. Working paper, Department of Philanthropic Studies, Vrije Universiteit Amsterdam.

Bekkers, R., and Wiepking, P. (2006). To give or not to give, that's the question. How methodology is destiny in Dutch data. Nonprofit and Voluntary Sector Quarterly, $35,533-540$.

Bekkers, R., and Wiepking, P. (2010). Accuracy of self-reports on donations to charitable organisations. Quality and Quantity. 45(6),1369-1383

Bekkers, R., and Wiepking, P. (2011a). A literature review of empirical studies of philanthropy: Eight mechanisms that drive charitable giving. Nonprofit and Voluntary Sector Quarterly, 40(5), 924-973. 
Bekkers, R., and Wiepking, P. (2011b). Who gives? A literature review of predictors of charitable giving 1 - Religion, education, age and socialization. Voluntary Sector Review, 2(3), 337-365.

Belfield, C. R., and Beney, A. P. (2000). What determines alumni generosity? Evidence for the UK. Education Economics, 8(1), 65-80.

Bendapudi, N., Singh, S.N. and Bendapudi, V. (1996). Enhancing helping behavior: An integrative framework for promotion planning. Journal of Marketing 60(3), 3349.

Bennett, R. , and Savani, S. (2003). Predicting the accuracy of public perceptions of charity performance. Journal of Targeting, Measurement, and Analysis for Marketing, 11(4), 326-342.

Bennett, R. (2003). Factors underlying the inclination to donate to particular types of charity. International Journal of Nonprofit and Voluntary Sector Marketing, 8(1), 12-29.

Bennett, R., and Gabriel, H. (2003). Image and reputational characteristics of UK charitable organizations: An empirical study. Corporate Reputation Review, 6, 276-289.

Bennett, R., and Kottasz, R. (2000). Emergency fund-raising for disaster relief. Disaster Prevention and Management, 9, 352-359.

Bentler, P.M. and Bonnet, D.C. (1980). Significance tests and goodness of fit in the analysis of covariance structures. Psychological Bulletin, 88(3), 588-606.

Bentler, P.M. and Bonnet, D.C. (1980). Significance tests and goodness of fit in the analysis of covariance structures. Psychological Bulletin, 88(3), 588-606.

Berkowitz, L. (1968). Responsibility, reciprocity, and social distance in help-giving: An experimental investigation of English social class differences. Journal of Experimental Social Psychology, 4, 46-63.

Berkowitz, L., and Daniels, L. R. (1964). Affecting the salience of the social responsibility norm: Effects of past help on the response to dependency relationships. Journal of Abnormal and Social Psychology, 68, 275-281.

Berry, L. L. (1997). The service nightmare: Can we sustain success? Marketing Management, Fall, 10-13.

Berry, L.L. (1980). Services marketing is different. Business, May, 24-29.

Berry, L.L. (1983). Relationship marketing. In L.L. Berry, G.L. Shostaack, and G. Upah (Eds.). Emerging perspectives on services marketing. Chicago: American Marketing Association.

Berry, L.L., and Parasuraman, A. (1991). Marketing services: Competing through quality. New York: Free Press.

Bhattacharya, C.B., and Sen, S. (2003). Consumer-company identification: A framework for understanding consumers' relationships with companies. Journal of Marketing 67(April), 76-88. 
Bhattacharya, C.B., Hayagreeva, R., and Glynn, M. A. (1995). Understanding the bond of identification: An investigation of its correlates among art museum members. Journal of Marketing 59(4), 46-57.

Bielefeld, W., Rooney, P., and Steinberg, K. (2005). How do need, capacity, geography, and politics influence giving? In A. C. Brooks (Ed.), Gifts of money in Americas communities (pp. 127-158). Lanham, MD: Rowman and Littlefield.

Bitner, M. J. (1990). Evaluating service encounters: The effects of physical surroundings and employee responses. Journal of Marketing, 54(April), 69-82.

Blau, P. M. (1968). Interaction: Social exchange, In International Encyclopedia of the Social Sciences 7(2000), (pp. 452-458).

Blau, P.M. (1964). Exchange and power in social life. New York: John Wiley and Sons.

Board Source. (2011). Knowledge center. Retrieved from http://www.boardsource.org

Boulding, W., Kalra, A., Staelin, R., and Zeithaml, V. A. (1993). A dynamic process model of service quality: From expectations to behavioural intentions. Journal of Marketing Research, 30(February), 7-27.

Bowman, W. (2006, June). Should donors care about overhead costs? Do they care? Nonprofit and Voluntary Sector Quarterly, 288-310.

Brooks, A. C. (2002). Welfare receipt and private charity. Public Budgeting and Finance, 22(3), 101-114.

Brooks, A. C. (2003). Taxes, subsidies, and listeners like you: Public policy and contributions to public radio. Public Administration Review, 63, 554-561.

Brooks, A. C. (2004). What do "don't know" responses really mean in giving surveys? Nonprofit and Voluntary Sector Quarterly 33: 324-434.

Brooks, A. C. (2005). Does social capital make you generous? Social Science Quarterly, $86,1-15$.

Brown, E. (2005). College, social capital, and charitable giving. In Gifts of Time and Money in Americas Communities, A. C. Brooks (Ed.). New York: Rowman and Littlefield.

Brown, E., and Ferris, J.M. (2007). Social capital and philanthropy: An analysis of the impact of social capital on individual giving and volunteering. Nonprofit and Voluntary Sector Quarterly 36, 85-99.

Brown, E., and Lankford, H. (1992). Gifts of money and gifts of time: Estimating the effects of tax prices and available time. Journal of Public Economics, 47, 321341.

Brown, M.W. and Cudeck, R. (1993). Alternative ways of assessing model fit. In Bollen, K.A. and Long, J.S. (eds). Testing Structural Equation Models. Newbury Park, CA: Sage.

Brown, S. W. and Swartz, T. A. (1989). A gap analysis of professional service quality. Journal of Marketing, 53(April), 92-98. 
Bruce, I. (1998). Successful charity marketing: marketing need. Hemel Hempstead, U.K. ICSA Publishing.

Brudney, J. and Meijs, L. (2009). It ain't natural: toward a new (natural) resource conceptualization for volunteer management. Nonprofit and Voluntary Sector Quarterly, 38(4), 564-581.

Bryan, J. H., and Test, M. A. (1967). Models and helping: Naturalistic studies in aiding behavior. Journal of Personality and Social Psychology, 6, 400-407.

Bryant, W. K., Slaughter, H. J., Kang, H., and Tax, A. (2003). Participating in philanthropic activities: Donating money and time. Journal of Consumer Policy, $26(1), 43-73$.

Buchanan, R., and Gilles, C. (1990). Value managed relationship: The key to customer retention and profitability. European Management Journal, 8(4), 523-526.

Buraschi, A., and Cornelli, F. (2002). Donations. CEPR discussion paper. (3488). Retrieved online at: http://www.cepr.org/pubs/dps/DP3488.asp.

Burgoyne, C. B., Young, B., and Walker, C. M. (2005). Deciding to give to charity: A focus group study in the context of the household economy. Journal of Community and Applied Social Psychology, 15, 383-405.

Burke, P. J. and Reitzes, D. C. (1981). The link between identity and role performance. Social Psychology Quarterly, 44, 83-92.

Burlingame, D. F. (1997). Critical issues in fund raising. New York: NSFRE/ Wiley.

Burnett, K. (1992). Relationship fundraising. London: White Lion Press.

Buttle, F. (1996). SERVQUAL: Review, critique, research agenda. European Journal of Marketing, 30(1), 8-32.

Byrne, B.M. (1998). Structural equation modeling with LISREL, PRELIS and SIMPLIS: Basic concepts, applications and programming. Mahwah, New Jersey: Lawrence Erlbaum Associates.

Byrne, B.M. (2001). Structural equation modeling with AMOS: Basic concepts, applications, and programming. New Jersey: Lawrence Erlbaum Associates.

Callen, J. L. (1994). Money donations, volunteering and organizational efficiency. Journal of Productivity Analysis, 5, 215-228.

Callero, P. L. (1985). Role identity salience. Social Psychology Quarterly, 48(3), 203215.

Carbone, R. (1986). An agenda for research on fund raising. College Park, MD: Clearinghouse for Research on Fund Raising.

Carman, J. M. (1990). Consumer perceptions of service quality: An assessment of the SERVQUAL dimensions. Journal of Retailing, 66, 33-55.

Carman, K. G. (2006). Social influences and the private provision of public goods: Evidence from charitable contributions in the workplace. Unpublished 
manuscript. Discussion Paper Stanford Institute for Economic Policy Research, Stanford University.

Carroll, J., McCarthy, S., and Newman, C. (2006). An econometric analysis of charitable donations in the Republic of Ireland. Economic and Social Review, 36, 229-249.

Chang, W. C. (2005). Religious giving, non-religious giving, and after-life consumption. Topics in Economic Analysis and Policy, 5(1), Article 13. Available at: http://www.bepress.com/bejeap/topics/vol5/iss1/art13

Chaves, M. (2002). Financing American religion. New Directions for Philanthropic Fundraising 35, 41-54.

Chen, Y., Li, X., and MacKie-Mason, J. K. (2006). Online fund-raising mechanisms: A field experiment. BE Contributions to Economic Analysis \& Policy, 5(2). Available from http://www. bepress.com/bejeap/contributions/vol5/iss $2 /$ art4.

Choe, Y. S., and Jeong, J. (1993). Charitable contributions by low and middle income taxpayers: Further evidence with a new method. National Tax Journal, 46(1), 3339.

Christensen, R., and Ebrahim, A. (2006). How does accountability affect mission? The case of a nonprofit serving immigrants and refugees. Nonprofit Management and Leadership, 17(2), 195.

Chua, V. C. H., and Wong, C. M. (1999). Tax incentives, individual characteristics and charitable giving in Singapore. International Journal of Social Economics, 26, 1492-1504.

Cialdini, R., Schaller, M., Houlihan, D., Arps, K., Fultz, J., and Beaman, A. (1987). Empathy-based helping: Is it selflessly or selfishly motivated?, Journal of Personality and Social Psychology, 52(4), 749-758.

Clary, E. G., and Miller, J. (1986). Socialization and situational influences on sustained altruism. Child Development, 57, 1358-1369.

Clotfelter, C.T. (1980). Tax incentives and charitable giving: Evidence from a panel of

Congram, C. A. (1987). Adding value through client service planning. In C. Suprenant (ed.), Add Value to Your Service. Chicago: American Marketing Association.

Cook, K. S., and Emerson, R. M. (1978). Power, equity and commitment in exchange networks. American Sociological Review, 43, 721-739.

Cronin, J. J., and Taylor, S. A., (1992). Measuring service quality: A reexamination and extension. Journal of Marketing, 56(July), 55-68.

Crosby, L. A., and Stephens, N. (1987). Effects of relationship marketing on satisfaction, retention and prices in the life insurance industry. Journal of Marketing Research, 24(November), 404-411.

Daneshvary, N., and Luksetich, W. A. (1997). Income sources and declared charitable tax deductions. Applied Economics Letters, 4, 271-274.

Davidson, J. D., and Pyle, R. E. (1994). Passing the plate in affluent churches: Why some members give more than others. Review of Religious Research, 36, 181-196. 
Desmet, P. (1998). The impact of mail order on subsequent donations: An experiment. Financial Accountability and Management, 14, 203-214.

Desrochers, S., Andreassi, J., and Thompson, C. (2004). Identity theory. Organizational Management Journal, 1, 61-69.

Diamantopoulos, A. and Siguaw, J.A. (2000). Introducing LISREL. London: Sage Publications.

Diamond, W. D., and Gooding-Williams, S. (2002). Using advertising constructs and methods to understand direct mail fundraising appeals. Nonprofit Management and Leadership, 12(3), 225-242.

Diamond, W. D., and Kashyap, R. K. (1997). Extending models of prosocial behavior to explain university alumni contributions. Journal of Applied Social Psychology, 27, 915-928.

Diamond, W. D., and Noble, S. M. (2001). Defensive responses to charitable direct mail solicitations. Journal of Interactive Marketing, 15(3), 2-12.

Dodge, Y. (2003). The Oxford Dictionary of Statistical Terms. London: Oxford University Press.

Duncan, B. (1999). Modeling charitable contributions of time and money. Journal of Public Economics, 72, 213-42.

Duncan, B. (2004). A theory of impact philanthropy. Journal of Public Economics, 88, 2159-2180.

Dwyer, F. R., Schurr, P. H., and Oh, S. (1987). Developing buyer-seller relationship. Journal of Marketing, 5I, 11-27.

Eaton, D. H. (2001). Charitable contributions and tax price elasticities for nonitemizing taxpayers. International Advances in Economic Research, 7, 432-442.

Eckel, C. C., and Grossman, P. J. (2003). Rebate versus matching: Does how we subsidize charitable contributions matter? Journal of Public Economics, 87, 681701.

Edlund, J. E., Sagarin, B. J., and Johnson, B. S. (2007). Reciprocity and the belief in a just world. Personality and Individual Differences, 43, 589-596.

Eikenberry, A. M. (2009, June). The hidden costs of cause marketing. Stanford Social Innovation Review.

Eisenberg, N. (2000). Emotion, regulation, and moral development. Annual Review of Psychology, 51, 665-697.

Eisenberg, N., and Mussen, P. H. (1989). The roots of prosocial behavior in children. Cambridge: Cambridge University Press.

Eschholz, S. L., and Van Slyke, D. M. (2002). New evidence about women and philanthropy: Findings from Metro Atlanta: United way of metropolitan Atlanta's women's legacy. 
Fan, X., Thompson, B., and Wang, L. (1999). Effects of sample size, estimation methods, and model specification on structural equation modeling fit indexes. Structural Equation Modeling, 6(1), 56-83.

Farmer, S. M., and Fedor, D. B. (2001). Changing the focus on volunteering: An investigation of volunteers' multiple contributions to a charitable organization. Journal of Management, 27, 191-211.

Feenberg, D. (1987). Are tax price models really identified: The case of charitable giving. National Tax Journal, 40, 629-633.

Feldman, D., and Feldman, B. (1985). The effect of a telethon on attitudes toward disabled people and financial contributions. Journal of Rehabilitation, 51, 42-45.

Feldman, N. E. (2007). Time is money: Choosing between charitable activities. Working paper, Ben-Gurion University, Israel.

Feldstein, M. (1975a). The income tax and charitable contributions: Part I-aggregate and distributional effects. National Tax Journal, 28, 81-99.

Feldstein, M. (1975b). The income tax and charitable contributions: Part II-the impact on religious, educational, and other organizations. National Tax Journal, 28, 209226.

Feldstein, M., and Taylor, A. (1976). The income tax and charitable contributions. Econometrica, 44, 1201-1222.

Forbes, K. F., and Zampelli, E. M. (1997). Religious giving by individuals: A cross denominational study. The American Journal of Economics and Sociology 56,1730 .

Fornell, C. and Larcker, D.F. (1981). Evaluating structural equation models with unobservable variables and measurement error. Journal of Marketing Research, $19(1), 39-50$.

Fultz, J. C, Batson, D., Fortenbach, V.A., McCarthy, P., and Varney, L.L. (1986). Social evaluation and the empathy altruism hypothesis. Journal of Personality and Social Psychology,50, 761-769.

Gaskin, K. (1999). Blurred vision: Public trust in charities. International Journal of Nonprofit and Voluntary Sector Marketing, 4(2).

George, W. R. (1977). The retailing of services: A challenging future." Journal of Retailing, Fall, 85-98.

German, S. D. (1997). Nonprofit relationship marketing: The role of identification. Ph.D. dissertation, Texas Tech University, United States -- Texas. Retrieved January 5, 2012, from Dissertations and Theses: Full Text.(Publication No. AAT 9736894).

Geyskens, I., Steenkamp, J. B., Scheer, L. K. and Kumar, N. (1996). The effects of trust and interdependence on relationship commitment: A transatlantic study, International Journal of Research in Marketing, 13, 303-17.

Glaser, J. S., (1994). The united way scandal - An insiders account of what went wrong and why, New York: John Wiley and Sons. 
Glenday, G., Gupta, A. K., and Pawlak, H. (1986). Tax incentives for personal charitable contributions. Review of Economics and Statistics, 68, 688-693.

Graddy, E. A., Ferris, J. M., and Sohn, Y. J. (2011). The evolution of research on philanthropy and nonprofit organizations as an intellectual field: an analysis of leading journals. Informally published manuscript, The Center on Philanthropy and Public Policy, University of Southern California, Los Angeles, California. Retrieved from http://cppp.usc.edu/research/FINAL-RP-35-FerrisGraddySohn.pdf

Greenwood, D. T. (1993). Price and income elasticities of charitable giving: How should income be measured? Public Finance Quarterly, 21, 186-209.

Greenwood, J. D. (1994). Realism, Identity, and Emotion. London: Sage Publications.

Grönroos, C. (1981). Internal marketing-An integral part of marketing theory. In J. H. Donelly and W. R. George (Eds.), Marketing of Services. Chicago: American Marketing Association.

Grönroos, C. (1991). The marketing strategy continuum: Toward a marketing concept for the services marketing. Management Decision, 29(1), 7-13.

Grönroos, C. (1994). From marketing mix to relationship marketing: Towards a paradigm shift in marketing. Management Decision, 32(2), 4-20.

Groves, R.M., F.J. Fowler, M.P. Couper, J.M. Lepkowski, E. Singer, and R. Tourangeau. (2009). Survey Methodology. Hoboken, NJ: John Wiley and Sons.

Gruber, J. (2004). Pay or pray? The impact of charitable subsidies on religious attendance. Journal of Public Economics, 88, 2635-2655.

Gundlach, G.T, Murphy, P.E. (1993). Ethical and legal foundations of relational marketing exchanges. Journal of Marketing, 57, 35-46.

Hager, M. A., and Brudney, J. L. (2004). Volunteer management practices and retention of volunteers. Washington, D.C.: The Urban Institute. Retrieved from http://www.urban.org/publications/411005.html

Haggberg, M. (1992). Why donors give. Fund Raising Management, 23(2),39-40.

Hair, J.F., Black, W.C., Babin, B.J., \& Anderson, R.L., (2010). Multivariate data analysis, $7^{\text {th }}$ ed. New Jersey: Prentice-Hall.

Harley, D. R. (1984). Customer satisfaction tracking improves sales, productivity, morale of retail chains. Marketing News, 15(June).

Harris, M. B., Liguori, R. A., and Stack, C. (1973). Favors, bribes, and altruism. Journal of Social Psychology, 89, 47-54.

Harvey, J. W. (1990). Benefit segmentation for fundraisers. Journal of the Academy of Marketing Science, 18(1), 77-86.

Harvey, J. W., and McCrohan, K. F. (1988). Fundraising costs - societal implications for philanthropies and their supporters. Business and Society 27(1), 15-22.

Havens, J. J., O'Herlihy, M. A., and Schervish, P. G. (2007). Charitable giving: How much, by whom, to what, and how? In W. W. Powell and R. S. Steinberg (Eds.), 
The non-profit sector: A research handbook (2nd ed., pp. 542-567). New Haven, CT: Yale University Press.

Hennig-Thurau, T., and Hansen, U. (2000). Relationship marketing - Some reflections on the state-of-the-art of the relational concept. In T. Hennig-Thurau and U. Hansen (Eds.). Relationship marketing: Gaining competitive advantage through customer satisfaction and customer retention. Berlin: Springer-Verlag.

Hodgkinson, V. A., and Weitzman, M. S. (1996). Giving and volunteering in the united states. Washington: Independent Sector.

Hoge, D. R., and Yang, F. (1994). Determinants of religious giving in American denominations: Data from two nationwide surveys. Review of Religious Research $36,123-48$.

Hogg, M., Terry, D. and White, K. (1995). A tale of two theories: A critical comparison of identity theory with social identity theory. Social Psychology Quarterly, 58, 255-269.

Holmbeck, G., (1997). Toward terminological, conceptual, and statistical clarity in the study of mediators and moderators: Examples from the child-clinical and pediatric psychology literatures. Journal of Consulting and Clinical Psychology, 65(4), 599-610.

Homans, G. C. (1958). Social behavior as exchange. American Journal of Sociology, 63(6), 597-606.

Homans, G. C. (1961). Social behavior: Its elementary forms. New York: Harcourt, Brace and World.

Hood, R. D., Martin, S. A., and Osberg, L. S. (1977). Economic determinants of individual charitable donations in Canada. Canadian Journal of Economics, 10, 653-669.

Hornstein, H. A. (1972). Promotive tension and prosocial behavior: The basis of prosocial behavior from a Lewinian perspective. Journal of Social Issues, 28, 191-218.

Hornstein, H. A. (1976). Cruelty and kindness: A new look at aggression and altruism. Englewood Cliffs, NJ: Prentice Hall.

Houston, D. J. (2006). Walking the walk of public service motivation: Public employees and charitable gifts of time, blood, and money. Journal of Public Administration Research and Theory 16, 67-86.

Houston, F. S., and Gassenheimer, J. B., (1987). Marketing and exchange, Journal of Marketing, 51(4).

Hrung, W. B. (2004). After-Life Consumption and Charitable Giving. American Journal of Economics and Sociology 63, 731-45.

http://www.impact.upenn.edu/our_work/documents/WhatisHighImpactPhilanthro py_initialconceptpaperApril2007_000.pdf 
Hu, L.T. and Bentler, P.M. (1999). Cutoff criteria for fit indexes in covariance structure analysis: Conventional criteria versus new alternatives. Structural Equation Modeling: A Multidisciplinary Journal, 6, 1-55.

Hunt, S. D. (1976). The nature and scope of marketing. Journal of Marketing 40 (July), 17-28.

Hunter, C. S., Jones, E. B., and Boger, C. (1999). A study of the relationship between alumni giving and selected characteristics of alumni donors of Livingstone College, NC. Journal of Black Studies 29, 523-39.

Jackson, E. F., Bachmeier, M. D., Wood, J. R., and Craft, E. A. (1995). Volunteering and charitable giving: Do religious and associational ties promote helping behavior? Nonprofit and Voluntary Sector Quarterly 24, 59-78.

Jackson, N. C., and Mathews, R. M. (1995). Using public feedback to increase contributions to a multipurpose senior center. Journal of Applied Behavior Analysis, 28, 449-455.

James, R. N., and Sharpe, D. L. (2007). The nature and causes of the u-shaped charitable giving profile. Nonprofit and Voluntary Sector Quarterly 36, 218-38.

Jencks, C. (1990). Varieties of altruism. In J.J. Mansbridge (Ed.) Beyond Self-interest.

Jones, A. M., and Posnett, J. W. (1991a). Charitable donations by UK households: Evidence from the Family Expenditure Survey. Applied Economics, 23, 343-351.

Jones, A. M., and Posnett, J. W. (1991b). The impact of tax deductibility on charitable giving by covenant in the UK. Economic Journal, 101, 1117-1129.

Jones, T. O., and Sasser, W. E. Jr. (1995). Why satisfied customers defect. Harvard Business Review. November-December, 88-99.

Jöreskog, K. and Long, J.S. (1993). Introduction. In Testing Structural Equation Models, Kenneth A. Bollen and J. Scott Long, (Eds). Newbury Park, CA: Sage.

Katz, S. N. (1999). Where did the serious study of philanthropy come from, anyway? Nonprofit and Voluntary Sector Quarterly, 8(1), 74-82.

Keegan, W., Moriarty, S., and Duncan, T. (1995). Marketing. Englewood Cliffs, NJ: Prentice Hall.

Kenny, D.A. and McCoach, D.B. (2003). Effect of the number of variables on measures of fit in structural equation modeling. Structural Equation Modeling, 10(3), 33351.

Key, P. (2009, April 10). Nonprofits report rising demand, shrinking purses. Philadelphia Business Journal. Retrieved from http://nonprofitfinancefund.org/files/docs/2010/4 $1016 \quad 09$ philadelphia business journal.pdf

Keyt, J. C., Yavas, U., and Riecken, G. (2002). Comparing donor segments to a causebased charity: The case of the American Lung Association. Journal of Nonprofit and Public Sector Marketing, 10(2), 117-134. 
Kihlstrom, J. F. and Cantor, N. (1984). Mental representations of the self. In L. Berkowitz (Ed.), Advances in experimental social psychology, 17. New York: Academic Press.

Kingma, B. (1989). An accurate measurement of the crowd-out effect, income effect and price effect for charitable contributions. Journal of Political Economy, 97, 11971207.

Kleinaltenkamp, M. (1994). Explaining relationships with new institutional economics. In K. Backhaus and H. Diller (Eds.), Proceedings of the 1st Workshop on Relationship Management Münster: Verband der Hochschullehrer für Betriebswirtschaftslehre.

Kline, R.B. (2005). Principles and practice of structural equation modeling, 2 nd edition. New York: The Guilford Press.

Knoke D. (1990). Organizing for collective action. New York: Aldine de Gruyter

Komter, A. (1996). The social and psychological significance of gift giving in the Netherlands. In A. Komter (Ed.), The gift: An interdisciplinary perspective (pp. 107-117). Amsterdam, Netherlands: Amsterdam University Press.

Kotler, P. (1972). A generic concept of marketing. Journal of Marketing. 36(2): 46-54.

Kotler, P. (1979). Strategies for introducing marketing into nonprofit organizations. Journal of Marketing. 43(1): 37-44.

Kotler, P. (1994). Marketing management. Analysis, planning, implementation and control. Englewood Cliffs, NJ: Prentice-Hall.

Kotler, P., and Andreasen, A. R. (1991). Strategic marketing for non-profit organizations. Upper Saddle River, NJ: Prentice-Hall.

Kotler, P., and Armstrong, G. (1999). Principles of marketing. (8 ed.). Upper Saddle River, NJ: Prentice Hall.

Kotler, P., and Clarke, R. N. (1987). Marketing for health care organizations. Englewood

Kotler, P., and Levy, S. J., (1969). Broadening the concept of marketing. Journal of Marketing 33, 10-15.

Kottasz, R. (2004). How should charitable organizations motivate young professionals to give philanthropically. International Journal of Nonprofit and Voluntary Sector Marketing, 9, 9-27.

Krebs, D., (1970). Altruism - A rational approach. In, Eisenberg, N. (Ed.), 1982. The development of prosocial behaviour. New York: Academic Press, (pp. 53-77).

Kumru, C., and Vesterlund, L. (2008). The effect of status on voluntary contribution. Working paper, Department of Economics, University of Pittsburgh. Retrieved online at: http://www.pitt.edu/ vester/status.pdf.

Landry, C., Lange, A., List, J. A., Price, M. K., and Rupp, N. G. (2006). Toward an understanding of the economics of charity: Evidence from a field experiment. Quarterly Journal of Economics, 121, 747-782. 
Lankford, R. H., and Wyckoff, J. H. (1991). Modeling charitable giving using a box-cox standard tobit model. Review of Economics and Statistics, 73, 460-470.

Laverie, D. A., Kleine III, R. E., and Kleine, S.S. (2002). Re-examination and extension of Kleine, Kleine, and Kernan's social identity model of mundane consumption: The mediating role of the appraisal process. Journal of Consumer Research, 28(4), 659-69.

Lee, B. A., and Farrell, C. R. (2003). Buddy, can you spare a dime? Homelessness, panhandling, and the public. Urban Affairs Review, 38, 299-324.

Leslie, L. L., and Ramey, G. (1988). Donor behavior and voluntary support for higher education institutions. Journal of Higher Education, 59(2), 115-132.

Levitt, L., and Kornhaber, R. C. (1977). Stigma and compliance. A re-examination. Journal of Social Psychology, 103(1), 13-18.

Levitt, T. (1981). Marketing intangible products and product intangibles. Harvard Business Review, May-June, 94-102.

Lincoln, A. J. (1977). Effects of the sex of the model and donor on donating to Amsterdam organ grinders. Journal of Social Psychology, 103(1), 33-37.

Lindahl, W. E. (2011). Principles of fundraising: Theory and practice. Sudbury, MA: Jones and Bartlett Publishers, Inc.

Lindahl, W. E., and Conley, A. T. (2002). Literature review: Philanthropic fundraising. Nonprofit Management and Leadership, 13(1), 91-112.

List, J. A., and Lucking-Reiley, D. (2002). The effects of seed money and refunds on charitable giving: Experimental evidence from a university capital campaign. Journal of Political Economy, 110, 215-234.

List, J. A., and Rondeau, D. (2003). The impact of challenge gifts on charitable giving: An experimental investigation. Economics Letters, 79, 153-159.

Long, J. E. (2000). Omitted-variable bias when using state tax rates to estimate the tax price effect on itemized deductions. Public Finance Review, 28(2), 120-133.

Lovelock, C. H., and Weinberg, C. B. (1984). Marketing for Public and Nonprofit Managers. (1 ed.), New York: John Wiley and Sons.

Low, B. (1996). Opportunistic behavior in business relationship: A synthesis of the transaction cost economics and the network governance structures. In Development, Management and Governance of Relationships: Proceedings of the 1996 International Conference on Relationship Marketing. J.N. Sheth and A. Sollner. (Eds.) Berlin: Humbold University Press, (pp. 35-49).

Lunn, J., Klay, R., and Douglass, A. (2001). Relationships among giving, church attendance, and religious beliefs: The case of the Presbyterian Church (USA). Journal for the Scientific Study of Religion, 40, 765-775.

Lusch, R. F. (2007). Marketing's evolving identity: Defining our future. Journal of Public Policy and Marketing, Retrieved from http://www.marketingpower.com/AboutAMA/Pages/AMA Publications/AMA 
Journals/Journal of Public Policy Marketing/TOCS/summary fall 07/MarketingsEvolvingippmfall07.aspx

Lyons, M., and Nivison-Smith, I. (2006). Religion and giving in Australia. Australian Journal of Social Issues 41, 419-36.

Lyons, M., and Passey, A. (2005). Giving Australia: Research on philanthropy in Australia. Sydney: University of Technology.

MacKinnon, D., Lockwood, C., Hoffman, J. (2002). A comparison of methods to test mediation and other intervening variable effects. Psychological Methods, 7(1), 83-104.

MacNeil, I. R. (1978). Contracts: Adjustment of long-term economic relations under classical, neoclassical and relational contract law. Northwestern University Law Review, 72, 854-902.

MacNeil, I. R. (1980). The new social contract: An inquiry into modern contractual relations. New Haven, CN: Yale University Press.

Mael, F., and Ashforth, B. E. (1992). Alumni and their alma mater: A partial test of the reformulated model of organizational identification. Journal of Organizational Behavior, 13, 103-123.

Marcuello, C., and Salas, V. (2000). Money and time donations to Spanish non governmental organizations for development aid. Investigaciones Económicas, 24, 51-73.

Marcuello, C., and Salas, V. (2001). Nonprofit organizations, monopolistic competition, and private donations: Evidence from Spain. Public Finance Review, 29, 183-207.

Marr, K. A., Mullin, C. H., and Siegfried, J. J. (2005). Undergraduate financial aid and subsequent alumni giving behavior. Quarterly Review of Economics and Finance, $45,123-143$.

Martin, M. W. (1994). Virtuous giving: Philanthropy, voluntary service, and caring. Indianapolis: Indiana University Press.

Marx, J. D. (2000). Women and human services giving. Social Work, 45(1), 27-38.

Mathur, A. (1996). Older adults' motivations for gift giving to charitable organizations: An exchange theory perspective. Psychology and Marketing, 13(1), 107.

Matsunaga Y. (2006). To give or not to give; to volunteer or not to volunteer; that is the question. Evidence on Japanese philanthropic behavior revealed by the JGS-2005 data set.

McClelland R., and Brooks, A.C. (2004). What is the real relationship between income and charitable giving? Public Finance Review 32(5): 483-498.

McClelland, R., and Kokoski, M. F. (1994). Econometric issues in the analysis of charitable giving. Public Finance Quarterly, 22, 498-517.

McDonald, G. W. (1981). Structural exchange and marital interaction. Journal of Marriage and Family, 43(4), 825-839. 
McDonald, R.P. and Ho, M. (2002). Principles and practice in reporting statistical equation analyses. Psychological Methods, 7(1), 64-82.

McIntosh, C. (2006). Rethinking fit assessment in structural equation modeling: A commentary and elaboration on Barrett (2007). Personality and Individual Differences, 42(5), 859-67.

Merriam-Webster. (2011). In Merriam-Webster.com.

Mesch, D. J., Rooney, P. M., Steinberg, K. S., and Denton, B. (2006). The effects of race, gender, and marital status on giving and volunteering in Indiana. Nonprofit and Voluntary Sector Quarterly 35, 565-87.

Midlarsky, E., and Hannah, M.E. (1989). The generous elderly: Naturalistic studies of donations across the life span. Psychology and Ageing 4(3), 346-351.

Miles, J. and Shevlin, M. (2007). A time and a place for incremental fit indices. Personality and Individual Differences, 42(5), 869-74.

Miller, K. (2005). Communication Theories. New York: McGraw Hill.

Mishra, D. B., Heide, J.B. and Cort, S. G. (1998). Information asymmetry and levels of agency relationships. Journal of Marketing Research, 35, 277-295.

Mixer, J. R. (1993). Principles of professional fundraising: Useful foundations for successful practice. San Francisco, CA: Jossey-Bass.

Moorman C., Zaltman, G., and Deshpandé, R. (1992). Relationships between providers and users of market research: The dynamics of trust within and between organizations. Journal of Marketing Research, 29 (August), 314-328.

Moorman, C., Deshpandé, R., and Zaltman, G. (1993). Factors affecting trust in marketing research relationships. Journal of Marketing, 57 (January), 81-101.

Morgan, R. M., and Hunt, S. (1994). The commitment-trust theory of relationship marketing. Journal of Marketing, 58(3), 20-38.

Mulaik, S.A., James, L.R., Van Alstine, J., Bennet, N., Lind, S., and Stilwell, C.D. (1989). evaluation of goodness-of-fit indices for structural equation models. Psychological Bulletin, 105(3), 430-45.

Mulaik, S.A., James, L.R., Van Alstine, J., Bennet, N., Lind, S., and Stilwell, C.D. (1989). evaluation of goodness-of-fit indices for structural equation models. Psychological Bulletin, 105(3), 430-45.

Nonprofit Research Collaborative. (2011, March). The 2010 nonprofit fundraising survey. Retrieved from http://foundationcenter.org/gainknowledge/research/pdf/nrc survey2011.pdf

Nord, W. (1973). Adam smith and contemporary social exchange theory. American Journal of Economics and Sociology, 32(4), 421-36.

Nunnally, J.C. \& Bernstein, I.H. (1994). Psychometric theory. New York: McGraw-Hill.

O'Neill, C. J., Steinberg, R. S., and Thompson, G. R. (1996). Reassessing the tax-favored status of the charitable deduction for gifts of appreciated assets. National Tax Journal, 49, 215-233. 
Okten, C., and Osili, U.O. (2004). Contributions in heterogeneous communities: Evidence from Indonesia. Journal of Population Economics 17, 603-26.

Okunade, A. A., and Berl, R. L. (1997). Determinants of charitable giving of business school alumni. Research in Higher Education, 38, 201-214.

Olsen, J. A., and Eidem, J. I. (2003). An inquiry into the size of health charities: The case of Norwegian patient organizations. Journal of Socio-Economics, 32, 457-466.

Olson, D. V., and Caddell, D. (1994). Generous congregations, generous givers: Congregational contexts that stimulate individual giving. Review of Religious Research, 36, 168-180.

Olson, M. (1965). The logic of collective action: Public goods and the theory of groups. Cambridge, MA: Harvard University Press.

Pancer, S. M., McMullen, L. M., Kabatoff, R. A., Johnson, K. G., and Pond, C. A. (1979). Conflict and avoidance in the helping situation. Journal of Personality and Social Psychology, 37, 1406-1411.

Parasuraman, A., Zeithaml, V.A. and Berry, L.L. (1985). A conceptual model of service quality and its implications for future research. Journal of Marketing, Fall, 41-50.

Parasuraman, A., Zeithaml, V.A. and Berry, L.L. (1988). SERVQUAL: A multiple-item scale for measuring consumer perceptions of service quality. Journal of Retailing, 64(1), 12-40.

Park, T. K., and Park, S. B. (2004). An economic study on charitable giving of individuals in Korea: Some new findings from 2002 survey data. Presented at 6th International Conference of the International Society for Third-sector Research, Ryerson University, Toronto, Canada.

Parsons, L. M. (2003). Is accounting information from nonprofit organizations useful to donors? A review of charitable giving and value-relevance. Journal of Accounting Literature, 22, 104-129.

Parsons, L. M. (2007). The impact of financial information and voluntary disclosures on contributions to not-for-profit organizations. Behavioral Research in Accounting, 19, 179-196.

Parvatiyar, A., Sheth, J. N., and Whittington, F. B. (1992) Paradigm shift in interfirm marketing relationships: Emerging research issues, (Working Paper No. CRM 92-101), Atlanta, GA: Center for Relationship Marketing, Emory University.

Payne A., and Holt, S. (2001). Diagnosing customer value: Integrating the value process and relationship marketing. British Journal of Management, 12, 159-182.

Payton, R. (1988). Philanthropy: Voluntary Action for the Public Good. New York: Macmillan.

Payton, R. L., Tempel, E. R., and Rosso, H. A. (1991). Taking fund raising seriously: An agenda. In D. F. Burlingame and L. J. Hulse (Eds.), Taking fund raising seriously. San Francisco: Jossey-Bass. 
Petersen, J. (1997). The statistics of loyalty and satisfaction. Journal of Targeting, Measurement and Analysis for Marketing, 6(1), 65-75.

Pharoah, C., and Tanner, S. (1997). Trends in charitable giving. Fiscal Studies, 18, 427433.Pilavian and Callero 1991

Pitts, R. E., and Skelly, G. U. (1984). Economic self-interest and other motivational factors underlying charitable giving. Journal of Behavioral Economics, 13(2), 93109.

Polonsky, M. J. (1995). A stakeholder theory approach to designing environmental marketing strategy. Journal of Business and Industrial Marketing, 10(3), 29-42.

Polonsky, M. J., Schuppisser, D. S. W. , and Beldona, S. (2002). A stakeholder perspective for analyzing marketing relationships. Journal of Market-Focused Management, 5, 109-202.

Polonsky, M. J., Shelley, L., and Voola, R. (2002). An examination of helping behavior-Some evidence from Australia. Journal of Nonprofit and Public Sector Marketing, 10(2), 67-82.

Potters, J., Sefton, M., and Vesterlund, L. (2005). After you-Endogenous sequencing in voluntary contribution games. Journal of Public Economics, 89, 1399-1419.

Radley, A., and Kennedy, M. (1992). Reflections upon charitable giving: A comparison of individuals from business, "manual" and professional backgrounds. Journal of Community and Applied Social Psychology, 2, 113-129.

Radley, A., and Kennedy, M. (1995). Charitable giving by individuals: A study of attitudes and practice. Human Relations, 48, 685-709.

Reece, W. S. (1979). Charitable contributions: New evidence on household behavior. American Economic Review, 69, 142-151.

Reece, W. S., and Zieschang, K. D. (1985). Consistent estimation of the impact of tax deductibility on the level of charitable contributions. Econometrica, 53, 271-293.

Reece, W. S., and Zieschang, K. D. (1989). Evidence on taxation and charitable giving from the 1983 U.S. treasury tax model file. Economics Letters, 3(1), 49-53.

Reed, P. B., and Selbee, L. K. (2002). Is there a distinctive pattern of values associated with giving and volunteering? The Canadian case. Retrieved January 18, 2010, from http://www .canadawhocares.ca/pdfs/ARNOVA\%20Ethos\%20Paper\%20Nov.pdf

Regnerus, M. D., Smith, C., and Sikkink, D. (1998). Who gives to the poor? The influence of religious tradition and political location on the personal generosity of Americans toward the poor. Journal for the Scientific Study of Religion, 37, 48193.

Reichers, A. E. (1985). A review and reconceptualization of organizational commitment. Academy of Management Review, 10, 465-476.

Reingen, P. H. (1982). Test of a list procedure for inducing compliance with a request to donate money. Journal of Applied Psychology, 67, 110-118. 
Rentschler, R., Radbourne, J., Carr, R., and Rickard, J. (2002). Relationship marketing, audience retention and performing arts organisation viability. International Journal of Nonprofit and Voluntary Sector Marketing, 7(2), 118-130.

Ricketts, R. C., and Westfall, P. H. (1993). New evidence on the price elasticity of charitable contributions. Journal of the American Taxation Association, 15(2), 125.

Robinson, J. (1990). Estimates of the price elasticity of charitable giving: A reappraisal using 1985 itemizer and nonitemizer charitable deduction data. Journal of the American Taxation Association, 12, 39-50.

Roeger, K. L., Blackwood, A., and Pettijohn, S. L. (2011). The nonprofit sector in brief. Washington D.C.: National Center for Charitable Statistics at the Urban Institute. Retrieved from http://www.urban.org/publications/412434.html on December 9, 2011.

Rooney, P. M., Mesch, D. J., Chin, W., Steinberg, K. S. (2005). The effect of race, gender, and survey methodologies on giving in the US. Econometrics Letters 86, 173-80.

Rooney, P. M., Steinberg, K., and Schervish, P. G. (2001). A methodological comparison of giving surveys: Indiana as a test case. Nonprofit and Voluntary Sector Quarterly 30, 551-568.

Rosenberg, M. (1979). Conceiving the self. New York: Basic Books.

Rousseau, D. M., Sitkin, S. B., Burt, R. S., and Camerer, C. (1998). Not so different after all: A cross-discipline view of trust. Academy of Management Review. 23(3). 393404.

Ryans, A. B., and Wittink, D. R. (1977). The marketing of services: Categorization with implications for strategy. In B. Greenberg and D. Bellenger (Eds.), Contemporary Marketing Thought. Chicago: American Marketing Association.

Sargeant, A. (1999). Charitable giving: Towards a model of donor behavior. Journal of Marketing Management, 15, 215-238.

Sargeant, A., and Jay, E. (2004). Fundraising management analysis, planning and practice. London: Routledge.

Sargeant, A., and Lee, S. (2004). Trust and relationship commitment in the United Kingdom voluntary sector: Determinants of donor behavior. Psychology and Marketing, 21, 613-635.

Sargeant, A., and Woodliffe, L. (2005). The antecedents of donor commitment to voluntary organizations. Nonprofit Management and Leadership, 16(1), 61-78.

Sargeant, A., and Woodliffe, L. (2007). Individual giving behaviour: A multi-disciplinary review. In A. Sargeant and W. Wymer (Eds.), The nonprofit marketing companion. London: Routledge.

Sargeant, A., Ford, J. B., and West, D. C. (2000). Widening the appeal of charity. International Journal of Nonprofit and Voluntary Sector Marketing, 5, 318-332. 
Sargeant, A., Ford, J. B., and West, D. C. (2006). Perceptual determinants of nonprofit giving behavior. Journal of Business Research, 59, 155-165.

Schervish, P. G. (1992). Adoption and altruism: Those with whom I want to share a dream. Nonprofit and Voluntary Sector Quarterly 21(4), 327-350.

Schervish, P. G., and Havens, J. J. (1995a). Do the poor pay more: Is the u-shaped curve correct? Nonprofit and Voluntary Sector Quarterly 24, 79-90.

Schervish, P. G., and Havens, J. J. (1995b). Explaining the curve in the U-shaped curve. Voluntas, 6, 202-225.

Schervish, P. G., and Havens, J. J. (1998b). Money and magnanimity: New findings on the distribution of income, wealth, and philanthropy. Nonprofit Management and Leadership, 8, 421- 34.

Schervish, P. G., and Havens, J. J. (2002). The Boston area diary study and the moral citizenship of care. Voluntas, 13(1), 47-71.

Schervish, P. G., and Havens, J. J. (2003). New findings on the patterns of wealth and philanthropy. Chesnut Hill, PA:, Social Welfare Research Institute.

Schervish, P., and Havens, J. (1997). Social participation and charitable giving: A multivariate analysis. Voluntas, 8(3), 235-260.

Schiff, J. (1990). Charitable giving and government policy: An economic analysis. New York: Greenwood Press.

Schlegelmilch, B. B., Diamantopoulos, A., and Love, A. (1997). Characteristics affecting charitable donations: Empirical evidence from Britain. Journal of Marketing Practice: Applied Marketing Science, 3(1), 14-28.

Schlegelmilch, B. B., Love, A., and Diamantopoulos, A. (1997). Responses to different charity appeals: The impact of donor characteristics on the amount of donations. European Journal of Marketing, 31, 548-560.

Schwartz, R. A. (1970). Personal philanthropic contributions. Journal of Political Economy, 78, 1264-1291.

Schwartz, S. H. (1974). Awareness of interpersonal consequences, responsibility denial, and volunteering. Journal of Personality and Social Psychology, 30(1), 57-63.

Schwartz, S. H. (1975). The justice of need and the activation of humanitarian norms. Journal of Social Issues, 31(3), 111-136.

Serpe, R. T. (1987). Stability and change in self: A structural symbolic interactionist explanation. Social Psychology Quarterly, 50(1), 44-55.

Sheth, J. N., and Uslay, C. (2007). Implications of the revised definition of marketing: From exchange to value creation. Journal of Public Policy and Marketing, Vol. 22(2), 302-307.

Sheth, J.N., and Parvatiyar, A. (1995). Relationship marketing in consumer markets: Antecedents and consequences. Journal of the Academy of Marketing Science, 23(4), 255-271. 
Sheth, J.N., and Parvatiyar, A. (2000). The evolution of relationship marketing. In J.N. Sheth and A. Parvatiyar (Eds.). Handbook of relationship marketing. Thousand Oaks, CA: Sage Publications, Inc.

Simmons, W. O., and Emanuele, R. (2004). Does government spending crowd out donations of time and money? Public Finance Review, 32, 498-511.

Simon, A. F. (1997). Television news and international earthquake relief. Journal of Communication, 47(3), 82-93.

Slemrod, J. (1989). Are estimated tax elasticities really just tax evasion elasticities? The

Small, D. A., and Simonsohn, U. (2006). Friends of victims: Personal experience and prosocial behavior. Journal of Consumer Research, 35, 532-542.

Smith, A. $(2008,1776)$. An inquiry into the nature and causes of the wealth of nations. Oxford, UK: Oxford Paperbacks.

Smith, A. (2010, 1759). The theory of moral sentiments. New York: Penguin Books.

Smith, J. R., and McSweeney, A. (2007). Charitable giving: The effectiveness of. a revised theory of planned behaviour model in predicting donating intentions and behavior. Journal of Community and Applied Social Psychology, 17.

Smith, S. M., and Beik, L. L. (1982). Market segmentation for fund raisers. Journal of the Academy of Marketing Science, 10(3), 208-216.

Sokolowski, S. W. (1996). Show me the way to the next worthy deed: Towards a microstructural theory of volunteering and giving. Voluntas, 7, 259-278.

Söllner, A. (1994). Commitment in exchange relationships: the role of switching costs in building and sustaining competitive advantages. In Relationship Marketing: Theory, Methods, and Applications (Conference Proceedings), J. N. Sheth and A. Parvatiyar, (Eds.). Atlanta, GA: Emory University.

Solomon, M. R. (1983). The role of products as social stimuli: A symbolic interactionism perspective. Journal of Consumer Research, 10(3), 319-329.

Sprinkel Grace, K. (1997). Beyond fund raising: new strategies for nonprofit innovation and investment. New York, NY: John Wiley \& Sons, Inc.

Srnka, K. J., Grohs, R., and Eckler, I. (2003). Increasing fundraising efficacy by segmenting donors. Australasian Marketing Journal 11, 70-86.

Staub, E. (1978). Positive social behavior and morality: Social and personal influences. New York: Academic Press.

Staub, E., and Baer, R. S. (1974). Stimulus characteristics of a sufferer and difficulty of escape as determinants of helping. Journal of Personality and Social Psychology, $30,279-284$.

Steiger, J.H. (2007), "Understanding the limitations of global fit assessment in structural equation modeling," Personality and Individual Differences, 42 (5), 893-98.

Steiger, J.H. (2007), "Understanding the limitations of global fit assessment in structural equation modeling," Personality and Individual Differences, 42 (5), 893-98. 
Stryker, S. (1968). Identity salience and role performance: The importance of symbolic interaction theory for family research. Journal of Marriage and the Family, 30, 558-564.

Stryker, S. (1980). Symbolic interactionism: A social structural version. Menlo Park, CA: Benjamin Cummings.

Stryker, S., and Burke, P. J. (2000). The past, present and future of identity theory. Social Psychology Quarterly, 63, 284-297.

Stryker, S., and Serpe, R. T. (1982). Commitment, identity salience and role behavior: Theory and research examples. In W. Ickes and E. S. Knowles (Eds.) Personality, roles, and social behavior. New York: Springer-Verlag.

Sullivan, D. H. (1985). Simultaneous determination of church contributions and church attendance. Economic Inquiry, 23, 309-320.

Tabachnick, B.G.; Fidell, L.S. (2001). Using Multivariate Analysis. Boston, MA: Allyn and Bacon, Inc.

Talansky, J., and Deshmukh, A. (2011, March). 2011 state of the sector survey. Retrieved from http://nonprofitfinancefund.org/2011-state-sector-survey-national-summary

Thibaut, J.W., and Kelley, H. H. (1959). The social psychology of groups. New Brunswick, NJ: Transaction Books.

Thompson, B. (2004). Communalities. In The SAGE Encyclopedia of Social Science Research Methods. M.S. Lewis-Beck, A. Bryman and T. F. Liao (Eds.) Thousand oaks, CA: Sage Publications.

Tiehen, L. (2001). Tax policy and charitable contributions of money. National Tax Journal, 54, 707-723.

Todd, S. J., and Lawson, R. W. (1999). Towards a better understanding of the financial donor: An examination of donor behavior in terms of value structure and demographics. International Journal of Nonprofit and Voluntary Sector Marketing, 4, 235-244.

Tonkiss, F., and Passey, A. (2001). Trust, confidence and voluntary organisations: Between values and institutions. Sociology, 33(2), 257.

Trussell, J. M., and Parsons, L. M. (2007). Financial factors affecting donations to charitable organizations. Advances in Accounting, 23, 265-287.

U.S. Department of Veterans Affairs, Office of Public Affairs. (2010). State summary. Retrieved from U.S. Government website: http://www.va.gov/opa/publications/factsheets/ssvirginia.pdf

Unger, L. S. (1991). Altruism as a motivation to volunteer. Journal of Economic Psychology, 12, 71-100.

Van Diepen, M., Donkers, B., and Franses, P. H. (2009). Does irritation induced by charitable direct mailings reduce donations? International Journal of Research in Marketing, 26, 180-188. 
Van Slyke, D. M., and Brooks, A. C. (2005). Why do people give? New evidence and strategies for nonprofit managers. American Review of Public Administration 35, 199-222.

Vriens, M., Scheer, H., Hoekstra, J. C., and Bult, J. R. (1998). Conjoint experiments for direct mail response optimization. European Journal of Marketing, 32, 323-339.

Wagner, C., and Wheeler, L. (1969). Model, need, and cost effects in helping behaviour. Journal of Personality and Social Psychology, 12(2), 111-116.

Warwick, M. (2001). How to write successful fundraising letters. San Francisco: Jossey Bass.

Webber, D. (2004). Understanding charity fundraising events. International Journal of Nonprofit and Voluntary Sector Marketing, 9(2),122-134.

Weerts, D. J., and Ronca, J. M. (2007). Profiles of supportive alumni: Donors, volunteers, and those who "do it all." International Journal of Educational Advancement, $7(1), 20-34$.

Wegener, D. T., and Petty, R.E. (1994). Mood management across affective states: The hedonic contingency hypothesis. Journal of Personality and Social Psychology, 66(6), 1034-1048.

What Is High Impact Philanthropy?" Center for High Impact Philanthropy. School of Social Policy \& Practice, University of Pennsylvania. 24 April 2007. Retrieved online at http://www.impact.upenn.edu/about/highimpactphilanthropy.

Wheaton, B., Muthen, B., Alwin, D., F., and Summers, G. (1977). Assessing reliability and stability in panel models. Sociological Methodology, 8(1), 84-136.

Wiepking, P. (2008). Picturing generosity: National campaigns for charitable causes in the Netherlands. For the love of mankind. A sociological study on charitable giving (73-94). Unpublished doctoral dissertation, Department of Philanthropic Studies, VU University Amsterdam: Amsterdam, Netherlands.

Wiepking, P., and Heijnen, M. (2011). The giving standard: Conditional cooperation in the case of charitable giving. International Journal of Nomprofit and Voluntary Sector Marketing 16(1), 13-22.

Wiepking, P., and Maas, I. (2009, June). Resources that make you generous: Effects of human and social resources on charitable giving. Social Forces, 86, 1973-1996.

Wilhelm, M. O., Brown, E., Rooney, P. M., and Steinberg, R. S. (2006). The intergenerational transmission of generosity. Working paper, IUPUI.

Wilhelm, M. O., Brown, E., Rooney, P. M., and Steinberg, R. S. (2008). The intergenerational transmission of generosity. Journal of Public Economics, 92, 2146-2156.

Wilson, A., and Pimm, G. (1996). The tyranny of the volunteer: The care and feeding of voluntary workforces. Management Decision, 34(4), 24-40. 
Wu, S. Y., Huang, J. T., and Kao, A. P. (2004). An analysis of the peer effects in charitable giving: The case of Taiwan. Journal of Family and Economic Issues, $25,483-505$.

Yamauchi, N., and Yokoyama, S. (2005). What determines individual giving and volunteering in Japan? An econometric analysis using the 2002 national survey data. Presented at 34th ARNOVA Conference, Washington, D. C.

Yavas, U., Riecken, G., and Parameswaran, R. (1981). Personality, organization-specific attitude, and socio-economic correlates of charity giving behavior. Journal of the Academy of Marketing Science, 9(1), 52-65.

Yen, S. T. (2002). An econometric analysis of household donations in the USA. Applied Economics Letters, 9(13), 837-841.

Zaleski, P. A., and Zech, C. E. (1992). Determinants of contributions to religious organizations. Free riding and other factors. American Journal of Economics and Sociology, 51, 459-472.

Zaleski, P. A., and Zech, C. E. (1994). Economic and attitudinal factors in Catholic and Protestant religious giving. Review of Religious Research, 36, 158-167.

Zaleski, P. A., Zech, C. E., and Hoge, D. R. (1994). Determinants of religious giving in urban Presbyterian congregations. Review of Religious Research, 36, 197-206. 


\title{
APPENDIX A
}

\author{
"Individual Giving Survey Instrument"
}

\section{Introduction:}

Thank you for agreeing to participate in this study. Your participation is voluntary, and you can withdraw from the study at any time. Neither your identity nor the identity of the organization to which you make charitable donations will be revealed in the publication of research results.

This survey is part of a doctoral research project designed to examine charitable giving motivations, and test and extend recent nonprofit relationship marketing research, which has sought to explain why people give, why they continue to give to a specific nonprofit, and how nonprofits can manage their relationships with donors. Charitable giving is defined as "a (usually tax-deductible) gift made to a not-for-profit organization" (AFP, 2011). Charitable giving can include several types of resources such as gifts of time, effort, money, or goods and services; however, this study exclusively examines charitable gifts of money.

Your participation involves completing this survey, which should take 10-15 minutes. There are no known or anticipated risks to participation in this survey. The data will be summarized and no individual responses can be identified for reporting purposes.

The nature of this study should not be invasive or embarrassing. Questions are confined to ones that address your beliefs, perceptions, and/or demographics. Any information provided by you in the study will be afforded professional standards for protection of confidentiality.

By completing this study, you are consenting to the terms of this research as stated above. This notice serves as your copy of the consent agreement. You may also request a copy of these consent terms by contacting the Principal Investigator of the study. This study has been reviewed by, and received clearance through, the Human Subjects Research Committee at Old Dominion University.

If you have any questions about the study, please contact the Principal Investigator:

William Leavitt, Principal Investigator

Department of Urban Studies and Public Administration, College of Business and Public Administration

Old Dominion University

2092 Constant Hall, Norfolk, Virginia 23529

757-683-5695,wleavitt@,odu.edu

Jennifer A. Taylor, Co-Principal Investigator Department of Urban Studies and Public Administration College of Business and Public Administration 
Old Dominion University 2092 Constant Hall, Norfolk, Virginia 23529

757-683-5695, jtayl078@odu.edu

If you have any questions regarding your rights as a research subject contact the Human Subjects Research Committee Chair at irbcbpa@odu.edu or 757-683-5109.

Thank you for taking the time to take this short survey on charitable donations.

S1. Have you personally, made a charitable donation to a non-for-profit organization in the past two years? By charitable donation, we mean voluntary gifts of money to a charity, social institution, associations and foundations, as well as financial donations to relief campaigns and sponsorships.

- Yes

- No-Terminate

S2. Thinking about the nonprofit organization you made the most donations to in the past two years, how many donations did you make to that nonprofit organization?

- 1 - Terminate

- $2-3$

- $4+$

- Unsure, but more than once in the past two years

S2. In the past two years, have you made two or more donations to the same nonprofit organization?

- Yes

- No-Terminate

In this survey, you will be asked about two or more of your personal (individual, not household) charitable donations to a nonprofit organization over the past two or more years. Think about the nonprofit to which you have made two or more financial contributions in the past two years.

Please consider this nonprofit when answering the following questions.

1. What is the name of the nonprofit organization that you made two or more charitable gifts to over the past two years?

2. To the best of your knowledge, what type of nonprofit organization is $(\mathrm{X})$ ? (Select one)

- Religious

- Education

- Foundation

- Human services

- Health

- Public-society benefit (relief)

- Arts, culture, and humanities 

- International affairs
- Environment/animals
- Military support organizations
Other (open field)

3. To the best of your knowledge, what is the size of the nonprofit organization?
o Small
- Medium
- Large

4. To the best of your knowledge, during the past 12 months, how much did you donate in total to $(\mathrm{X})$ ? Please include donations through direct mail, online, tickets to special events, raffles, sponsorships, and team fundraising events. Do not include donations to capital (buildings, facilities) campaigns.

$\$$

5. In the past 12 months, how frequent were your donations to (X)?
- Once
- 2 to 3 times per year
- 4 to 8 times per year
- Monthly
- Weekly

6. How long have you been a donor of $(\mathrm{X})$ ?
- Less than 1 year
- $1-3$ years
- 3-5 years
- More than 5 years

7. When thinking of the future and this charity, how much do you agree or disagree with the following statements on a scale from 1 to 7 , where 1 means Strongly disagree and 7 means Strongly agree?

- I am likely to donate to the charity in question.

- I will donate the next time.

- I will definitely donate.

- I will recommend the charity to others to donate.

Please rate the following statements on a scale from 1 to 7 , where 1 means Strongly disagree and 7 means Strongly agree?

8. Donating to $(X)$ is something I rarely think about. (R)

9. I would feel a loss if I were forced to give up donating to $(X)$.

10. I really don't have clear feelings about $(\mathrm{X})$ donation. $(\mathrm{R})$

11. For me, being a donor means more than just giving money.

12. Donating to $(X)$ is an important part of who I am. 
13. I feel confident that $X$ is using my monies appropriately.

14. $X$ 's communications are always courteous.

15. $X$ 's employees have the best interests of society at heart.

16. $X$ is the charity most likely to have an impact on this cause.

17. When $X$ promises to provide a service to society, it does so.

18. I feel safe in my transactions with $X$.

19. Their communications are visually appealing.

20. $X$ keeps me informed about how my monies are being used.

21. Employees in $X$ are always courteous

22. $X$ 's communications are always timely.

23. The behavior of X's employees instills confidence.

24. Employees in $X$ have the knowledge to answer my questions.

25. $X$ 's employees have the best interests of their supporters at heart.

26. $X$ makes me feel that it is always willing to help me if $I$ have a question.

27. Employees at $X$ are never too busy to speak with me.

28. $\mathrm{X}$ always responds promptly to requests I might have for information.

29. $X$ gives me individual attention.

30. $X$ writes to me at the times of the year I find most convenient.

31. Employees of $X$ seem to understand my specific needs.

32. When $I$ have a problem, $X$ shows an interest in solving it.

33. How often do you attend church or other religious places of worship, such as temples, mosques, or synagogues? (Select One)

- More than once per week

- Once a week

- A couple of times a month

- Once a month

- Less than once a month

- A couple of times a year

- Never

Please rate the following statements on a scale from 1 to 7, where 1 means Strongly disagree and 7 means Strongly agree?

34. We should leave the world in a good state for the following generation

35. Society is endangered because people increasingly care less about each other.

36. The world needs responsible citizens.

37. My faith has a lot of influence on my life.

Please rate the following statements on a scale from 1 to 7, where 1 means Strongly disagree and 7 means Strongly agree?

38. I would trust this nonprofit to always act in the best interest of the cause.

39. I would trust this nonprofit to conduct their operations ethically.

40. I would trust this nonprofit to use donated funds appropriately. 
41. I would trust this nonprofit not to exploit their donors.

42. I would trust this nonprofit to use fundraising techniques that are appropriate and sensitive.

43. (X)'s need for financial support from its donors will be even greater in the future.

44. Nonprofit organizations that receive some public funding need the financial support of their donors just as much as those nonprofits that do not.

45. (X) presently needs strong financial support from its donors.

46. This nonprofit is the nonprofit most likely to have an impact on this cause.

47. This nonprofit spends a high proportion of its income on this cause.

48. When I give to this nonprofit I receive some benefit in return for my donation.

49. I give to this nonprofit to gain local prestige.

50. I donate money to this nonprofit to receive their publications.

51. Contributing to this nonprofit enables me to obtain recognition.

52. I may one day benefit from the work this organization undertakes:

53. I often give to this nonprofit because I would feel guilty if I didn't.

54. If I never gave to this nonprofit I would feel bad about myself.

55. I give money to this nonprofit in memory of a loved one.

56. I felt that someone I know might benefit from my support.

57. My family had a strong link to this nonprofit.

On a scale from 1 to 7 , where 1 means Strongly disagree and 7 means Strongly agree, How much do you agree that $(X)$ does a good job of ...

58. Asking for appropriate levels of support.

59. Leaving it to me how much to donate.

60. Thanking me for my support.

61. Responding quickly when I contact them.

62. Demonstrating they care about their supporters.

63. Being polite in all their communications.

64. Informing me about how money is spent.

65. Not asking me for support too often.

66. Making me feel important.

Please rate the following statements on a scale from 1 to 7 , where 1 means Strongly disagree and 7 means Strongly agree.

67. My parents rarely donated money to charitable causes. (R)

68. My father treated his job as one in which he tried to help other people.

69. My parents actively participated in volunteer organizations (such as the Red Cross, March of Dimes, etc.)

70. My mother treated her job (in home and/or out-of home) as one in which she helped other people.

71. In my family, we always helped one another.

72. My parents very frequently donated money to people who collected money door to door (Such as March of Dimes, Heart Fund, etc.)

73. Concerning strangers experiencing distress, my parents generally thought that it 
was more important to "not to get involved." $(R)$

74. My parents frequently discussed moral values with me (values like the "Golden Rule," etc.)

75. When I was growing up, my parents told me I should be willing to "lend a helping hand."

76. My parents often urged me to donate money to charities.

77. When I was younger, my parents very often urged me to get involved with volunteer projects for children (for example, UNICEF, walkathons, etc.)

Thank you for your participation. If you have any questions, concerns, or would like to see the final product for this research project, please contact William Leavitt, wleavitt@odu.edu 


\section{APPENDIX B}

"Hypotheses and Constructs"

\begin{tabular}{|c|c|c|c|}
\hline Hypothesis & $\begin{array}{l}\text { Construct / } \\
\text { Variable }\end{array}$ & $\begin{array}{c}\text { Survey } \\
\text { Questions }\end{array}$ & $\begin{array}{c}\text { Source \& } \\
\text { Reliability in this } \\
\text { study }\end{array}$ \\
\hline $\begin{array}{l}\text { Questions } 4-7 \text { are used to } \\
\text { measure the dependent } \\
\text { variable, charitable giving. }\end{array}$ & Charitable Giving & $\begin{array}{c}\text { Questions } \\
4-7\end{array}$ & $\begin{array}{l}\text { Ranganathan and } \\
\text { Henley, }(2007) \\
\text { Reliability }=.905\end{array}$ \\
\hline $\begin{array}{l}\text { H1: The greater the identity } \\
\text { saliency of a donor, the } \\
\text { greater the level of } \\
\text { charitable giving of the } \\
\text { donor. }\end{array}$ & Identity Saliency & $\begin{array}{l}\text { Questions } \\
8-12\end{array}$ & $\begin{array}{l}\text { Callero, }(1985) \\
\text { Reliability }=.709\end{array}$ \\
\hline $\begin{aligned} \mathrm{H} 2: & \text { The greater the relationship } \\
& \text { satisfaction of a donor, the } \\
& \text { greater the level of } \\
& \text { charitable giving of the } \\
& \text { donor. }\end{aligned}$ & $\begin{array}{l}\text { Relationship } \\
\text { Satisfaction }\end{array}$ & $\begin{array}{l}\text { Questions } \\
13-32\end{array}$ & $\begin{array}{l}\text { Sargeant, (2001) } \\
\text { Parasuraman, } \\
\text { Zeithaml, and } \\
\text { Berry (1988) } \\
\text { Reliability }=.969 \\
\end{array}$ \\
\hline $\begin{array}{l}\text { H3: The greater the identity } \\
\text { saliency and the } \\
\text { relationship satisfaction, } \\
\text { the greater the level of } \\
\text { charitable giving of the } \\
\text { donor. }\end{array}$ & $\begin{array}{l}\text { Identity Saliency } \\
\text { and Relationship } \\
\text { Satisfaction }\end{array}$ & $\begin{array}{c}\text { Questions } \\
8-32\end{array}$ & $\begin{array}{l}\text { Callero, }(1985) \\
\text { Reliability }=.709 \\
\text { Sargeant, }(2001) \\
\text { Parasuraman, } \\
\text { Zeithaml, and } \\
\text { Berry }(1988) \\
\text { Reliability }=.969\end{array}$ \\
\hline $\begin{aligned} \text { H4: } & \text { Donors with a higher level } \\
& \text { of trust in a nonprofit } \\
& \text { organization will be more } \\
& \text { satisfied with the } \\
& \text { relationship with the } \\
& \text { nonprofit organization. }\end{aligned}$ & Trust & $\begin{array}{c}\text { Questions } \\
38-42\end{array}$ & $\begin{array}{l}\text { Sargeant, Ford, \& } \\
\text { West, (2006) } \\
\text { Reliability }=.937\end{array}$ \\
\hline $\begin{array}{l}\text { H5: The greater the perceived } \\
\text { financial need for the } \\
\text { nonprofit organization, the } \\
\text { higher the identity salience } \\
\text { for the donor. }\end{array}$ & $\begin{array}{c}\text { Perceived } \\
\text { Financial Need }\end{array}$ & $\begin{array}{c}\text { Questions } \\
43-45\end{array}$ & $\begin{array}{l}\text { Arnett, German, \& } \\
\text { Hunt, }(2003) \\
\text { Reliability }=.724\end{array}$ \\
\hline $\begin{array}{l}\text { H6: The greater the perceived } \\
\text { financial need for the } \\
\text { nonprofit organization, the } \\
\text { higher the relationship } \\
\text { satisfaction for the donor. }\end{array}$ & $\begin{array}{c}\text { Perceived } \\
\text { Financial Need }\end{array}$ & $\begin{array}{l}\text { Questions } \\
43-45\end{array}$ & $\begin{array}{l}\text { Arnett, German, \& } \\
\text { Hunt, (2003) } \\
\text { Reliability }=.724\end{array}$ \\
\hline $\begin{aligned} & \text { H7: } \text { The greater the perceived } \\
& \text { organizational } \\
& \text { performance, the greater } \\
& \text { the identity salience of the }\end{aligned}$ & $\begin{array}{c}\text { Perceived } \\
\text { Organizational } \\
\text { Performance }\end{array}$ & $\begin{array}{c}\text { Questions } \\
46-47\end{array}$ & $\begin{array}{l}\text { Sargeant, Ford \& } \\
\text { West, }(2006) ; \\
\text { Reliability }=.721\end{array}$ \\
\hline
\end{tabular}




\begin{tabular}{|c|c|c|c|c|}
\hline \multicolumn{5}{|c|}{ donor. } \\
\hline H8: & $\begin{array}{l}\text { The greater the perceived } \\
\text { organizational } \\
\text { performance, the greater } \\
\text { the relationship satisfaction } \\
\text { of the donor. }\end{array}$ & $\begin{array}{c}\text { Perceived } \\
\text { Organizational } \\
\text { Performance }\end{array}$ & $\begin{array}{c}\text { Questions } \\
46-47\end{array}$ & $\begin{array}{l}\text { Sargeant, Ford \& } \\
\text { West, (2006); } \\
\text { Reliability }=.721\end{array}$ \\
\hline H9: & $\begin{array}{l}\text { Reciprocity in } \\
\text { demonstrable utility will } \\
\text { relate positively to } \\
\text { charitable giving mediated } \\
\text { by identity saliency and } \\
\text { relationship satisfaction. }\end{array}$ & $\begin{array}{c}\text { Demonstrable } \\
\text { Utility }\end{array}$ & $\begin{array}{c}\text { Questions } \\
48-52\end{array}$ & $\begin{array}{l}\text { Sargeant, Ford, \& } \\
\text { West, }(2006) \\
\text { Reliability }=.71\end{array}$ \\
\hline & $\begin{array}{l}\text { Reciprocity in emotional } \\
\text { utility will relate positively } \\
\text { to charitable giving } \\
\text { mediated by identity } \\
\text { saliency and relationship } \\
\text { satisfaction. }\end{array}$ & Emotional Utility & $\begin{array}{c}\text { Questions } \\
53-54\end{array}$ & $\begin{array}{l}\text { Sargeant, Ford, \& } \\
\text { West, }(2006) ; \\
\text { Reliability }=.768\end{array}$ \\
\hline & $\begin{array}{l}\text { Reciprocity in familial } \\
\text { utility will relate positively } \\
\text { to charitable giving } \\
\text { mediated by identity } \\
\text { saliency and relationship } \\
\text { satisfaction. }\end{array}$ & Familial Utility & $\begin{array}{c}\text { Questions } \\
55-57\end{array}$ & $\begin{array}{l}\text { Sargeant, Ford, \& } \\
\text { West, }(2006) ; \\
\text { Reliability }=.622\end{array}$ \\
\hline & $\begin{array}{l}\text { The greater the satisfaction } \\
\text { with the solicitation } \\
\text { process, the greater the } \\
\text { identity saliency of the } \\
\text { donor. }\end{array}$ & Solicitation & $\begin{array}{c}\text { Questions } \\
58-66\end{array}$ & $\begin{array}{l}\text { Sargeant (2001); } \\
\text { Reliability }=.919\end{array}$ \\
\hline & $\begin{array}{l}\text { The greater the satisfaction } \\
\text { with the solicitation } \\
\text { process, the greater the } \\
\text { relationship satisfaction of } \\
\text { the donor. }\end{array}$ & Solicitation & $\begin{array}{c}\text { Questions } \\
58-66\end{array}$ & $\begin{array}{l}\text { Sargeant }(2001) \\
\text { Reliability }=.919\end{array}$ \\
\hline & $\begin{array}{l}\text { The greater the parental } \\
\text { socialization and youth } \\
\text { participation, the greater } \\
\text { the identity saliency of the } \\
\text { donor. }\end{array}$ & $\begin{array}{c}\text { Parental } \\
\text { Socialization \& } \\
\text { Youth } \\
\text { Participation }\end{array}$ & $\begin{array}{c}\text { Questions } \\
67-77\end{array}$ & $\begin{array}{l}\text { Perry (1997), } \\
\text { Clary \& Miller } \\
(1986) \\
\text { Reliability }=.866\end{array}$ \\
\hline & $\begin{array}{l}\text { The greater the parental } \\
\text { socialization and youth } \\
\text { participation, the greater } \\
\text { the relationship satisfaction } \\
\text { of the donor. }\end{array}$ & $\begin{array}{c}\text { Parental } \\
\text { Socialization \& } \\
\text { Youth } \\
\text { Participation }\end{array}$ & $\begin{array}{c}\text { Questions } \\
67-77\end{array}$ & $\begin{array}{l}\text { Perry, (1997), } \\
\text { Clary \& Miller, } \\
(1986) \\
\text { Reliability }=.866\end{array}$ \\
\hline
\end{tabular}




\title{
APPENDIX C
}

\author{
“Moderator's Guide”
}

\section{Focus Group Schedule}

Introduction

Statement of Rules \& Guidelines

Short Question and Answer Discussion

Giving motivations

Repeat giving

Barriers to giving

Total
5 minutes

10 minutes

50 minutes

15 minutes

15 minutes

10 minutes

10 minutes

65 minutes

\section{Introduction}

My name is Jennifer Taylor, I am a doctoral candidate at Old Dominion University in the College of Business and Public Administration. Your participation in this focus group is part of my dissertation on measuring the relationship between donor motivations and donor giving. There is also an observer, also a PhD student at ODU, sitting in the back of the room. The observer's role is to take detailed field notes during the focus group. The purpose of this focus group is to understand the various motivations for charitable giving in Hampton Roads, really to understand 'why' people give and continue to give to nonprofit organizations. The results from today's discussion will be used to develop a survey instrument that will measure the relationship between donor motivations and donor giving in a sample population from Hampton Roads later this year.

\section{Statement of Rules and Guidelines}

A focus group is a group discussion that produces a dynamic conversation, which leads to an in-depth exploration of the topic - donor motivations and donor/nonprofit relationships. My expectation of this process is for an open, polite and orderly environment where everyone is encouraged to participate. This focus group is expected to last about one hour and will begin by the moderator asking questions and follow up questions to stimulate a free-flowing conversation about the topic. I will toss out questions to the group and open it up for discussion and/or I may ask questions individually and then we will discuss. Everyone may have a different opinion or answer and I want to hear it all. There will be a digital audio recording device in use, which will record the focus group interview, and the data will be confidentially transcribed for analysis. Participating in this focus group brings a risk for potential embarrassment, discomfort, and potential emotional distress. What is discussed here is expected to stay confidential within the members of the group. By participating, you are agreeing to hold the information confidential. You should not participate if you think that you cannot maintain the confidentiality. It is okay to leave the room, at any time, if you feel uncomfortable. Do you understand the project and your role in the research?

First, let's go around the room, introduce ourselves, first name only please, and tell the group how you came to live in Hampton Roads. 


\section{Short Question and Answer Discussion}

\section{Giving motivations}

What are some of the reasons that you have decided to make a donation to a nonprofit organization?

When you make a donation do you:

- Feel good about it?

- Give to effect a change?

- Understand the individual need?

- Understand why the cause is important?

- Expect recognition for your gift?

- Am proud of donating to the nonprofit?

- Think your friends also give to the nonprofit?

Warm feeling or glow

Desire to cause social change

Empathy, sympathy

Belief in the mission

Prestige, Recognition

Respect

Peer pressure

- Receive a monetary or economic benefit by giving, i.e. sponsorship, perks, benefits? Economic, Reciprocity

- Give because someone close to you has been affected by the cause?

Familial

\section{Repeat giving}

Have you made more than one donation to the same nonprofit organization?

Is there anything that stands out as influencing you to make a repeat donation?

Does the nonprofit:

- Value your contribution?

- Appreciate your extra effort to volunteer or give?

- Listen to any concerns you may have?

- Recognizes you when you do something for or give something to the nonprofit?

- Provides you with information on how my gift is being used?

- Use organizational resources appropriately?

\section{Barriers or deterrents to charitable giving}

Can you think of a time when you wanted to make a donation but did not?

Had you made donations previously to that organization?

What reasons do you think caused you not to become a repeat donor?

- Financial?

- Other more deserving causes?

- Death or relocation?

- Lack of recognition of gift?

- Information about gift was used?

(Follow up list derived from Sargeant, 2001)

\section{Attitudes about giving}

Of the organizations that you give to on a regular basis, why do you keep giving to them?

Can you describe your relationship with the organization?

How are your charitable gifts valued, recognized, thanked?

Do you think the money given to nonprofit organizations is for good causes?

Do you think that the nonprofits perform a useful function for society? 
Do you think that nonprofit organizations have been successful in helping the needy? Is money donated to nonprofit organizations wasted?

(Webb, Green, Brashear, 2000)

\section{Close}

Is there anything we missed that you would like to talk about?

What is the most important point we discussed? 


\section{APPENDIX D}

"Informed Consent"

PROJECT TITLE: Relational Exchange in Nonprofits: The Role of Identity Saliency and Relationship Satisfaction

\section{INTRODUCTION}

The purposes of this form are to give you information that may affect your decision whether to say YES or NO to participation in this research, and to record the consent of those who say YES. The focus groups for the Relational Exchange in Nonprofits study will be conducted, here in the conference room (location will vary based on group).

\section{RESEARCHERS}

Jennifer A. Taylor, M.A.

William Leavitt, Ph.D.

College of Business and Public Administration

Department of Urban Studies and Public Administration

\section{DESCRIPTION OF RESEARCH STUDY}

Several studies have been conducted looking into the subject of why people make charitable donations. None of them have explained the role of identification with the cause and relationship satisfaction and their impact on giving.

If you decide to participate, then you will join a study involving participation in a focus group, which is similar to a group discussion of charitable giving by individuals. This research is non-experimental in nature and will be confidentially recorded in a digital audio format. If you say YES, then your participation will last for approximately 60 minutes in this location. Approximately 7-9 other individuals with similar experiences will be participating in this study.

\section{EXCLUSIONARY CRITERIA}

You should have completed the initial questionnaire prior to this. To the best of your knowledge, you have made a charitable donation to a nonprofit organization within the last 24 months to participate in this study.

\section{RISKS AND BENEFITS}

RISKS: If you decide to participate in this study, then you may face a risk of social or emotional distress in discussing your past experiences with charitable giving. You may experience some discomfort in being audio recorded. There is also a risk of breech of confidentiality due to the other participants in the focus group. In addition to the facilitator, there is an observer in the room whose role is to take detailed, confidential field notes. The researcher tried to reduce these risks by asking participants to keep the discussion confidential and to treat each other with respect during the discussion. And, as with any research, there is some possibility that you may be subject to risks that have not yet been identified. If for any reason, you are uncomfortable with the research, you are 
free to leave the room and the study at any time.

Participating in this focus group brings a risk for potential embarrassment, discomfort, and potential emotional distress. What is discussed here is expected to stay confidential within the members of the group. By participating, you are agreeing to hold the information confidential. You should not participate if you think that you cannot maintain the confidentiality.

BENEFITS: The main benefit to you for participating in this study is a boxed lunch. Others may benefit by gaining further insight into their charitable giving behaviors.

\section{COSTS AND PAYMENTS}

The researchers want your decision about participating in this study to be absolutely voluntary. Yet they recognize that your participation may pose some inconvenience. In order to minimize that, you will receive a boxed lunch. The researchers are unable to give you any additional payment for participating in this study.

\section{NEW INFORMATION}

If the researchers find new information during this study that would reasonably change your decision about participating, then they will give it to you.

\section{CONFIDENTIALITY}

All information obtained about you in this study is strictly confidential unless law requires disclosure. The results of this study may be used in reports, presentations and publications, but the researcher will not identify you.

\section{WITHDRAWAL PRIVILEGE}

It is OK for you to say NO. Even if you say YES now, you are free to say NO later, and walk away or withdraw from the study -- at any time. Your decision will not affect your relationship with Old Dominion University, or otherwise cause a loss of benefits to which you might otherwise be entitled.

\section{COMPENSATION FOR ILLNESS AND INJURY}

If you say YES, then your consent in this document does not waive any of your legal rights. However, in the event of harm, injury, or illness arising from this study, neither Old Dominion University nor the researchers are able to give you any money, insurance coverage, free medical care, or any other compensation for such injury. In the event that you suffer injury as a result of participation in any research project, you may contact Dr. William Leavitt at 757-683-5695, who will be glad to review the matter with you.

\section{VOLUNTARY CONSENT}

By signing this form, you are saying several things. You are saying that you have read this form or have had it read to you, that you are satisfied that you understand this form, the research study, and its risks and benefits. The researchers should have answered any questions you may have had about the research. If you have any questions later on, then the researchers should be able to answer them: 
Jennifer A. Taylor

$361-779-2392$

Dr. William Leavitt

If at any time you feel pressured to participate, or if you have any questions about your rights or this form, then you should call Dr. Adam Rubenstein Director of Research Compliance, at 757-683-3686, or the Old Dominion University Office of Research, at 757-683-3460.

And importantly, by signing below, you are telling the researcher YES, that you agree to participate in this study. The researcher should give you a copy of this form for your records.

INVESTIGATOR'S STATEMENT I certify that I have explained to this subject the nature and purpose of this research, including benefits, risks, costs, and any experimental procedures. I have described the rights and protections afforded to human subjects and have done nothing to pressure, coerce, or falsely entice this subject into participating. I am aware of my obligations under state and federal laws, and promise compliance. I have answered the subject's questions and have encouraged him/her to ask additional questions at any time during the course of this study. I have witnessed the above signature(s) on this consent form.

Subject's Printed Name \& Signature

Date

Investigator's Printed Name \& Signature

Date 


\section{APPENDIX E}

"Recruitment Flyer"

Do you make donations to charity?

\section{FOCUS GROUP}

"Relational Exchange in Nonprofits"

FREE LUNCH FOR

PaRTICIPANTS

Jennifer A. Taylor, Doctoral Candidate in the College of Business and Public Administration at ODU, is sponsoring a series of focus groups to learn why people give to charity and why they make repeat donations.

If you have a made a donation, cash or in-kind, to a nonprofit organization in the past 24 months, you are invited to join a small group of other donors to discuss your giving motivations and experiences with nonprofit organizations. The audio-recorded feedback from the focus groups will be used to develop a survey of donors.

Time: $\quad 12$ Noon $-130 \mathrm{pm}$

When: $\quad$ Thursday, September 8, 2011

Where:

To learn more and to reserve your space in one of the focus groups, please email Jennifer A. Taylor, jtayl078@odu.edu 


\section{APPENDIX F}

"Recruitment Flyer"

Do you make donations to charity?

FOCUS GROUP

"Relational Exchange in Nonprofits"

FREE LUNCH FOR

PARTICIPANTS

Jennifer A. Taylor, Doctoral Candidate in the College of Business and Public Administration at ODU, is sponsoring a series of focus groups to learn why people give to charity and why they make repeat donations.

If you have a made a donation, cash or in-kind, to a nonprofit organization in the past 24 months, you are invited to join a small group of other donors to discuss your giving motivations and experiences with nonprofit organizations. The audio-recorded feedback from the focus groups will be used to develop a survey of donors.

Time: $\quad 12$ Noon $-130 \mathrm{pm}$

When: Tuesday, September 6, 2011

Where:

To learn more and to reserve your space in one of the focus groups, please email Jennifer A. Taylor, jtay1078@odu.edu 


\section{APPENDIX F}

\section{"Codebook"}

\begin{tabular}{|l|l|l|}
\hline I & Identification & 25 \\
\hline ASK & Way in which asked, asked, authenticity of \\
ask & 21 \\
\hline PN & Perceived need & 18 \\
\hline OEffi & Organizational efficiency & 18 \\
\hline GB & Giving back & 17 \\
\hline PS & Parental socialization & 15 \\
\hline OEffe & Organizational effectiveness & 12 \\
\hline REC & Recognition & 11 \\
\hline A & Altruism & 10 \\
\hline PB & Perceived benefits & 10 \\
\hline E2G & Easy to give & 9 \\
\hline R & Religion & 8 \\
\hline COM & Communications & 8 \\
\hline MD & Making a difference & 6 \\
\hline ES & Economic Situation & 6 \\
\hline OC & Other cause & 3 \\
\hline PP & Peer pressure & 3 \\
\hline F & Familial & 2 \\
\hline S & Spouse & 2 \\
\hline TD & Tax deduction & 3 \\
\hline STA & Status & 2 \\
\hline PRE & Prestige & 2 \\
\hline SCD & Scandal & 2 \\
\hline
\end{tabular}




\section{APPENDIX H}

\section{"IRB Certificate of Approval"}

\section{(i) \\ OLDDOMINION \\ UN \\ IDEA FusioN}

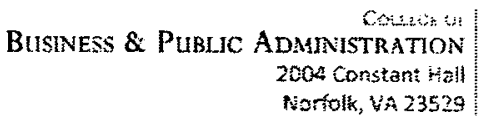

757.683 .3520

\section{Certificate of Approval}

Date:

Responsible Project Investigator (RPI):

Co-Investigator:

Proposal Number:

Effective Date:

Expiration Date:

Exemption Category:

Title:
9/5/11

William Leavitt

Jennifer A. Taylor

003

9/5/11

9/5/12

6.2

Relational Exchange in Nonprofits: The Role of Identity Saliency and Relationship Satisfaction

All IRB Approved Investigators must comply with the following:

- For the duration of your protocol, any change in the experimental design/Consent and/or Assent Form must be approved by the IRB before implementation of the changes.

- Use only a copy of the IRB signed and dated Consent and/or Assent Form. The investigator bears the responsibility for obtaining from all subjects "Informed Consent" as approved by the IRB. The IRB requires that the subject be given a copy of the Consent and/or Assent Form. Consent and/or Assent Forms must include the name and the telephone number of the investigator.

- Provide non-English speaking subjects with a certified translation of the approved Consent and/ or Assent Form in the subject's first language.

- The investigator also bears the responsibility for informing the IRB immediately of any unanticipated problems that are unexpected and related to the study in accordance with IRB Policy and Procedures.

- Obtain IRB approval for all advertisements, questionnaires and surveys before use.

- Federal regulations require a Continuing Review to renew approval of this project within a 12 month period from the last approval date unless otherwise indicated in the review cycle listed below. If you have any restricted/high risk protocol, specific details will be outlined in this letter. Non-compliance with Continuing Review will result in termination of this study.

You will be sent a Continuing Review reminder 75 days prior to the expiration date. Any questions regarding this IRB action can be referred to the CBPA College IRB Chair at 757-683-5109.

Sincerely, 


\section{APPENDIX I}

Proposed Measurement Model

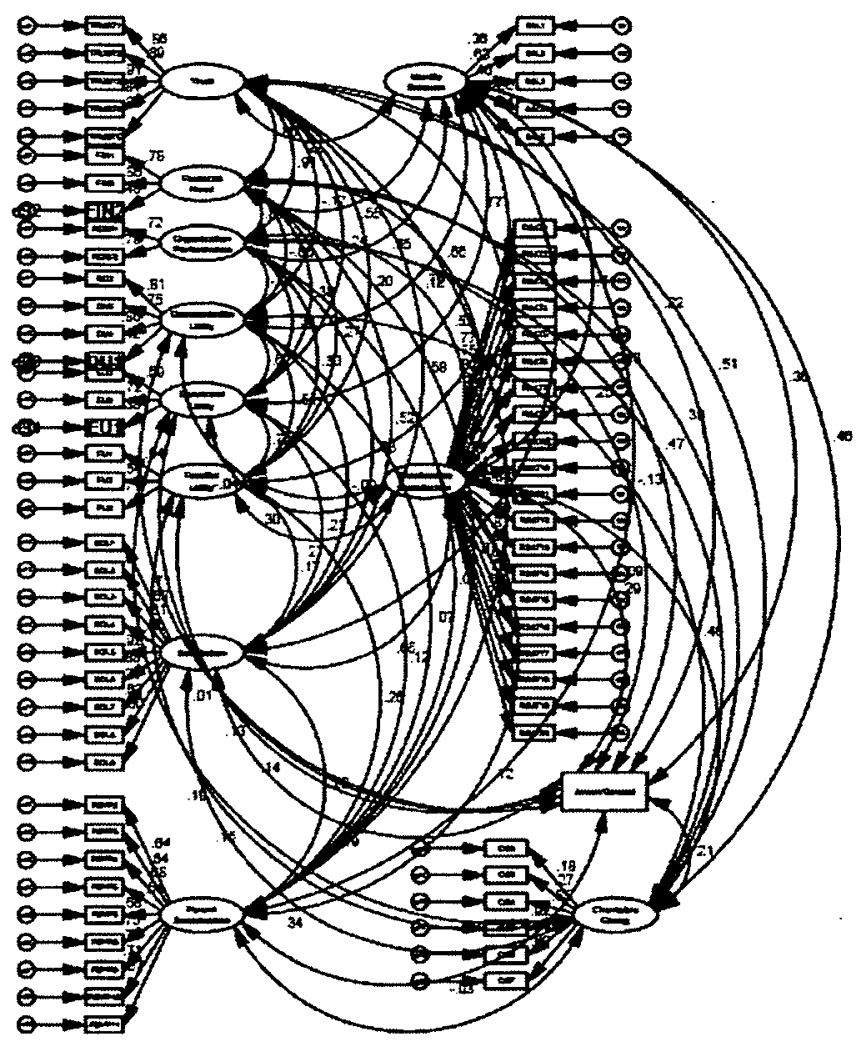


APPENDIX J

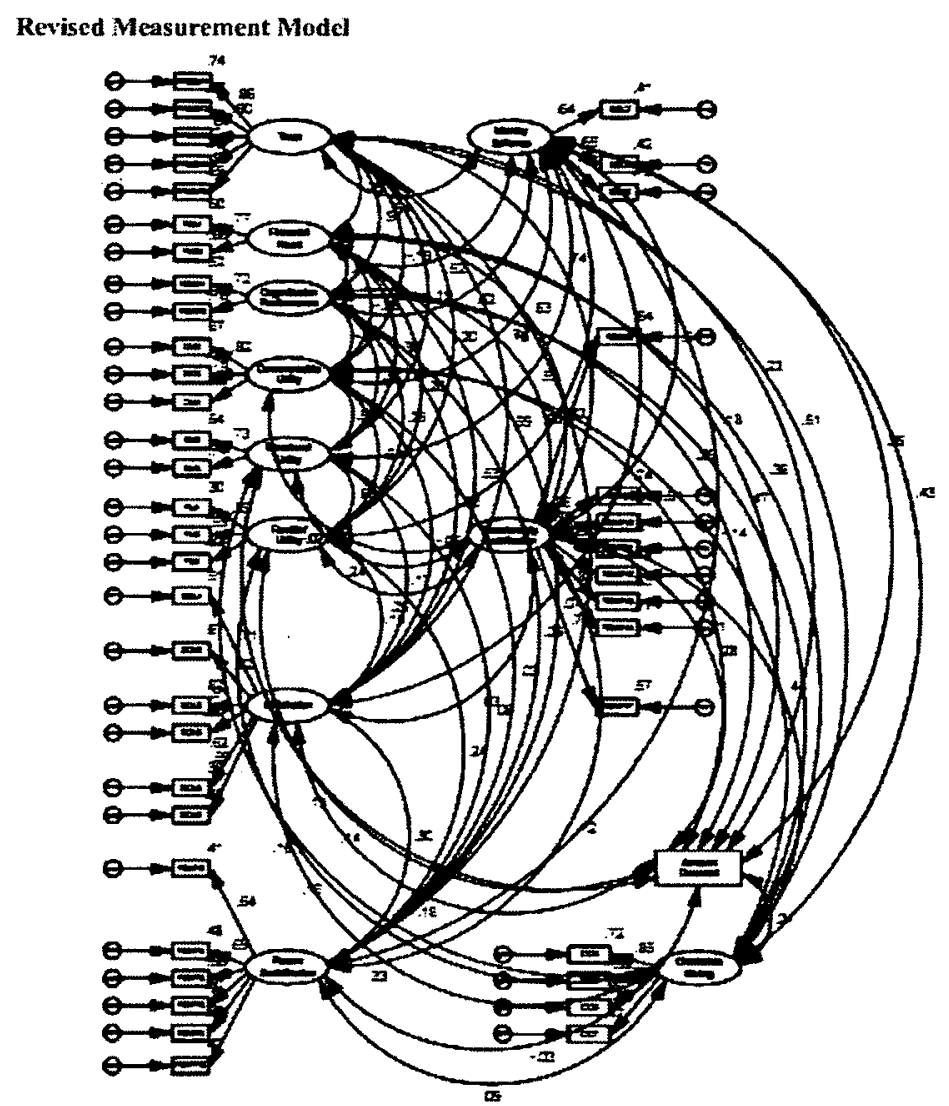


APPENDIX K

Proposed Structural Model

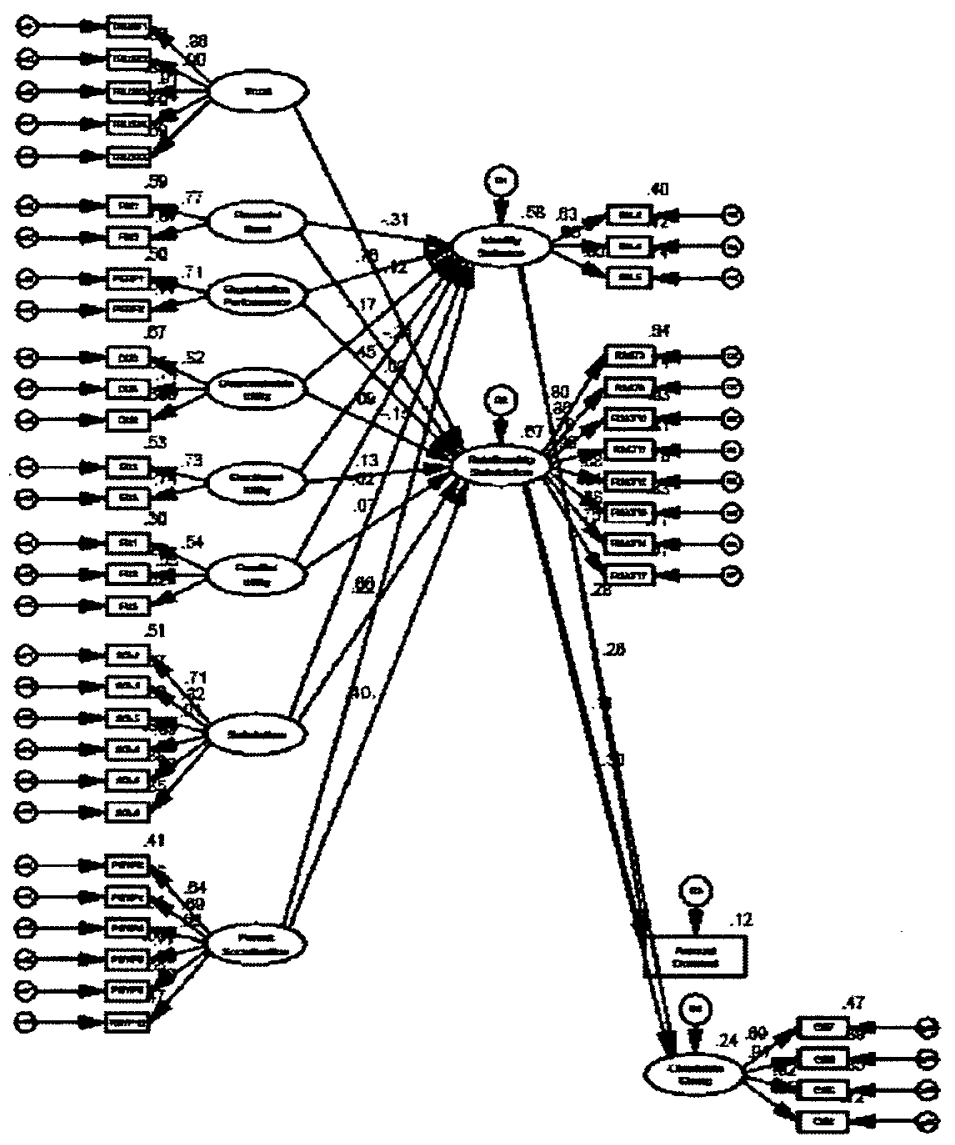




\section{APPENDIX L}

Structural Model without Identity Saliency and Relationship Satisfaction

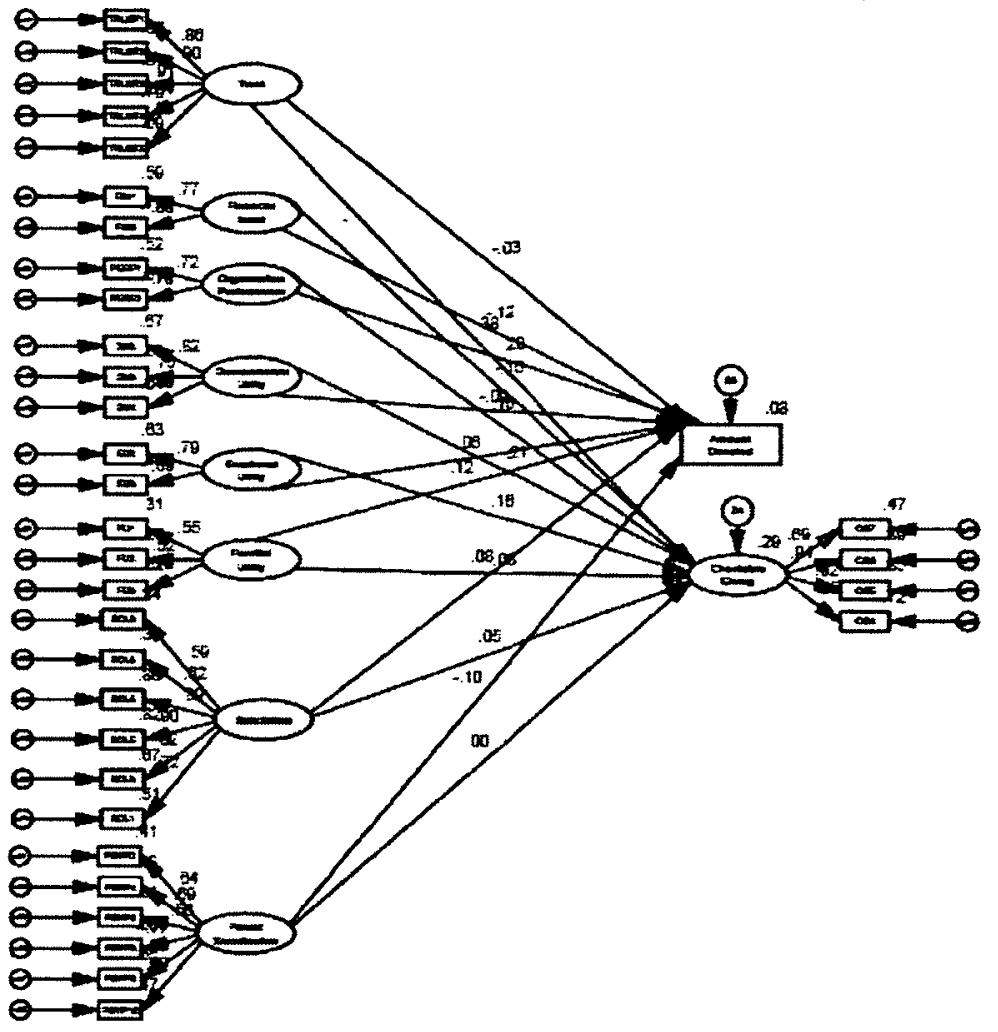


APPENDIX M

Structural Model with only Identity Saliency

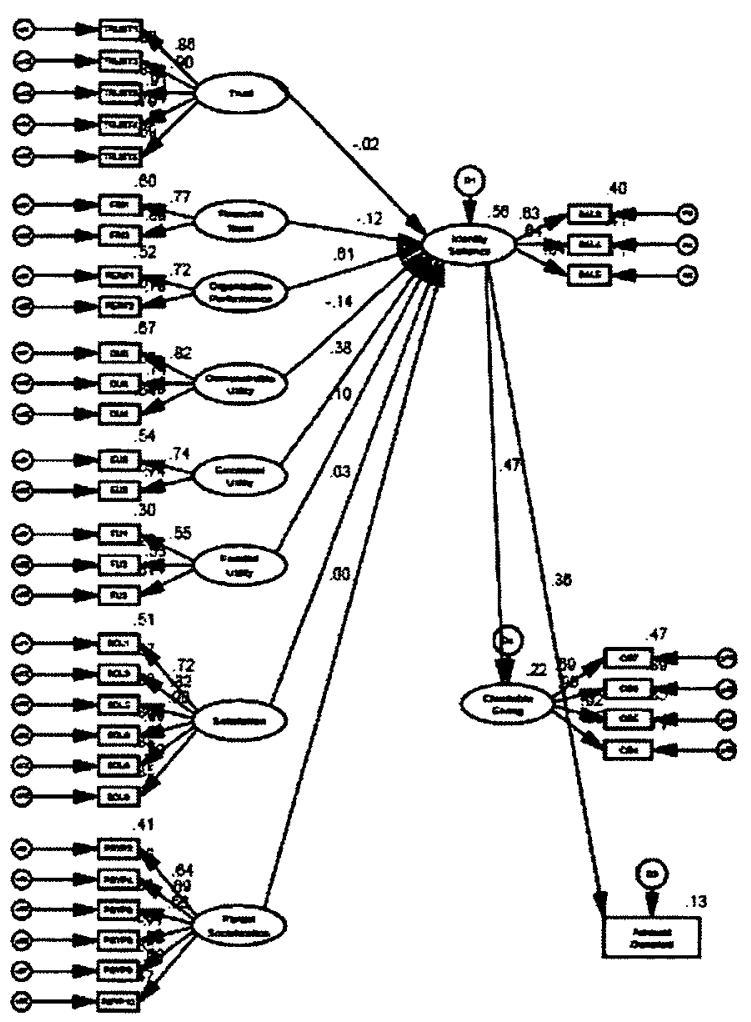




\section{APPENDIX N}

Structural Model with only Relationship Satisfaction

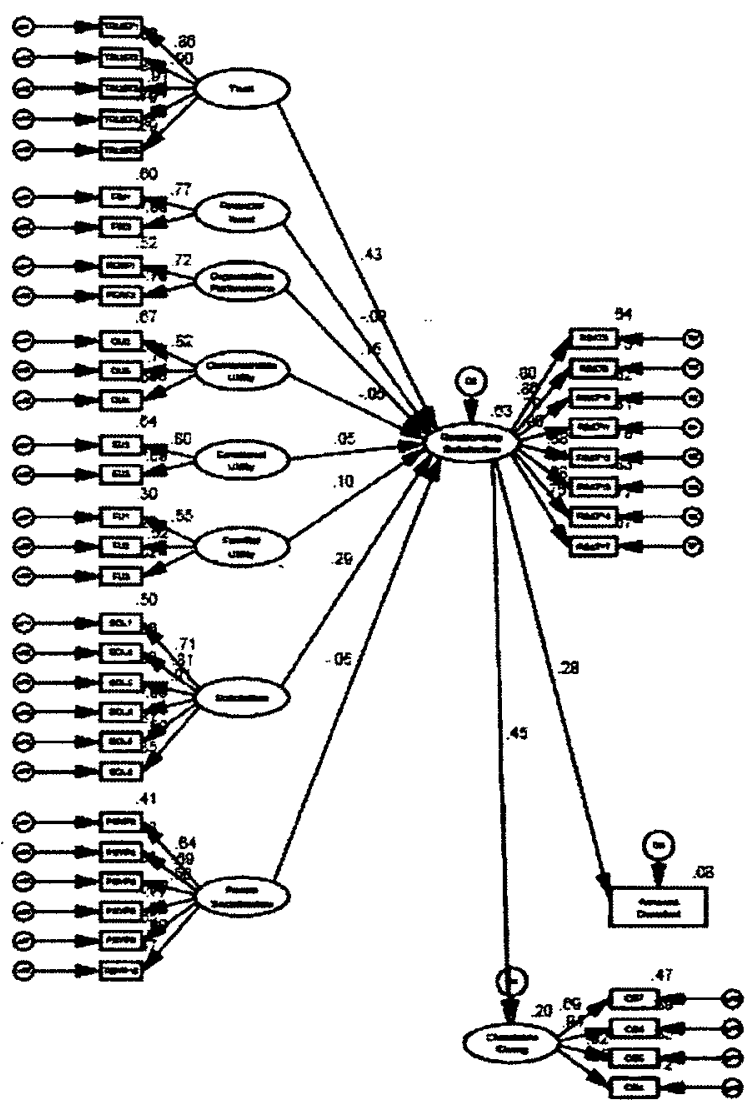


JENNIFER A. TAYLOR

College of Business and Public Administration

Department of Urban Studies \& Public Administration

Old Dominion University

2084 Constant Hall, Norfolk, Virginia 23529

jtay1078@odu.edu

$361-779-2392$

Education

Old Dominion University, Norfolk, Virginia

College of Business and Public Administration

Doctoral Candidate, Public Administration and Urban Policy

Major Fields: Public Administration/Nonprofit Management; Cognate: Marketing

Dissertation: Relational Exchange in Nonprofits: The Role of Identity

Saliency and Relationship Satisfaction in Donor Behavior.

Chair: Dr. William Leavitt

The Ohio State University, Columbus, Ohio

John Glenn School of Public Affairs and Department of Art Education

M.A., Policy and Administration, Arts 1998.

Public/Nonprofit Policy and Administration; Arts

University of South Carolina, Columbia, South Carolina

College of the Arts and Sciences

B.A., Art History, 1995.

Art History, Art Education, and Art Studio

\section{Publications}

Taylor, Jennifer A. (March, 2011). Pluralism, Participation, and Progress. Administrative Theory and Praxis.

Williams, Andrew; \& Jennifer A. Taylor (2012) Accountability Ambiguities: The Holistic Accountability Framework. Voluntas. 
2010-2011 Instructor/Teaching Assistant

College of Business and Public Administration

Old Dominion University, Norfolk, Virginia

Courses: Foundations of Public Service (PAS 300); Administrative Theory I

(PADM 651); Introduction to the Nonprofit Sector (PADM 695).

2005-2011 Adjunct Instructor

Distance Learning Program

Park University, Parkville, Missouri

Courses: Introduction to the Humanities, (LS211), In Class and Online Teaching.

2004-2007 Adjunct Instructor

Small Business Development Center

Del Mar College, Corpus Christi, Texas

Courses: Marketing for Small Businesses \& Nonprofits, Accounting for Small

Businesses \& Nonprofits.

\section{Working Papers and Manuscripts Under Review}

Morris, John C.; Greentree, Vivian; \& Jennifer A. Taylor (Submitted) It's Not All About Me: Tracing the Myth of the "Rugged Individual." Public Voices.

Taylor, Jennifer A. Coming Home to Feminine: A Foundational Shift in Public Service Values.

\section{Research In Progress}

Miller-Stevens, Katrina; Taylor, Jennifer A.; \& John C. Morris. Are We Really On the Same Page? An Empirical Examination of Value Congruence Between Public and Nonprofit Managers

Taylor, Jennifer A. Relational Exchange in Nonprofits: The Role of Identity Saliency and Relationship Satisfaction in Donor Behavior.

\section{Funded Research In Progress}

2012 Annual Survey of Military Families, Survey design \& data analysis on behalf of Blue Star Families, Alexandria, Virginia; a military families advocacy nonprofit. $\$ 5,000$

2012 Military Community Blueprint Grant by Bristol Myers Squibb, community organizing and grant implementation on behalf of Give an Hour, Arlington, Virginia; a nonprofit providing free mental health services to military families. $\$ 34,000$ 
Miller-Stevens, Katrina; Taylor, Jennifer A.; \& John C. Morris, Are We Really On the Same Page? An Empirical Examination of Value Congruence Between Public and Nonprofit Managers. Research results presented at American Society of Public Administration (ASPA), Las Vegas, Nevada: April, 2012.

Miller-Stevens, Katrina; Taylor, Jennifer A.; \& John C. Morris, Are We Really On the Same Page? An Empirical Examination of Value Congruence Between Public and Nonprofit Managers. Research design to be presented at Southeast Conference on Public Administration (SeCOPA), New Orleans, Louisiana: September, 2011.

Taylor, Jennifer A. Paths to Public Service. Panel chair and discussant at the American Society of Public Administrators Hampton Roads Annual Conference, (ASPA-HR), Old Dominion University, Norfolk, Virginia: March, 2011.

Taylor, Jennifer A. Developing a Culture of Philanthropy: A Relationship Marketing Model for Nonprofit Organizations. Research presented at Association of Research on Nonprofit \& Voluntary Associations (ARNOVA), Arlington, Virginia: November, 2010.

Taylor, Jennifer A. and Andrew Williams. Nonprofit Accountability: The Holistic Accountability Framework. Paper presented at the Southeast Conference on Public Administration (SECOPA), Wilmington, North Carolina: October, 2010.

Morris, John C.; Greentree, Vivian; \& Taylor, Jennifer A. The Myth of the Self-Sufficient Individual and the Role of Public Service in American Politics. Paper presented at the Southeast Conference on Public Administration (SECOPA), Wilmington, North Carolina: October, 2010.

Taylor, Jennifer A. Coming Home to Feminine: A Foundational Shift in Public Service Values. Paper presented at the Public Administration Theory Network (PAT-Net), Omaha, Nebraska: May, 2010.

Williams, Andrew; Taylor, Jennifer A. and et al. Nonprofit Accountability: Negotiating the Network. Paper presented at International Research Society for Public Management (IRSPM), Berne, Switzerland: April, 2010.

Taylor, Jennifer A. Coming Home to Feminine: A Foundational Shift in Public Service Values. Paper presented at the American Society of Public Administrators Hampton Roads Annual Conference, (ASPA-HR), Virginia Beach, Virginia: March, 2010.

Kesterson, Misty and Jennifer A. Taylor. Electronic Portfolios: A Product of Student and Faculty Success. Paper presented at the Center for Educational, Development, Evaluation, and Research Conference (CEDER), Corpus Christi, Texas: February, 2006. 
Taylor, Jennifer A. Empty Their Pockets! Revenue Enhancers for Community Theatres. Paper presented for the Texas Nonprofit Theatre Alliance Annual Conference, (TNTA), Corpus Christi, Texas: January, 2004.

\section{Other Publications}

Taylor, Jennifer A. (2009, August 26). The Effects of Deployment on Military Children. The Flagship, B1.

Taylor, Jennifer A. (2009, November 6). The Case for Halloween. The Flagship, B1.

\section{Work Experience}

Graduate Teaching \& Research Assistant, Old Dominion University, 2009-2011.

Director of Development, Deputy Managing Director, Virginia Stage Company, 2007-2009. Led a development team of staff, volunteers, and board members in meeting the annual contributed income goal of $\$ 1.6$ million and additional capital, endowment, and planned giving efforts.

Nonprofit Consultant, Taylored Resources, 1998-2011.

United Way, Elizabeth River Project, USS Lexington Museum, The Dwelling Place, Art Center of Corpus Christi among others

Self-employed as a nonprofit consultant for thirteen years; presenting seminars and workshops, managing employees, cash flow, accounting, fundraising, program and business development, and marketing and public relations. Exemplar projects follow:

Director of Marketing, Corpus Christi Blue Angels Air Show, 2005, 2007.

Secured federal contract to solicit corporate support on behalf of the U.S. Navy Morale, Welfare, and Recreation programs. In less than 60 days, secured over $\$ 65,000$ in direct corporate support, of which $63 \%$ represented new donors; negotiated $\$ 85,000$ in in-kind donations.

Interim Executive Director, Harbor Playhouse, 2003-2004.

Recruited to rebuild local performing arts organization on the brink of bankruptcy. Responsibilities included operations, fiscal management of an operating budget of $\$ 500,000$; marketing, public relations, fundraising, and the supervision and leadership of seven employees and over 300 volunteers.

Interim Executive Director, Family Outreach Corpus Christi, 2001-2003.

Recruited to remedy a chaotic situation in a local social service agency. Responsibilities included but were not limited to board, volunteer, and staff leadership, marketing and public relations, fiscal management, operations and facilities management, program evaluation and fundraising. Supervised five employees and over 100 volunteers. Implemented a debt reduction plan for agency. 
Director of Development, American Cancer Society, Florida Division, 1999-2000.

Served as Development Director of two counties in Northwest Florida. Managed multiple annual fund revenue sources including special events, major gifts, planned giving, corporate sponsorship, memorials, and direct mail. Raised special event income $61 \%$ over the previous year's net, surpassed annual goal in special events revenue by $31 \%$, $\$ 468,000$.

Graduate Administrative Assistant, Office of the President \& Department of Art Education, The Ohio State University, 1997-1998.

\section{University Service}

- Treasurer, Public Administration \& Urban Studies PhD Student Association, Old Dominion University, 2009-2011.

- Site Committee Member, Public Administration Theory Network Conference, Old Dominion University, 2010-2011.

- Member, Public Service Minor, Undergraduate Curriculum Development Committee, Old Dominion University, 2009.

- Member, Public Service Minor Marketing, Old Dominion University, 2009-2011.

- Member, Public Service Week Planning Committee, Old Dominion University, 20092010.

- Site Committee Member, Lawrence and Isabel Barnett Symposium, The Ohio State University, 1998.

\section{Community Service}

- Girl Scouts of America, Daisy \& Brownie Troop 135, Troop Leader, 2008-present.

- Cultural Alliance of Hampton Roads, Board member, 2009-2011.

- Tidewater Officers' Spouses' Association, Board of Directors, 2007-2010.

- Downtown 100 Member, Norfolk Downtown District, 2008-2009.

- The Hermitage Museum of Art, The Art of Glass Committee Member, 2009.

- Idaho Commission on the Arts, General Operating Support Panelist, 2002.

- Idaho Commission on the Arts, Project Support Panelist, 2002.

- National Endowment for the Arts, Challenge America Grant Review Panelist, 2002.

- Coastal Bend Officers' Spouses' Association, Board of Directors, 2005-2007.

- Corpus Christi Chamber of Commerce Ambassador, 2001-2003.

- Santa Rosa Medical Center Women's Advisory Board, 2000.

- Santa Rosa County School District Visual Arts Juror, 2000.

- Northwest Arts Partnership, Board of Directors, 1996-1998. 


\section{Awards}

- Department of Urban Studies and Public Administration, Old Dominion University, Travel Award, 2010, 2011.

- Division of Student Affairs, Graduate Student Travel Award, Old Dominion University, 2011.

- Public Administration Theory Network PhD Student Grant, 2010.

\section{Affiliations/Memberships}

- Reviewer, International Journal of Nonprofit and Voluntary Sector Marketing

- Association of Fundraising Professionals (AFP), 1999 - Present.

- Association for Research on Nonprofit Organizations and the Voluntary Action (ARNOVA), 2009 - Present.

- American Society of Public Administrators (ASPA), 2009 - Present.

- Public Administration Theory Network (PAT-Net), 2009 - Present.

\section{Research and Teaching Interests}

Administrative Theory

Citizenship

Ethics and Values

Governance and Accountability

Human Resources

Inter-Sectoral Relations

Military Families

Nonprofit Finance

Philanthropy, Volunteerism, \& Civic Engagement

Public and Nonprofit Organization Management

Public Policy Process

Research Design

Social Marketing 